UNIVERSIDADE DE SÃO PAULO

ESCOLA DE ENFERMAGEM DE RIBEIRÃO PRETO

Mortalidade por Homicídios, Acidentes de Transporte e Suicídios no Município de Belo Horizonte e Região Metropolitana, em Série Histórica de 1980 - 2000

Lenice de Castro Mendes Villela

RIBEIRÃO PRETO 
LENICE DE CASTRO MENDES VILLELA

\section{Mortalidade por Homicídios, Acidentes de Transporte e Suicídios no Município de Belo Horizonte e Região} Metropolitana, em Série Histórica de 1980 - 2000

Tese apresentada à Escola de Enfermagem de Ribeirão Preto da Universidade de São Paulo, para obtenção do título de Doutor em Enfermagem. Área de Concentração: Enfermagem em Saúde Pública. Inserida na Linha de Pesquisa: Processo Saúde - Doença e Epidemiologia.

Orientadora:

Prof $^{\mathrm{a}}$ Dr $^{\mathrm{a}}$ Suzana Alves de Moraes 
AUTORIZO A REPRODUÇÃO E DIVULGAÇÃO TOTAL OU PARCIAL DESTE TRABALHO POR QUALQUER MEIO CONVENCIONAL OU ELETRÔNICO, PARA FINS DE ESTUDO E PESQUISA, DESDE QUE CITADA A FONTE.

\section{FICHA CATALOGRÁFICA}

Villela, Lenice de Castro Mendes

Mortalidade por Homicídios, Acidentes de Transporte e Suicídios no município de Belo Horizonte e Região Metropolitana, em série histórica de 1980 - 2000. Ribeirão Preto, 2005. 160 p.

Tese de Doutorado, apresentada à Escola de Enfermagem de Ribeirão Preto / USP - Área de concentração: Enfermagem em Saúde Pública.

Orientadora: Moraes, Suzana Alves de.

1. Séries Temporais. 2. Causas Violentas. 3. Mortalidade por Homicídios, Acidentes de Transporte e Suicídios. 


\section{FOLHA DE APROVAÇÃO}

Lenice de Castro Mendes Villela

Mortalidade por Homicídios, Acidentes de Transportes e Suicídios no município de Belo

Horizonte e Região Metropolitana, em série histórica de 1980 - 2000

Tese apresentada à Escola de Enfermagem de Ribeirão Preto da Universidade de São Paulo para obtenção do título de Doutor. Área de Concentração: Enfermagem em Saúde Pública

Aprovado em:

\section{Banca Examinadora}

Prof.

Instituição: Assinatura

Prof.

Instituição:

Assinatura

Prof.

Instituição: Assinatura

Prof.

Instituição:

Assinatura

Prof.

Instituição: Assinatura 
Ao Nélio, meu esposo e querido companheiro, você foi a maior fonte de coragem e incentivo...

Aos meus amores, Gabriel e Mateus, o "para casa" está concluído. 


\section{Agradecimentos}

Este trabalho é o resultado de um esforço conjunto de instituições e profissionais que contribuíram de diversas formas em sua construção. Do mesmo modo, outras pessoas participaram de maneira constante e ativa me proporcionando o apoio e tranquilidade necessários para que eu desenvolvesse a contento o cronograma estabelecido para o programa de doutorado. Especialmente agradeço:

À minha orientadora, professora Dra. Suzana Alves de Moraes, meu agradecimento pelo incentivo, dedicação, solidariedade e pelos aconselhamentos permanentes "nas idas e vindas" durante todos os anos trabalhados. Com sua amizade e compreensão nos momentos difíceis, a jornada e a condução do trabalho tornou-se mais amena e agradável.

À professora Dra. Maria Helena Prado de Mello Jorge, pelo seu estímulo e acesso às valiosas contribuições de seu acervo bibliográfico, o que contribuiu para ampliar o meu saber sobre o tema. Por outro lado, sua participação na pré banca esclareceu pontos até então não elucidados.

Ao professor Dr. Jair Lício Ferreira dos Santos que gentilmente contribuiu desde o meu exame de qualificação apresentando sugestões fundamentais, sobretudo na área de epidemiologia e pelo seu incentivo e estimulo referente ao meu estudo.

À professora Dra. Silvana Martins Mishima, com sua longa experiência, proporcionou-me também durante o exame de qualificação sugestões para a reelaboração do meu estudo.

À professora Dra. Cláudia Benedita dos Santos pela sua valiosa competência e didática na área de estatística contribuiu para ampliar meu conhecimento durante o curso de doutorado. 
À Isabel Cristina de Freitas, por seu saber e imensa generosidade acessorou-me na elaboração do banco de dados e durante toda a execução deste trabalho.

Ao programa de Doutorado do Departamento Materno Infantil e de Saúde Pública da Escola de Enfermagem de Ribeirão Preto por ter me acolhido para cursar o doutorado.

A todos os funcionários dos órgãos de apoio da Escola de Enfermagem de Ribeirão Preto que direta ou indiretamente me possibilitaram uma permanência com mais tranquilidade e carinho nesta instituição.

À Maria Cristina Manduca Ferreira, bibliotecária, pela valiosa colaboração nas correções da referência bibliográfica.

Ao Departamento de Enfermagem Materno Infantil e de Saúde Pública da Escola de Enfermagem da Universidade Federal de Minas Gerais, por ter me liberado para cursar o doutorado e apresentar este estudo que possivelmente servirá ao desenvolvimento de novos trabalhos neste área.

À Coordenação de Aperfeiçoamento de Pessoal de Nível Superior (CAPES), pela bolsa de estudo concedida.

Ao Serviço de Epidemiologia, especialmente Dra. Salete Maria Novaes Diniz e Dra. Sônia Gesteira de Matos, pela oportunidade de participar de um estágio no geoprocessamento do Sistema de Informação de Mortalidade da Secretaria Municipal de Saúde de Belo Horizonte.

Às minhas amigas Iêda, Salete, Regina de Oliveira, Regina Witt, Yolanda, Celmira, Mariza e à minha sobrinha Cristina, por partilharem das angústias na elaboração deste trabalho e sobretudo por me encorajarem a concluí-lo.

Aos colegas do doutorado que me proporcionaram uma grande convivência e um crescimento pessoal e profissional durante os anos de convivência. 
Ao Celso e Jussara que gentilmente me acolheram e ofereceram sua residência nesta cidade.

À minha família, por todo o apoio, carinho e amor, especialmente à minha mãe, pelo meu distanciamento durante quatro anos. No entanto, é ela mesma a razão disto tudo, pelo incentivo que sempre nos proporcionou. É uma alegria estar com vocês.

Ao meu pai, in memoriam, hoje estaria compartilhando toda sua alegria por eu ter cumprido mais uma etapa de minha vida.

A todos agradeço, profundamente, e dedico este estudo. 


\section{O Sal da Terra}

Anda quero te dizer nenhum segredo

Falo nesse chão da nossa casa Vem que tá na hora de arrumar Tempo, quero viver mais duzentos anos Quero não ferir meu semelhante

Nem por isso quero me ferir Vamos precisar de todo mundo Pra banir do mundo a opressão

Para construir a vida nova

Vamos precisar de muito amor

A felicidade mora ao lado

E quem não é tolo pode ver A paz da terra, amor, o pé na terra A paz na terra, amor, o sal da terra

És o mais bonito dos planetas

Tão te maltratando por dinheiro

Tu que és a nave nossa irmã Canta, leva tua vida em harmonia E nos alimenta com seus frutos

Tu que és do homem a maçã Vamos precisar de todo mundo Um mais um é sempre mais que dois

Pra melhor juntar as nossas forças

É só repartir melhor o pão Recriar o paraíso agora

Para merecer quem vem depois Deixa nascer o amor, deixa fluir o amor Deixa crescer o amor, deixa viver o amor 


\section{RESUMO}

Villela LCM. Mortalidade por Homicídios, Acidentes de Transporte e Suicídios no município de Belo Horizonte e Região Metropolitana, em série histórica de 1980 - 2000. 2005. 160f. Tese de Doutorado - Escola de Enfermagem de Ribeirão Preto, Universidade de São Paulo, Ribeirão Preto, 2005.

Objetivo: Estudar o perfil epidemiológico da mortalidade por Homicídios, Acidentes de Transporte e Suicídios no município de Belo Horizonte e Região Metropolitana, na série histórica de 1980 a 2000. Métodos: O estudo apresenta um desenho ecológico, do tipo série histórica. Os indicadores de mortalidade foram os coeficientes específicos por sexo, idade e gerais padronizados; a mortalidade proporcional; a razão de mortalidade segundo sexo e idade e os incrementos / decrementos percentuais. A população utilizada como padrão foi a de 1980. Os óbitos por Homicídios, Acidentes de Transporte e Suicídios e as estimativas populacionais, segundo o ano calendário, sexo, idade e município de residência foram extraídos da base de dados do DATASUS. No período entre 1980 e 1995, os óbitos foram codificados, segundo a IX Classificação Internacional de Doenças - CID 9a Revisão, e, a partir de 1996, segundo a CID - $10^{a}$ Revisão. A análise de tendência temporal foi desenvolvida no software SPSS para Windows, utilizando-se a técnica de regressão linear simples, com nível de significância $(\alpha<0,05)$. Resultados: Nas duas regiões geográficas, os indicadores de mortalidade apresentaram maior magnitude para o sexo masculino. A razão de coeficientes específicos de mortalidade apresentou maior magnitude nas faixas etárias entre 20 e 49 anos. Os coeficientes específicos de mortalidade por Homicídios apresentaram maior magnitude na região Metropolitana e os Suicídios e Acidentes de Transporte, em Belo Horizonte. Os maiores coeficientes de mortalidade por Homicídios e Suicídios, em ambas regiões e sexos, ocorreram entre a faixa de 15 a 49 anos, e por Acidentes de Transporte, na faixa etária de "70 anos e mais". Com relação à variação percentual dos coeficientes de mortalidade, verificaram-se incrementos percentuais para os Homicídios, exceto na faixa etária de 40 a 49 anos, ocorrendo decrementos destes indicadores para os Acidentes de Transporte, em todas as faixas etárias. Os Suicídios, mesmo com oscilações, apresentaram incrementos nas faixas etárias de "15 a 19 anos" e "40 a 49 anos". As tendências dos coeficientes específicos de mortalidade, ao longo da série, apresentaram ascensão para os Homicídios ( $\mathrm{p}<$ 0,05), exceto, na faixa etária de "40 a 49 anos". Os Acidentes de Transporte 
apresentaram tendência de declínio ou estabilização, ao longo do período. Para os Suicídios ocorreu uma tendência de ascensão no sexo masculino, na faixa etária de "20 a 29" e de “40 a 49 anos". A tendência dos coeficientes gerais padronizados de mortalidade por Homicídios, em ambas regiões, apresentou um padrão de ascensão (p $<0,05)$. Nos Acidentes de Transporte e nos Suicídios observou-se uma tendência de estabilização, com um discreto declínio no sexo feminino. $(\mathrm{p}<0,05)$. Conclusão: A evolução dos coeficientes, ao longo da série histórica, evidenciou a importância epidemiológica dos três grupos de causas externas, entre as quais destacaram-se os Homicídios, em ambas as regiões estudadas. Considerando os diferentes espaços geográficos e, as desigualdades sócio-espaciais, esses resultados sugerem a necessidade de implantação de programas efetivos de promoção e prevenção em saúde, direcionados para os jovens, adultos e idosos, principalmente do sexo masculino. Tais medidas podem contribuir para o controle e para a diminuição da expansão destes agravos, de fundamental importância para a Saúde Pública.

Descritores: Series Temporais. Causas Violentas. Mortalidade por Homicídios, Acidentes de Transporte e Suicídios. 


\begin{abstract}
Villela LCM. Mortality from Homicides, Traffic Accidents and Suicides in Belo Horizonte and the Metropolitan region, in a historical time series from 1980 2000. 2005. 160p. Doctoral Thesis - University of São Paulo at Ribeirão Preto College of Nursing, Ribeirão Preto, 2005.
\end{abstract}

Objective: To study the epidemiological profile of mortality from Homicides, Traffic Accidents and Suicides in Belo Horizonte and its Metropolitan Region, Brazil, in a historical time series from 1980 to 2000. Methods: The study adopts an ecological design, by means of a time series. The mortality indices used were the age-specific and general standardized coefficients, proportional mortality, mortality rates according to gender and percentage increases / decreases. The 1980 population was as standard Homicides, Traffic Accidents and Suicides deaths and population estimates, according to calendar year, gender, age and city of residence were extracted from the DATASUS database. For the period between 1980 and 1995, deaths were coded according to the IX International Classification of Diseases - ICD $9^{\text {th }}$ Review and, from 1996 onwards, according to the ICD $-10^{\text {th }}$ Review. The temporal tendency analysis was carried out using SPSS software for Windows, by means of the simple linear regression technique, with an $\alpha<0,05$ significance level. Results: In both regions, mortality rates were higher among men. The age-specific mortality coefficient ratio was higher in the age ranges from 20 to 49 years. While age-specific Homicides mortality rates were more elevated in the Metropolitan region, a larger number of Suicides and Traffic Accidents occurred in Belo Horizonte. For both regions and genders, the highest Homicides and Suicides mortality rates occurred in the age range from 15 to 49 years, while Traffic Accidents deaths were highest in the range of "70 years and older". Concerning the percentage variation in mortality coefficients, a percentage increase occurred for Homicides, except in the age range from 40 to 49 years, while Traffic Accidents mortality rates decreased along all age ranges. In spite of oscillations, Suicides deaths increased in the group " 15 to 19 years" and from "40 to 49 years". The time series displayed a rising tendency in specific Homicides mortality rates $(\mathrm{p}<$ 0,05), except in the age group "40 to 49 years". Traffic Accidents revealed a downward or stabilizing tendency throughout the period. For Suicides, an upward tendency appeared among men between " 20 and 29" and between " 40 and 49 " years old. In both regions, there was a rising tendency in the general standardized 
Homicide mortality rates $(\mathrm{p}<0,05)$. A stabilizing tendency was observed for Traffic Accidents and Suicides, with a slight decrease among women. $(\mathrm{p}<0,05)$. Conclusion: The evolution in mortality rates in the time series disclosed the epidemiological importance of these three groups of external causes, especially Homicides, in both regions. In view of different geographical areas and socio-spatial inequalities, these results point towards the need to implant efficient health promotion and prevention programs, mostly at men, aimed young, adult and aged persons. These measures can contribute to the control and decrease in the expansion of these harmful situations, which is essential for Public Health.

Key words: Time series; Violence Causes; Homicides, Traffic Accidents, Suicides Mortality. 


\section{RESUMEN}

Villela LCM. Mortalidad por Homicidios, Accidentes de Transporte y Suicidios en el municipio de Belo Horizonte y Región Metropolitana, en una serie histórica de 1980 - 2000. 2005. 160h. Tesis Doctorado - Escuela de Enfermería de Ribeirão Preto, Universidad de São Paulo, Ribeirão Preto, 2005.

Objetivo: Estudiar el perfil epidemiológico de la mortalidad por Homicidios, Accidentes de Transporte y Suicidios en el municipio de Belo Horizonte y Región Metropolitana, Brasil, en una serie histórica de 1980 a 2000. Métodos: El estudio muestra un diseño ecológico de tipo serie histórica. Los indicadores de mortalidad fueron los coeficientes específicos puer edad y generales estandarizados, la mortalidad proporcional, la razón de mortalidad según sexo y edad, y los aumentos / disminuciones porcentuales. La población utilizada como estándar fue la de 1980. Las defunciones por Homicidios, Accidentes de Transporte y Suicidios y las estimativas poblacionales, según año calendario, sexo, edad y municipio de residencia fueron extraídas de la base de datos del DATASUS. En el período entre 1980 y 1995, las defunciones fueron codificados, según la IX Clasificación Internacional de Enfermedades - CID 9ª Revisión y, a partir de 1996, según la CID - 10ª Revisión. El análisis de la tendencia temporal fue desarrollado mediante el software SPSS para windows, utilizándose la técnica de regresión linear simple, con nivel de significancia $(\alpha<0,05)$. Resultados: En las dos regiones geográficas, el sexo masculino presentó los indicadores de mortalidad los más altos. La razón de coeficientes específicos de mortalidad fue mayor en las franjas etarias entre 20 y 49 años. Los coeficientes específicos de mortalidad por Homicidios fueron mayores en la región Metropolitana y los Suicidios y Accidentes de Transporte en Belo Horizonte. En ambas regiones y sexos, la franja etaria desde 15 hasta 49 años presentó los mas altos coeficientes de mortalidad por Homicidios y Suicidios, y la de "70 años y mas" por Accidentes de Transporte. Respecto a la variación porcentual de los coeficientes de mortalidad, ocurrieron aumentos porcentuales para los Homicidios, excepto en la franja etaria de 40 a 49 años, mientras disminuyeron estos indicadores para los Accidentes de Transporte, en todas las franjas etarias. Los Suicidios, aunque con oscilaciones, presentaron aumentos en las franjas etarias de "15 a 19 años" y "40 a 49 años". A lo largo de la serie ocurrieron tendencias ascendentes en los coeficientes específicos de 
mortalidad para los Homicidios $(\mathrm{p}<0,05)$, excepto en la franja etaria de "40 a 49 años". Los Accidentes de Transporte exhibieron tendencia de disminución o estabilización a lo largo del período. Para los Suicidios ocurrió una tendencia ascendente en el sexo masculino, en la franja etaria de "20 a 29" y de "40 a 49 años". La tendencia de los coeficientes generales estandarizados de mortalidad por Homicidios, en ambas regiones, exhibió un patrón ascendente $(\mathrm{p}<0,05)$. Ocurrió una tendencia de estabilización en los Accidentes de Transporte y en los Suicidios, con una discreta disminución en el sexo femenino. $(\mathrm{p}<0,05)$. Conclusión: La evolución de los coeficientes, a lo largo de la serie histórica, evidenció la importancia epidemiológica de los tres grupos de causas externas, entre las cuales se destacaron los homicidios, en ambas regiones estudiadas. Considerando los diferentes espacios geográficos y las desigualdades socio-espaciales, esos resultados apuntan a la necesidad de implantación de programas efectivos de promoción y prevención en salud, dirigidos a los jóvenes, adultos y ancianos, principalmente del sexo masculino. Tales medidas pueden contribuir a controlar y disminuir la expansión de estos hechos graves, de fundamental importancia en Salud Pública.

Términos-clave: Serie Histórica. Causas Violentas. Mortalidad por Homicidios, Accidentes de Transporte y Suicidios. 


\section{LISTA DE FIGURAS}

Figura 1 - Pirâmides populacionais, Brasil, 1980, 1991, 2000......

Figura 2- Evolução temporal da mortalidade proporcional por quatro principais grupos de causas definidas no Brasil, 1930 a 1999.

Figura 3 - Mapa da Região Metropolitana de Belo Horizonte, 2000......

Figura 4 - Pirâmides populacionais, Minas Gerais, 1980, 1991, 2000.

Figura 5 - Pirâmides populacionais, Região Metropolitana de Belo Horizonte, 1980, 1991, 2000.

Figura $6-$ Pirâmides populacionais, Belo Horizonte, 1980, 1991, 2000.

Figura $\quad 7-$ Mortalidade proporcional por homicídios, Belo Horizonte, 1980 a 2000...

Figura 8- Mortalidade proporcional por homicídios, Região Metropolitana de Belo Horizonte, 1980 a 2000.

Figura 9- Variação percentual dos coeficientes de mortalidade por homicídios entre 1980 e 2000, segundo faixa etária - sexo masculino - Belo Horizonte.

Figura 10 - Variação percentual dos coeficientes de mortalidade por homicídios entre 1980 e 2000, segundo faixa etária - sexo feminino - Belo Horizonte.

Figura 11 - Variação percentual dos coeficientes de mortalidade por homicídios entre 1980 e 2000 , segundo faixa etária - sexo masculino - Região Metropolitana de Belo Horizonte.

Figura 12 - Variação percentual dos coeficientes de mortalidade por homicídios entre 1980 e 2000, segundo faixa etária - sexo feminino - Região Metropolitana de Belo Horizonte.

Figura 13 - Coeficientes específicos de mortalidade por homicídios, segundo sexo faixa etária de "15 a 19 anos", Belo Horizonte, 1980 - 2000.

Figura 14 - Coeficientes específicos de mortalidade por homicídios, segundo sexo faixa etária de "15 a 19 anos", Região Metropolitana de Belo Horizonte, $1980-2000$.

Figura 15 - Coeficientes específicos de mortalidade por homicídios, segundo sexo faixa etária de "20 a 29 anos", Belo Horizonte, 1980 - 2000.

Figura 16 - Coeficientes específicos de mortalidade por homicídios, segundo sexo faixa etária de "20 a 29 anos", Região Metropolitana de Belo Horizonte, 1980 - 2000. 
Figura 17 - Coeficientes específicos de mortalidade por homicídios, segundo sexo faixa etária de "30 a 39 anos", Belo Horizonte, 1980 - 2000.

Figura 18 - Coeficientes específicos de mortalidade por homicídios, segundo sexo faixa etária de "30 a 39 anos", Região Metropolitana de Belo Horizonte, $1980-2000$.

Figura 19 - Coeficientes específicos de mortalidade por homicídios, segundo sexo faixa etária de "40 a 49 anos", Belo Horizonte, 1980 - 2000

Figura 20-Coeficientes específicos de mortalidade por homicídios, segundo sexo faixa etária de "40 a 49 anos", Região Metropolitana de Belo Horizonte, $1980-2000$.

Figura 21 - Coeficientes gerais padronizados de mortalidade por homicídios, segundo sexo, Belo Horizonte, 1980 - 2000.

Figura 22 - Coeficientes gerais padronizados de mortalidade por homicídios, segundo sexo, Região Metropolitana de Belo Horizonte, 1980 - 2000...

Figura 23 - Mortalidade proporcional por acidentes de transporte, município de Belo Horizonte, 1980 - 2000.

Figura 24-Mortalidade proporcional por acidentes de transporte, Região Metropolitana de Belo Horizonte, 1980 - 2000.

Figura 25 - Coeficientes específicos de mortalidade por acidentes de transporte, segundo sexo - faixa etária de "0 a 9 anos", Belo Horizonte, 1980 - 2000.

Figura 26- Coeficientes específicos de mortalidade por acidentes de transporte, segundo sexo - faixa etária de "0 a 9 anos", Região Metropolitana de Belo Horizonte, 1980 - 2000.

Figura 27 - Coeficientes específicos de mortalidade por acidentes de transporte, segundo sexo - faixa etária de "10 a 19 anos", Belo Horizonte, 1980 2000 .

Figura 28 - Coeficientes específicos de mortalidade por acidentes de transporte, segundo sexo - faixa etária de "10 a 19 anos", Região Metropolitana de Belo Horizonte, 1980 - 2000.

Figura 29- Coeficientes específicos de mortalidade por acidentes de transporte, segundo sexo - faixa etária de "20 a 29 anos", Belo Horizonte, 1980 2000 .

Figura 30-Coeficientes específicos de mortalidade por acidentes de transporte, segundo sexo - faixa etária de "20 a 29 anos", Região Metropolitana de Belo Horizonte, 1980 - 2000. 
Figura 31-Coeficientes específicos de mortalidade por acidentes de transporte, segundo sexo - faixa etária de "30 a 39 anos", Belo Horizonte, 1980 2000 .

Figura 32 - Coeficientes específicos de mortalidade por acidentes de transporte, segundo sexo - faixa etária de "30 a 39 anos", Região Metropolitana de Belo Horizonte, 1980 - 2000.

Figura 33 - Coeficientes específicos de mortalidade por acidentes de transporte, segundo sexo - faixa etária de "40 a 49 anos", Belo Horizonte, 1980 2000

Figura 34 - Coeficientes específicos de mortalidade por acidentes de transporte, segundo sexo - faixa etária de "40 a 49 anos", Região Metropolitana de Belo Horizonte, 1980 - 2000.

Figura 35 - Coeficientes específicos de mortalidade por acidentes de transporte, segundo sexo - faixa etária de "50 a 59 anos", Belo Horizonte, 1980 2000 .

Figura 36- Coeficientes específicos de mortalidade por acidentes de transporte, segundo sexo - faixa etária de "50 a 59 anos", Região Metropolitana de Belo Horizonte, 1980 - 2000.

Figura 37-Coeficientes específicos de mortalidade por acidentes de transporte, segundo sexo - faixa etária de "60 a 69 anos", Região Metropolitana de Belo Horizonte, 1980 - 2000.

Figura 38 - Coeficientes específicos de mortalidade por acidentes de transporte, segundo sexo - faixa etária de "60 a 69 anos", Região Metropolitana de Belo Horizonte, 1980 - 2000.

Figura 39- Coeficientes específicos de mortalidade por acidentes de transporte, segundo sexo - faixa etária de "70 anos e mais", Belo Horizonte, 1980 2000 .

Figura 40-Coeficientes específicos de mortalidade por acidentes de transporte, segundo sexo - faixa etária de "70 anos e mais", Região Metropolitana de Belo Horizonte, 1980 - 2000.

Figura 41-Coeficientes gerais padronizados de mortalidade por acidentes de transporte, segundo sexo, Belo Horizonte, 1980 - 2000.

Figura 42 - Coeficientes gerais padronizados de mortalidade por acidentes de transporte, segundo sexo, Região Metropolitana de Belo Horizonte, 1980 $-2000$.

Figura 43 - Mortalidade proporcional por suicídios, município de Belo Horizonte, $1980-2000$. 
Figura 44 - Mortalidade proporcional por suicídios, Região Metropolitana de Belo Horizonte, 1980 - 2000.

Figura 45 - Variação percentual dos coeficientes de mortalidade por suicídios, entre 1980 e 2000, segundo faixa etária - sexo masculino - Belo Horizonte.

Figura 46 - Variação percentual dos coeficientes de mortalidade por suicídios, entre 1980 e 2000, segundo faixa etária - sexo feminino - Belo Horizonte.

Figura 47 - Variação percentual dos coeficientes de mortalidade por suicídios, entre 1980 e 2000, segundo faixa etária - sexo masculino - Região Metropolitana de Belo Horizonte.

Figura 48 - Variação percentual dos coeficientes de mortalidade por suicídios, entre 1980 e 2000, segundo faixa etária - sexo feminino - Região Metropolitana de Belo Horizonte.

Figura 49 - Coeficientes específicos de mortalidade por suicídios, segundo sexo faixa etária de "15 a 19 anos", Belo Horizonte, 1980 - 2000

Figura 50- Coeficientes específicos de mortalidade por suicídios, segundo sexo faixa etária de "15 a 19 anos", Região Metropolitana de Belo Horizonte, $1980-2000$.

Figura 51 - Coeficientes específicos de mortalidade por suicídios, segundo sexo faixa etária de "20 a 29 anos", Belo Horizonte, 1980 - 2000.

Figura 52 - Coeficientes específicos de mortalidade por suicídios, segundo sexo faixa etária de "20 a 29 anos", Região Metropolitana de Belo Horizonte, $1980-2000$.

Figura 53 - Coeficientes específicos de mortalidade por suicídios, segundo sexo faixa etária de "30 a 39 anos", Belo Horizonte, 1980 - 2000.

Figura 54- Coeficientes específicos de mortalidade por suicídios, segundo sexo faixa etária de "30 a 39 anos", Região Metropolitana de Belo Horizonte, $1980-2000$.

Figura 55 - Coeficientes específicos de mortalidade por suicídios, segundo sexo faixa etária de "40 a 49 anos", Belo Horizonte, 1980 - 2000.

Figura 56- Coeficientes específicos de mortalidade por suicídios, segundo sexo faixa etária de "40 a 49 anos", Região Metropolitana de Belo Horizonte, $1980-2000$.

Figura 57 - Coeficientes gerais padronizados de mortalidade por suicídios, segundo sexo, Belo Horizonte, 1980 - 2000.

Figura 58 - Coeficientes gerais padronizados de mortalidade por suicídios, segundo sexo, Região Metropolitana de Belo Horizonte, 1980 - 2000. 


\section{LISTA DE TABELAS}

Tabela 1 - Número absoluto, proporção de óbitos e taxa de mortalidade para 100.000 habitantes, por homicídios, 1996 a 1999.

Tabela 2 - Número absoluto, proporção de óbitos e taxa de mortalidade para 100.000 habitantes por acidentes de transporte, Brasil, 1996 a 1999

Tabela 3 - Número absoluto, proporção de óbitos e taxa de mortalidade para 100.000 habitantes por suicídios, Brasil, 1996 a 1999

Tabela 4 - Distribuição das taxas de mortalidade para 100.000 habitantes por homicídios, acidentes de transporte e suicídios, segundo faixa etária e sexo, Região Metropolitana de Belo Horizonte, 2001

Tabela 5- Distribuição das taxas de mortalidade para 100.000 habitantes por homicídios, acidentes de transporte e suicídios, segundo faixa etária e sexo, Belo Horizonte, 2001

Tabela 6- Distribuição dos coeficientes específicos de mortalidade por homicídios, segundo sexo e faixa etária, Belo Horizonte, 1980 - 2000....

Tabela 7 - Distribuição dos coeficientes específicos de mortalidade por homicídios, segundo sexo e faixa etária, Região Metropolitana de Belo Horizonte, $1980-2000$.

Tabela 8- Coeficientes específicos de mortalidade por homicídios e razão de coeficientes segundo sexo e faixas etárias, Belo Horizonte, 1980, 1990, 2000

Tabela 9- Coeficientes específicos de mortalidade por homicídios e razão de coeficientes segundo sexo e faixas etárias, Região Metropolitana de Belo Horizonte, 1980, 1990, 2000.

Tabela 10 - Distribuição dos coeficientes específicos de mortalidade por acidentes de transporte, segundo sexo e faixa etária, Belo Horizonte, 1980 2000

Tabela 11 - Distribuição dos coeficientes específicos de mortalidade por acidentes de transporte, segundo sexo e faixa etária, Região Metropolitana de Belo Horizonte, $1980-2000$.

Tabela 12 - Coeficientes específicos de mortalidade por acidentes de transporte e razão de coeficientes segundo sexo e faixas etárias, Belo Horizonte, 1980, 1990, 2000. 
Tabela 13 - Coeficientes específicos de mortalidade por acidentes de transporte e razão de coeficientes segundo sexo e faixas etárias, Região Metropolitana de Belo Horizonte, 1980, 1990, 2000.

Tabela 14 - Variação percentual dos coeficientes de mortalidade por acidentes de transporte entre 1980 e 2000 , segundo faixa etária - sexo masculino e feminino, Belo Horizonte

Tabela 15 - Variação percentual dos coeficientes de mortalidade por acidentes de transporte entre 1980 e 2000 , segundo faixa etária - sexo masculino e feminino, Região Metropolitana de Belo Horizonte.

Tabela 16- Distribuição dos coeficientes específicos de mortalidade por suicídios, segundo sexo e faixa etária, Belo Horizonte, 1980 - 2000.

Tabela 17 - Distribuição dos coeficientes específicos de mortalidade por suicídios, segundo sexo e faixa etária, Região Metropolitana de Belo Horizonte, $1980-2000$

Tabela 18 - Coeficientes específicos de mortalidade por suicídios e razão de coeficientes segundo sexo e faixas etárias, Belo Horizonte, 1980, 1990, 2000 .

Tabela 19- Coeficientes específicos de mortalidade por suicídios e razão de coeficientes segundo sexo e faixas etárias, Região Metropolitana de Belo Horizonte, 1980, 1990, 2000. 


\section{SUMÁRIO}

1. INTRODUÇÃO.................................................................................................. 26

1.1 A transição demográfica...................................................................... 27

1.1.1 A transição demográfica e as mudanças da população nos países da América Latina................................................................................... 29

1.1.2 A transição demográfica no Brasil................................................ 30

1.2 A transição epidemiológica...................................................................... 34

1.2.1 Os estágios da transição epidemiológica........................................... 35

1.2.2 Os modelos da transição epidemiológica.......................................... 36

1.2.3 A transição epidemiológica nos países da América Latina............... 38

1.2.4 A transição epidemiológica no Brasil............................................... 39

1.3 A mortalidade por causas externas como problema de saúde pública e de saúde coletiva.

1.3.1 Mortalidade por causas externas nos países desenvolvidos e em desenvolvimento.................................................................................... 44

1.3.2 A evolução da mortalidade por causas externas no Brasil................. 46

1.3.3 Grupos de causas ................................................................... 48

1.3.3.1 Homicídios................................................................... 48

1.3.3.2 Acidentes de transporte.................................................. 51

1.3.3.3 Suicídios...................................................................... 53

1.4 As estatísticas de óbitos no Brasil............................................................... 55

1.4.1 O registro de óbito no Brasil.......................................................... 55

1.4.2 O sistema de informação sobre mortalidade no Brasil....................... 57

1.4.3 O sistema de informações sobre mortalidade por acidentes e violência.............................................................................................. 58

1.4.3 O fluxo do sistema de informação de mortalidade por causas externas e violência no município e Região Metropolitana de Belo Horizonte.

1.5 Caracterização da Região Metropolitana e do Horizonte e município de Belo Horizonte.

1.5.1 Aspectos demográficos e epidemiológicos 


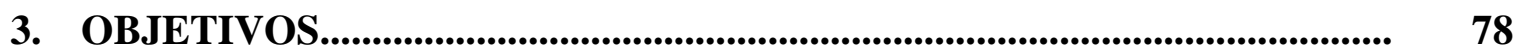

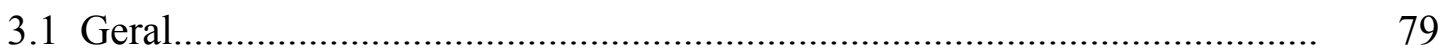

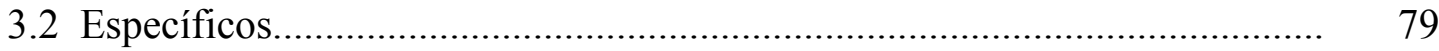

4 MATERIAL E MÉTODOS........................................................................ 80

4.1 Delineamento do estudo......................................................................... 81

4.2 Local e prazo do estudo......................................................................... 81

4.3 População de estudo.................................................................................. 81

4.3.1 Óbitos.................................................................................... 81

4.3.2 População..................................................................................... 82

4.4 Definição dos grupos etários específicos....................................................... 82

4.5 Indicadores de mortalidade....................................................................... 83

4.6 Processamento dos dados.......................................................................... 84

4.7 Análise dos dados............................................................................. 84

4.8 Considerações éticas................................................................................ 85

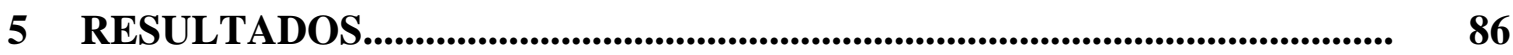

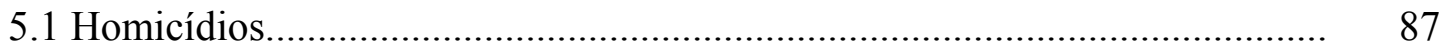

5.1.1 Mortalidade proporcional por Homicídios......................................... $\quad 87$

5.1.2 Coeficientes específicos de mortalidade por Homicídios..................... 87

5.1.3 Razão de mortalidade por Homicídios segundo sexo........................... 90

5.1.4 Variação percentual dos coeficientes específicos de mortalidade por Homicídios........................................................................................ 91

5.1.5 Tendências dos coeficientes específicos de mortalidade por

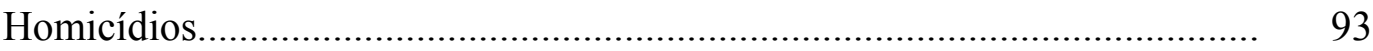

5.1.6 Tendências dos coeficientes gerais padronizados de mortalidade por

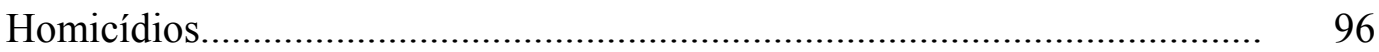

5.2 Acidentes de Transporte........................................................................ 97

5.2.1 Mortalidade proporcional por Acidentes de Transporte...................... 97 
5.2.2 Coeficientes específicos de mortalidade por Acidentes de Transporte

5.2.3 Razão de mortalidade por Acidentes de Transporte segundo sexo........

5.2.4 Variação percentual dos coeficientes específicos de mortalidade por Acidentes de Transporte.

5.2.5 Tendências dos coeficientes específicos de mortalidade por Acidentes de Transporte.

5.2.6 Tendências dos coeficientes gerais padronizados de mortalidade por Acidentes de Transporte.

5.3 Suicídios 108

5.3.1 Mortalidade proporcional por Suicídios. 108

5.3.2 Coeficientes específicos de mortalidade por Suicídios........................ 108

5.3.3 Razão de mortalidade por Suicídios segundo sexo.

5.3.4 Variação percentual dos coeficientes específicos de mortalidade por Suicídios

5.3.5 Tendências dos coeficientes específicos de mortalidade por Suicídios

5.3.6 Tendências dos coeficientes gerais padronizados de mortalidade por Suicídios.

6 . DISCUSSÃO.

6.1 Homicídios.

6.2 Acidentes de Transporte

6.3 Suicídios

8. REFERÊNCIAS.

ANEXOS

ANEXO 1 Taxa de mortalidade por Homicídios, município de Belo Horizonte, 1990 
ANEXO 2 Taxa de mortalidade por Homicídios, Região Metropolitana de Belo Horizonte, 1990

ANEXO 3 Taxa de mortalidade por Acidentes de Transporte, município de Belo Horizonte, 1990

ANEXO 4 Taxa de mortalidade por Acidentes de Transporte, Região Metropolitana de Belo Horizonte, 1990

ANEXO 5 Taxa de mortalidade por Suicídios, município de Belo Horizonte, 1990

ANEXO 6 Taxa de mortalidade por Suicídios, Região Metropolitana de Belo Horizonte, 1990 
1 INTRODUÇÃO 


\section{INTRODUÇÃO}

\subsection{A Transição Demográfica.}

A população humana, por sua própria natureza, é passível de mudanças determinadas pelas diversas formas de organização social e pela história de vida construída pelos indivíduos. Para garantir sua preservação e o seu tamanho, passa pelo processo de transição demográfica referente à mudança de um padrão caracterizado por elevadas taxas de mortalidade e fecundidade, para um outro, cujas taxas passam a ser significativamente mais baixas. A mortalidade e a fecundidade, ao longo do tempo, destacaram-se por seu declínio progressivo, resultando em aumento gradual dos adultos e idosos, acelerando, portanto, o envelhecimento da população. A migração é outro fator que contribuiu para o envelhecimento de uma determinada população, pois são os adultos que, com maior freqüência, deslocam-se em busca de melhores oportunidades de trabalho, para preservar a sobrevivência de sua família. ${ }^{1,2}$

A teoria da transição demográfica está fundamentada, basicamnte, nas alterações ocorridas no perfil da mortalidade e da fecundidade. O declínio dessas variáveis, durante um longo período de tempo, determinará o envelhecimento populacional que se caracterizará por uma diminuição relativa e progressiva da população jovem e por um aumento contínuo da população idosa, então, as pessoas poderão viver mais tempo. ${ }^{3}$

As pesquisas demográficas de Camargo ${ }^{1}$ e do Centro Latino Americano de Demografia (CELADE) ${ }^{4}$ sobre os estudos populacionais, identificaram três evidências básicas na dinâmica da transição demográfica:

a) A primeira refere-se à queda da taxa de mortalidade;

b) A segunda, ao aumento da população e à estabilidade da fecundidade; 
c) A terceira, caracteriza-se pela baixa taxa de mortalidade e de fecundidade, proporcionando um equilíbrio populacional, denominado crescimento populacional sustentado.

Segundo Vermelho e Monteiro, ${ }^{5}$ a teoria da transição demográfica postula quatro fases que os países podem percorrer, progressivamente, na sua dinâmica populacional:

a) A fase "pré-industrial”, quando as taxas de mortalidade e fecundidade eram elevadas, determinando, portanto, um equilíbrio e um crescimento populacional moderado.

b) A fase "intermediária de divergência dos coeficientes", quando as taxas de mortalidade decresceram, enquanto as de fecundidade permaneciam altas, resultando no crescimento acelerado da população, que determinou a explosão populacional.

c) A fase “intermediária de convergência dos coeficientes", quando as taxas de fecundidade e mortalidade passaram a diminuir, resultando num crescimento populacional para idades mais avançadas, determinando, conseqüentemente o envelhecimento populacional.

d) A fase “moderna” ou de "pós-transição", em que tem havido uma maior aproximação dos coeficientes de fecundidade e de mortalidade. Suas taxas apresentaram-se próximas e baixas. Em consequência, a população torna-se estável, com um crescimento populacional quase nulo. Contudo, o número de jovens diminui, a esperança de vida aumenta e a população envelhece.

Para Nadalin, ${ }^{6}$ a transição demográfica está diretamente relacionada com a história social, cultural e econômica de cada população. Sua complexidade está determinada pela associação entre as condições essenciais de sobrevivência e as variáveis demográficas, de forma diferenciada de época para época, de região para região, de civilização para civilização, e em função do modo de produção e dos fatores dinâmicos da população. 


\subsubsection{A Transição Demográfica e as Mudanças da População nos Países da América} Latina.

$\mathrm{Na}$ época atual, os países desenvolvidos apresentam baixas taxas de fecundidade, com uma dinâmica populacional relativamente estável. Em sentido contrário, os países menos desenvolvidos têm comparativamente, em sua maioria, taxas de fecundidade mais alta, com um crescimento populacional considerável, em consequência, apresentam sérios problemas sociais, culturais, econômicos e ambientais.

Nos países da América Latina, as grandes transformações sociais e econômicas, o acelerado processo de urbanização e o desenvolvimento dos meios de comunicação contribuíram para melhorar a saúde dos indivíduos, bem como mudar os valores, crenças e comportamentos referentes à vida familiar e ao número desejado de filhos. Entretanto, o comportamento demográfico se mostrou diferenciado para cada país, pois além de dependerem diretamente da expansão da economia, sofreram modificações em função da difusão e aplicação dos avanços da medicina, do melhoramento do estado nutricional da população e, ainda, do maior acesso à atenção à saúde e à educação. ${ }^{3}$ A transição demográfica dos países latino-americanos iniciou-se em épocas distintas e com características próprias. De um modo geral, o declínio da mortalidade ocorreu rapidamente, graças à importação da tecnologia de saúde, enquanto a fecundidade se manteve elevada, gerando crescimento populacional e explosão demográfica. A partir da década de 1970, em virtude da aceleração do declínio da fecundidade, ocorreu uma diminuição gradativa do número de filhos / mulher, em média 2,5 nascimentos, com tendência de decréscimo para média de um filho / mulher. ${ }^{7}$

Para compreender a situação da transição demográfica na América Latina, o CELADE $^{4}$ destacou quatro grupos, segundo o crescimento natural da população e estrutura por idade. No primeiro grupo, encontram-se os países com alta fecundidade e mortalidade e 
uma estrutura por idade com indivíduos muito jovens, classificado como transição incipiente. Nesse grupo, destacam-se a Bolívia e Haiti. O segundo grupo, classificado como de transição moderada, apresenta alta fecundidade e moderada mortalidade, principalmente no primeiro ano de vida, em que se reflete um rejuvenescimento da estrutura por idades. Destacam-se os países de El Salvador, Guatemala, Honduras, Nicarágua e Paraguai. Nos países destacados acima, constantes do primeiro e segundo grupos, classificados como de estrutura jovem, $50 \%$ de sua população estão abaixo de 15 anos. O terceiro grupo apresenta-se em plena transição, com fecundidade moderada e mortalidade moderada ou baixa. A população ainda se mantém jovem, com proporções que variam de 32 a 36\% com menos de 15 anos. Enquadram-se neste, os seguintes países: Brasil, Colômbia, Costa Rica, Equador, México, Panamá, Peru, República Dominicana e Venezuela. No quarto grupo, de um modo geral, a fecundidade e a mortalidade são de moderadas a baixas. Caracteriza-se por uma estrutura etária de idades maduras, podendo ser chamadas de envelhecidas, com percentuais menores do que $20 \%$ da população abaixo de 15 anos de idade. Destacam-se os países do Chile, Uruguai, Porto Rico, Argentina e Cuba.

\subsubsection{A Transição Demográfica no Brasil}

No decorrer do século XX, a transição demográfica efetivou-se pela ruptura de um regime demográfico tradicional, fundamentado por altas taxas de fecundidade e mortalidade para um regime moderno, caracterizado por baixas taxas de fecundidade e mortalidade. $\mathrm{O}$ declínio da fecundidade fez diminuir o tamanho das famílias, aumentar o intervalo das gestações e, conseqüentemente favoreceu a queda da mortalidade dos recém-nascidos e das

gestantes. ${ }^{6,2}$ Segundo alguns autores, nas últimas décadas, a industrialização, a urbanização e o desenvolvimento científico e tecnológico acham-se entre os principais responsáveis pela transição demográfica. Entretanto, as mudanças dos indicadores de mortalidade se explicam 
mediante a melhoria do saneamento básico e do progresso da medicina, que evoluiu com a medicamentação dos antibióticos e quimioterapia, com a descoberta do DDT, com a vigilância e controle das doenças infecciosas e com a ampliação dos serviços de prevenção e assistência médica. $^{5,7}$

A estrutura etária da população brasileira apresentou mudanças, tendo em vista o decréscimo em percentuais do grupo etário relativo aos jovens. Segundo Menezes, ${ }^{\mathbf{8}}$ no período entre o ano de 1950 ao de 1991, a faixa etária de jovens (0 a 14 anos) decresceu de $42 \%$ para $35 \%$ e o percentual de idosos (mais de 60 anos) quase duplicou, passando de $4 \%$ para 7,5\%. Nesse mesmo período, a expectativa de vida do brasileiro passou de 46 para 65,5 anos. Em seus estudos, ao analisar distintamente as diversas regiões do país, o autor encontrou algumas disparidades demográficas, como:

a média de vida dos brasileiros mais ricos gira em torno de 70 anos, muito superior à dos brasileiros mais pobres, que é cerca de 50 anos;

a esperança de vida da população residente na região Sul é de 69 anos, enquanto na região Nordeste é de 64 anos;

a taxa de fecundidade da população residente na região Sul é de 2,3 por mil mulheres e, na região Nordeste, de 4,0 por mil mulheres;

os idosos residentes na região Sudeste representam $8 \%$ da população e, na região Norte $5,4 \%$ da população total.

A evolução da fecundidade com sua diminuição progressiva alterou a estrutura etária da população brasileira e contribuiu para o envelhecimento populacional, principalmente nos estados da região Sudeste (Rio de Janeiro, São Paulo e Minas Gerais). O processo de migração de pessoas jovens, deslocando-se das zonas rurais para as zonas urbanas e do Nordeste para os estados do Sudeste, modificou a estrutura etária da população, causando, ao longo do tempo, a concentração de pessoas idosas nas áreas urbanas e mais desenvolvidas 
economicamente, com melhor infra-estrutura de serviços, condições de vida mais adequadas, onde, conseqüentemente, a esperança de vida tornou-se mais elevada. ${ }^{\mathbf{8}}$

No Brasil, as modificações ocorridas na estrutura etária da população transformaram o país de tipicamente "jovem" para um país "adulto", se posicionando em uma situação intermediária frente aos países de população jovem e os de população idosa. A estrutura da pirâmide etária se distanciou daquelas encontradas nas nações subdesenvolvidas, aproximando-se das pirâmides identificadas nas nações desenvolvidas. ${ }^{\mathbf{9}}$

As pirâmides etárias da Figura 1 demonstram o processo de mudanças demográficas, ocorrido no Brasil, referentes à composição e à estrutura da população. Inicialmente, verificou-se um declínio da mortalidade, a seguir da fecundidade e, posteriormente, um aumento da população adulta e de idosos. A partir de 1980, observou-se gradativamente o decréscimo da população infantil, o aumento dos jovens, dos adultos e dos idosos. Em 2000, o desenho da pirâmide, ilustra a transição demográfica, que se distingue pelo estreitamento de suas bases e um alargamento nos ápices. Essas mudanças se relacionam com as grandes transformações sociais e econômicas que determinaram o perfil demográfico das populações, que, por sua vez, recebeu em parte, influência do processo de urbanização e dos meios de comunicação que proporcionaram uma melhoria da saúde e da qualidade de vida dos indivíduos. Em conseqüência, novas demandas e grandes desafios surgirão para o setor saúde, o que implicará na implantação de ações e programas específicos adequados à idade senil, e na alocação de recursos humanos e financeiros. 
Figura 1: Pirâmides Populacionais, Brasil, 1980, 1991, 2000

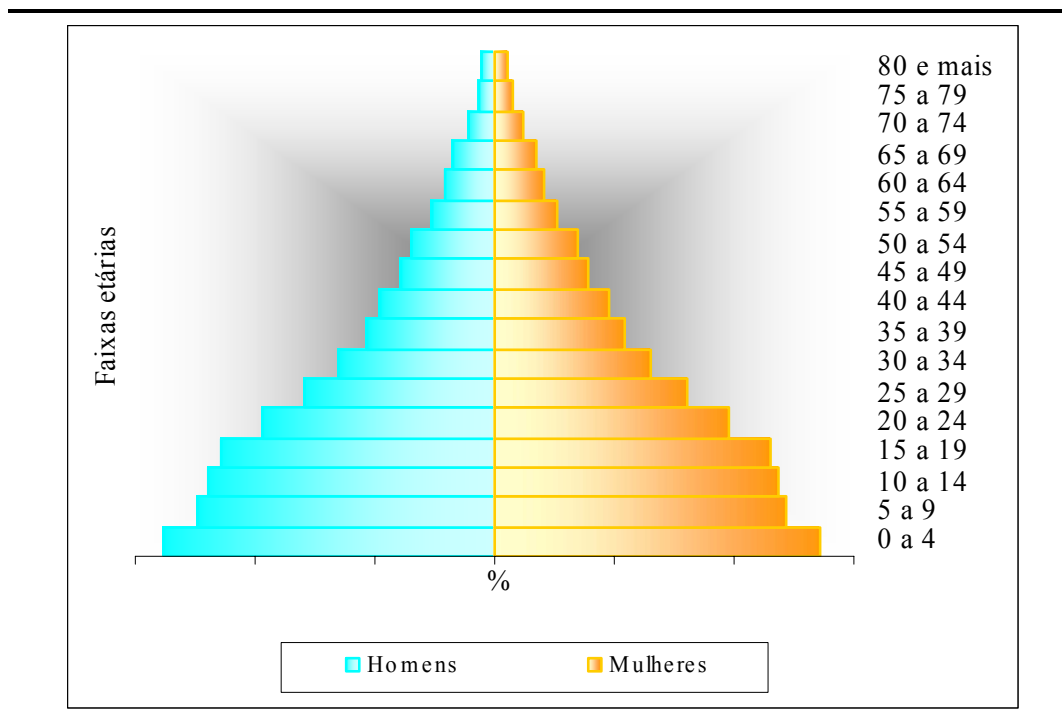

Pirâmide relativa a 1980

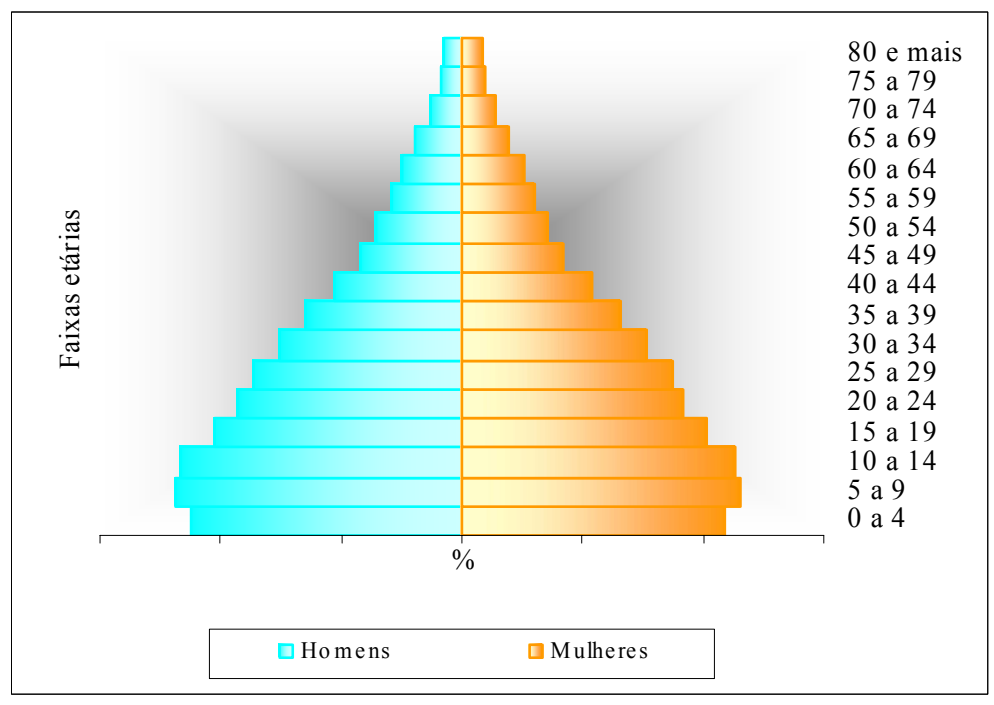

Pirâmide relativa a 1991

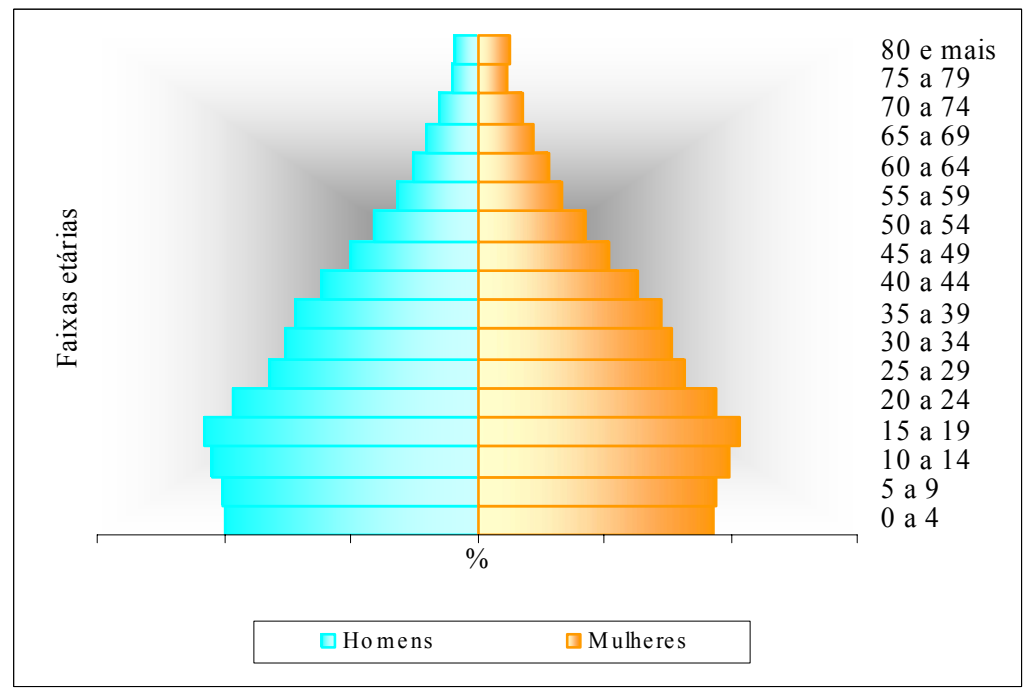

Pirâmide relativa a 2000

Fonte: Ministério da Saúde / DATASUS ${ }^{\mathbf{1 0}}$ 


\subsection{A Transição Epidemiológica}

A expressão "transição epidemiológica" refere-se fundamentalmente, às mudanças na troca de uma situação de alta prevalência e mortalidade por doenças infecciosas e parasitárias para uma outra condição em que passam a prevalecer as doenças não infecciosas ou crônico degenerativas, especialmente as relativas ao sistema circulatório, tumores e aquelas referentes às causas externas, nas quais se incluem os acidentes e violências. ${ }^{3}$

A teoria da transição epidemiológica foi descrita pela primeira vez por Omran. ${ }^{11}$ Segundo o autor, à medida que os países evoluem e progridem em seu desenvolvimento, naturalmente, diminuem a incidência e a prevalência das doenças infecciosas e parasitárias, passando de altas taxas de mortalidade em grupos etários precoces, para um estado aonde vêm a predominar as doenças degenerativas ou causadas pelo homem, em grupos etários mais avançados. Como essas últimas são de longa duração, ocorre uma situação paradoxal, qual seja, a de declínio da mortalidade e aumento da morbidade, com um acúmulo de doenças na população, notadamente em adultos e idosos.

Omran ${ }^{11}$ utiliza a teoria da transição epidemiológica para analisar o processo de mudança nos países, a partir das seguintes proposições:

Proposição 1: A mortalidade é um fator fundamental na dinâmica populacional;

Proposição 2: As mudanças nos padrões de morbidade e mortalidade são lentas, com um decréscimo das doenças infecto-contagiosas substituídas ao longo do tempo pelas doenças crônicas não transmissíveis, e por aquelas provocadas pelo homem, relacionadas diretamente ao estilo de vida;

Proposição 3: As mudanças ocorridas no padrão de morbi-mortalidade referem-se aos riscos relativos segundo o sexo e a faixa etária;

Proposição 4: As mudanças nos padrões de saúde / doença estão diretamente relacionadas com a transição demográfica e com os padrões sócio-econômicos da população. 


\subsubsection{Os Estágios da Transição Epidemiológica}

Segundo Omran, ${ }^{12}$ cinco estágios distintos se destacam na transição epidemiológica, no decorrer dos tempos, a saber:

Estágio 1: Idade das pestilências e da fome. Período entre a idade média e meados do século XIX, caracterizava-se pela alta mortalidade e fecundidade, com predominância das doenças infecciosas e parasitárias. A mortalidade destacava-se pelas doenças endêmicas, desnutrição, alta mortalidade de crianças, falta de terapias decisivas e acesso limitado aos serviços de saúde. Nesse estágio, a população era jovem, e a esperança de vida ao nascer, oscilava entre 20 e 50 anos.

Estágio 2: Idade do desaparecimento das pandemias (final do século XIX e início do século XX) caracterizava-se pela diminuição das epidemias. As taxas de mortalidade por doenças cardiovasculares e câncer aumentavam lentamente, enquanto as taxas de mortalidade e fecundidade decresciam. A esperança de vida ao nascer atingiu uma média de 50 anos, acarretando um crescimento populacional.

Estágio 3: Idade das doenças degenerativas e as provocadas pelo homem (meados do século XX). A mortalidade continuou declinando, a esperança de vida ao nascer aumentou gradualmente, ultrapassando os 50 anos. A fecundidade tornou-se o fator primordial na determinação do padrão etário da população. Nesse estágio, houve predomínio do aumento das doenças degenerativas e daquelas ocasionadas pelo homem, tais como os acidentes radioativos, os de veículos a motor, os ocupacionais, e os ocasionados por produtos carcinogênicos e das doenças relativas ao estresse.

Estágio 4: Idade do declínio da mortalidade por doenças cardiovasculares, das mudanças no modo de vida, do envelhecimento populacional, do aparecimento de novas doenças e o ressurgimento de outras já controladas (quatro últimas décadas do século XX até os dias atuais). A mortalidade manteve-se em níveis menores, apresentando aumentos 
ocasionais por idades e grupos sociais distintos. As taxas de fecundidade e de mortalidade diminuíram, resultando num crescimento populacional negativo.

Estágio 5: Idade da longevidade paradoxal, do aparecimento das doenças enigmáticas e de capacidade tecnológica para a sobrevivência dos doentes e reabilitação dos incapacitados (século XXI, entre 2004 a 2025). Esse é o estágio do futuro, quando se espera que as doenças degenerativas e as doenças ocasionadas pelo homem estarão na liderança das principais causas de morbi-mortalidade. Presume-se que essas doenças poderão se agregar com as novas doenças da senilidade e aquelas ocasionadas pelos microorganismos oportunistas. A expectativa de vida continuará aumentando até os 90 anos ou mais, devido aos avanços nos recursos tecnológicos de diagnósticos e tratamento das doenças e reabilitação dos indivíduos, associados às mudanças de estilo de vida. Omran ${ }^{12}$ caracteriza esse momento com uma "longevidade paradoxal", uma vez que nos maiores anos de idade é que se encontram as doenças, os enfraquecimentos físicos e psicológicos, o isolamento, as separações, as depressões e o declínio do status social. A dependência do idoso fica sob a responsabilidade e o reforço da família, que aumenta suas necessidades econômicas com tratamentos e reabilitações, sobretudo quando se exige um sistema de suporte psicológico e terapêutico que demanda custos altíssimos. $\mathrm{O}$ autor pressupõe ainda, que as mortes violentas e acidentais persistirão, mantendo-se em patamares altos. A eutanásia e os suicídios poderão apresentar uma tendência de aumento entre os idosos, os deficientes físicos e entre aqueles que convivem com a dor e a depressão.

\subsubsection{Os Modelos da Transição Epidemiológica}

Os modelos da transição epidemiológica são determinados tendo como referência o momento histórico, a velocidade e a magnitude por que cada país atravessou as etapas de sua transição epidemiológica. Omran ${ }^{11}$ destaca distintos modelos da transição epidemiológica: 
a) Modelo clássico ou ocidental: caracteriza-se por uma progressiva redução da mortalidade

e fecundidade, acompanhada de um predomínio das doenças degenerativas e daquelas causadas pelo homem, vivenciadas nos países da América do Norte e da Europa Ocidental.

b) Modelo acelerado ou de transição acelerada: caracteriza-se pela rápida e acentuada queda das taxas da mortalidade e fecundidade. Como exemplo, temos o Japão.

Esses dois modelos se referem aos países onde ocorreu o declínio da mortalidade antes do século XX e a queda da fecundidade após um pequeno intervalo de tempo.

c) Modelo contemporâneo ou de transição retardada: caracteriza-se por uma queda da mortalidade muito lenta, não sendo seguida pela redução da fecundidade. Essas mudanças são recentes e ainda se encontram em processo nos países em desenvolvimento. O declínio da mortalidade começa a suceder nos primórdios do século XX e o da fecundidade, após a metade desse. Para o referido modelo, o autor identifica três variantes: a variante transicional rápida, a variante transicional intermediária e a variante transicional lenta.

A variante transicional rápida ocorreu em sociedades recém industrializadas ou de rápido desenvolvimento, entre as quais se distinguem países como Taiwan, Coréia do Sul, Srilanka, Chile e outros. A mortalidade começou a declinar antes da metade do século XX e a fecundidade posteriormente, apresentando, na década de 60 , a relação de cinco crianças por mulher em idade fértil.

A variante transicional intermediária é representada por países com níveis de renda média que se agrupam, como: Indonésia, Brasil, Venezuela e Líbano, ou se aproximam daqueles com patamares de renda baixa, como: Egito, Marrocos, Índia, Peru e Paraguai. Apesar de evidenciarem programas de planejamento familiar bem estruturados, vêm enfrentando outros problemas relacionados à má nutrição, ao crescente aumento das doenças transmissíveis, às elevadas taxas de morbidade pelas doenças crônicas degenerativas e 
àquelas provocadas pelo homem. Convivem ainda, com o aparecimento das doenças reemergentes, como a malária, o cólera e das emergentes, como a AIDS.

A variante lenta é típica de algumas regiões da África, América Latina e Ásia. Nessas sociedades, a mortalidade começou a declinar de níveis altos para níveis moderados até a metade do século XX, e a fecundidade se manteve em níveis altos até os dias atuais. Outros agravos ainda sobrecarregam essa população e contribuem para o aumento das taxas de mortalidade, como a desnutrição, as doenças transmissíveis, as doenças degenerativas e aquelas provocadas pelo homem, além das reemergentes e emergentes.

\subsubsection{A Transição Epidemiológica nos Países da América Latina.}

Para Frenk, ${ }^{13}$ os países da América Latina estão incluídos no modelo contemporâneo ou retardado, proposto por Omran. ${ }^{11}$ A queda da mortalidade ocorreu lentamente e a fecundidade se manteve alta ainda por um determinado período. Ao mesmo tempo, as doenças infecciosas e parasitárias foram declinando, deixando de se posicionarem como principal causa de óbito, sendo substituídas, lentamente, pelas doenças crônicas degenerativas.

Luna ${ }^{14}$ observa um quadro de grande heterogeneidade entre e dentro de cada país da América Latina. Alguns se apresentam em uma etapa mais avançada de transição, dentro de uma modalidade próxima dos países desenvolvidos, como Cuba, Costa Rica e Chile, respondendo bem ao que Omran, ${ }^{11}$ em 1971, denominou de modelo contemporâneo ou retardado. Outras nações se integram em um processo inicial de transição como Haiti, Bolívia e Peru, onde ainda predominam altas taxas de mortalidade por doenças infecciosas aliadas, a um aumento das doenças crônicas degenerativas. Entre estes grupos, que se encontram em uma etapa avançada e aqueles que se encontram em uma etapa inicial de transição, surge um terceiro grupo, que apresenta características específicas que não se amolda aos modelos 
anteriores, embora se enquadre numa transição intermediária e se identifica como Modelo Polarizado Prolongado. Este modelo caracteriza-se principalmente, pela coexistência de um relativo recrudescimento das doenças infecciosas, controladas anteriormente e com um incremento das doenças crônico-degenerativas. O México e o Brasil constituem um dos melhores exemplos desse processo.

Em síntese, a transição epidemiológica, na América Latina, ocorreu muito mais pela aplicação de tecnologia de saúde, com extensão de cobertura dos serviços de saúde do que devido a grandes mudanças estruturais, determinadas por melhores condições de vida, nutrição, habitação, saneamento e melhorias sociais.

\subsubsection{A Transição Epidemiológica no Brasil}

Segundo Omran, ${ }^{11}$ o Brasil se enquadra no modelo de transição contemporânea ou retardada, cuja principal referência é a tecnologia da assistência médica e das ações de saúde. Diferentemente dos países desenvolvidos, como Europa, América do Norte e Japão, sua transição foi determinada, prioritariamente, pelos fatores ambientais, sociais e econômicos.

$\mathrm{Na}$ figura 2, observam-se mudanças proporcionais da mortalidade nos quatro principais grupos de causas definidas, responsáveis pela alteração do perfil da mortalidade da população brasileira. No período de 1930 a 1999, as doenças infecciosas e parasitárias (DIP), ao longo das décadas, apresentaram mudanças significativas, com decréscimo da mortalidade. Porém, as doenças referentes ao aparelho circulatório, as causas externas e as neoplasias exibem, de modo proporcional, uma tendência de crescimento contínuo e sobressaíram como os principais grupos de causas de óbito nas últimas décadas. Ressalta-se que o grupo das doenças do aparelho circulatório, apesar de se posicionar como principal causa de óbito a partir de meados da década de 60 apresentou, proporcionalmente, um crescimento menor do que as neoplasias e as causas externas. 
Figura 2. Evolução temporal da mortalidade proporcional por quatro principais grupos de causas definidas no Brasil, 1930 a 1999.

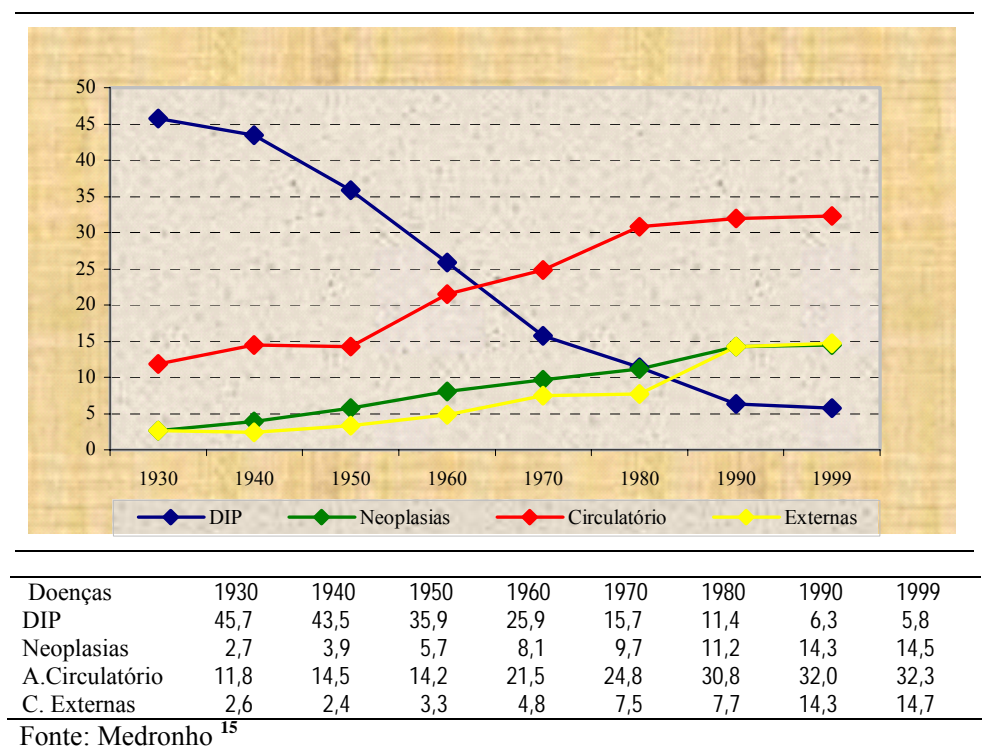

Para Mello Jorge et al, ${ }^{16}$ o efeito da transição sobre a composição populacional referese a uma maior mortalidade no sexo masculino e uma tendência de crescimento entre os jovens e adultos. As principais causas de óbitos são as causas externas, seguidas do aparelho circulatório, neoplasias e doenças do aparelho digestivo. Para o sexo feminino, destacam-se as doenças do aparelho circulatório, seguida das neoplasias e das causas externas. Duchiade, ${ }^{2}$ relata que as alterações nos padrões epidemiológicos da população brasileira determinaram um aumento na esperança de vida ao nascer, na vida média e na sobrevivência da população. Entretanto, a partir da década de 1990, a tendência de crescimento da morbidade / mortalidade referente aos acidentes e violência vêm alterando o perfil epidemiológico dos indivíduos do sexo masculino, mormente nas faixas etárias de 5 a 19 e 20 a 29 anos.

O processo de industrialização, a urbanização crescente do país, a melhoria do saneamento básico contribuíram para a melhoria das condições de vida da população brasileira. O decréscimo das taxas de mortalidade e fecundidade alterou a estrutura etária brasileira, determinando o envelhecimento populacional. Em conseqüência, agravou-se a 
morbidade das doenças relativas ao aparelho circulatório, das degenerativas e de outras decorrentes da idade senil. ${ }^{9}$

Alguns autores buscam nas teorias de Omran ${ }^{\mathbf{1 1}, 12}$ referências que possam subsidiá-lo na análise da mudança do perfil epidemiológico brasileiro. Laurenti ${ }^{3}$ identifica no Brasil, o estágio intermediário da transição, destaca a queda da mortalidade, o aumento da morbidade e o predomínio das doenças crônicas degenerativas. Prata ${ }^{17}$ identificou diferentes causas de mortalidade nas distintas regiões geográficas do Brasil. Para Reichenheim e Werneck, ${ }^{18}$ a transição epidemiológica se manifesta de forma diferenciada nas regiões e grupo sociais distintos. Para uma expressiva parcela da população, vem ocorrendo uma superposição de doenças, na medida em que se associam às doenças infecciosas e parasitárias com as crônicodegenerativas e as causas externas. Entretanto, para outras, mediante os extratos sócioeconômicos privilegiados, seu quadro nosológico se aproxima ao dos países desenvolvidos, com predomínio das doenças crônico-degenerativas e causas externas.

\subsection{A Mortalidade por Causas Externas como Problema de Saúde Pública e de Saúde}

\section{Coletiva.}

As "causas externas" ou "causas não naturais" ou "causas violentas" englobam os acidentes e violências, referem-se às ocorrências e circunstâncias ambientais que causam as lesões, envenenamentos e demais efeitos adversos. Sempre se sobressaíram por acontecerem em circunstâncias inesperadas e por produzirem danos imensuráveis, que matam ou lesam as pessoas.

Na série histórica entre o período de 1980 a 1995, as causas externas estão codificadas pela $9^{a}$ Revisão da Classificação Internacional de Doenças - CID-9. ${ }^{19}$ Sua tabulação e codificação estão definidas no capítulo referente à "Classificação Suplementar de Causas 
Externas de Lesões e de Envenenamentos" e abrange as categorias E800 a E999. A partir de

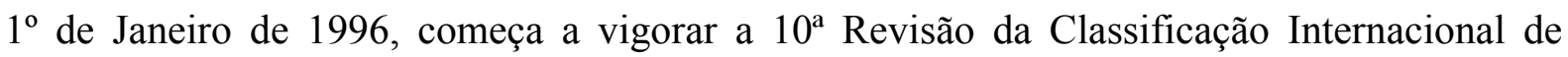
Doenças - CID 10. ${ }^{20}$ As causas externas passam a serem tabuladas e codificadas no capítulo XX referente às "Causas Externas de Morbidade e Mortalidade", nas categorias V01 a Y98.

A mortalidade por causas externas está diretamente relacionada com os óbitos decorrentes de acidentes e violências, existem desde o início da humanidade, quando os indivíduos enfrentavam os perigos ambientais para sua sobrevivência, principalmente para se defenderem ou para proteger suas propriedades. Com a evolução dos tempos, o avanço tecnológico, a complexidade da industrialização e da urbanização, ampliou-se nas exposições, os riscos de acidentes e violências no domicílio, no trabalho, no transporte e no lazer.

Ao refletir sobre seus fatores determinantes, verifica-se que são múltiplos e estão em consonância com a estrutura de cada país, seja nos países desenvolvidos, seja naqueles em desenvolvimento. Apesar de parecer paradoxal, é na medida que os países evoluem que aumenta a diversidade e complexidade dos agravos por causas externas. Os envenenamentos, antes resultantes de produtos naturais, evoluíram para os produtos químicos; os acidentes por máquinas a vapor foram substituídos pelos de veículos motorizados; surgiram os acidentes ocasionados por naves espaciais, por bombas diversas e outros. O uso de armas de fogo ou branca, que se tornou comum no dia a dia da população brasileira, até mesmo para autoproteção ou defesa, aumentou em aproximadamente $90 \%$ os casos de óbitos por homicídios. A dependência química desenvolve nos indivíduos uma violência sem limites, levam-nos a assassinatos, roubos e seqüestros para fomentarem seus próprios vícios. A cultura da televisão se torna, em parte, responsável pela veiculação da violência, na medida em que vulgariza as relações psicossociais na formação e construção dos indivíduos e da sociedade Mello Jorge et al. ${ }^{16}$ 
O crescimento da violência e dos acidentes, nas últimas décadas, veio a se tornar uma das mais graves preocupações da sociedade contemporânea, constituindo-se em um dos problemas mais difíceis de serem abordados. O grupo de causa externa de maior impacto epidemiológico e que atinge populações com diferenças sociais, econômicas e geográficas, encontram-se nos homicídios, seguidos dos acidentes de transporte e, posteriormente os suicídios. Apresentam-se com uma maior predominância em grupos etários jovens, de preferência nos adolescentes e adultos jovens, deslocando-se para faixas etárias menores, avolumando, conseqüentemente, os Anos Potenciais de Vida Perdidos (APVP) e colocando em risco a esperança de vida da população brasileira. Mello Jorge et al. ${ }^{16}$

Segundo Minayo, ${ }^{21}$ embora a violência e os acidentes não se constituam um problema de saúde, a complexidade de seus fatores determinantes tem sido responsável por deixar seqüelas e incapacidades ou levar ao óbito os indivíduos, exigindo do setor saúde recursos financeiros para cobrir as despesas nas urgências, nas emergências e nas reabilitações e recursos humanos, cada vez mais especializados para o mesmo fim. A incapacidade governamental de prover as mínimas condições de sobrevivência a vastas parcelas da população, a tendência de crescimento da violência ligada ao crime organizado, o aumento do número de veículos a motores e a incapacidade de manutenção das estradas de rodagem, amplia a probabilidade de ocorrência desses agravos, posicionando-os como sérios problemas de saúde pública e de saúde coletiva.

Sua prevenção deve ser priorizada em todas as esferas sociais. Além do cuidar das conseqüências dos atos violentos, é preciso enfrentar o problema, identificar os fatores de risco e as causas, delineando e avaliando intervenções, implementando programas locais efetivos, ampliando recursos, treinando e qualificando profissionais envolvidos, numa proposta de integralidade com setores e grupos multiprofissionais e com instituições governamentais e não-governamentais. Necessário se faz também, associar ações efetivas 
voltadas para a segurança do trânsito, para a vigilância e para a segurança pública, de preferência para o segmento mais jovem da sociedade. Para o setor saúde, torna-se essencial aglutinar esforços com os demais segmentos, compartilhando, tanto quanto possível, as atividades de coordenação, visando manter sistemas de gerenciamento epidemiológico para o planejamento de saúde e elaboração de políticas públicas. ${ }^{22,23}$

Segundo Mello Jorge et al, ${ }^{16}$ o perfil brasileiro relativo às causas de morte vem sendo alterado ano a ano, preferencialmente pelos acidentes e violência, necessitando, portanto, de medidas intervencionistas, enérgicas e urgentes, principalmente das autoridades governamentais, o que justifica sua prioridade nos programas e ações de saúde para a população brasileira.

\subsubsection{Mortalidade por Causas Externas nos Países Desenvolvidos e em Desenvolvimento}

Em 1985, a OMS estimou que aproximadamente 7\% do total de óbitos no mundo eram devidos às causas externas e que cerca de $2 \%$ da população mundial estava inabilitada, em conseqüência a uma ação causada por acidente ou violência. Em alguns países se encontram entre as dez e ou cinco principais causas de óbito. ${ }^{24,25}$

Os Estados Unidos, em 1965, reconheceram a violência e os acidentes como epidemia e problema de saúde pública. Desde então, implantaram um Sistema de Vigilância em Acidentes com o objetivo de quantificar os gastos financeiros em saúde, identificar os possíveis fatores de risco, avaliar, planejar e organizar programas de prevenção e controle dos acidentes. $^{26}$

Segundo a OPAS ${ }^{27}$ em alguns países, o desenvolvimento de uma cultura da violência foi em parte, responsável pelo aumento dos anos potenciais de vida perdidos, principalmente por afetar indivíduos jovens. No Canadá, onde a violência atingia pequena parcela da população, nos últimos anos houve um crescimento considerável da criminalidade, também 
prioritariamente nas faixas etárias jovens. Nos Estados Unidos e França se destacam os acidentes de transporte; na Áustria e Japão, os suicídios; na Colômbia, México e Brasil, os homicídios se sobressaem, com altas taxas de mortalidade e um crescimento contínuo, com mais probabilidade entre os jovens.

Nos estudos de Macedo et al, ${ }^{28}$ o Brasil, México, Nicarágua, Panamá e Venezuela se equiparam em termos de risco de morte por causas externas, sendo apenas superados pela Colômbia. Quando se comparam os dados do Brasil com os Estados Unidos, Canadá e Suécia, verificou-se que esses últimos apresentaram praticamente a metade dos valores expressos para o Brasil.

Na América Latina, no início do século XXI, a mortalidade por causas externas incide de preferência nos adolescentes e jovens nas faixas etárias entre 10 e 24 anos, o que representa uma perda de aproximadamente 20,5\% e 8,1\% dos Anos Potenciais de Vida Perdidos (APVP), respectivamente, para os homens e para as mulheres. No Brasil, destacamse as causas externas com as maiores taxas de mortalidade no sexo masculino, sendo 2,3 vezes maiores do que as da Suécia e 2,9 vezes maiores do que as do Japão. De um modo geral, há uma maior mortalidade no sexo masculino, evidenciando-se uma relação aproximada de 4,5 homens para 1 mulher. As diferenças mais acentuadas encontram-se na Colômbia (4,7 para 1), Porto Rico (5 para 1) e Guatemala (5,2 para 1). A menos acentuada está em Cuba, numa razão de 2 homens para 1 mulher. Os autores enfatizam que a maior concentração de óbitos por causas externas no sexo masculino e em faixas etárias mais jovens é uma tendência mundial e se justifica pelos fatores comportamentais dos homens que, usualmente, se expõem com maior freqüência, aos perigos dos acidentes e violência. ${ }^{\mathbf{1 6}, 21}$ 


\subsubsection{A Evolução da Mortalidade por Causas Externas no Brasil.}

No decorrer dos anos, no Brasil, a mortalidade por causas externas vem se agravando, sendo responsável pela mudança do perfil epidemiológico e se posicionando como problema de saúde coletiva, principalmente nas grandes metrópoles. Ao final da década de 1970, a mortalidade por esse grupo de causas se mostrava preocupante, com uma taxa de 50 óbitos para 100.000 habitantes, constituindo o quarto grupo mais importante das causas definidas. Ao final da década de 1980 já apresentava uma taxa de 69 óbitos por 100.000 habitantes. Em 1996, essa taxa evoluiu para 76 óbitos por 100.000 habitantes e em 1999 passou para 71,3 óbitos por 100.000 habitantes. ${ }^{\mathbf{1 6}}$

Nas regiões e estados do Brasil, o comportamento dos coeficientes de mortalidade apresenta-se diferente e é determinado pelas distintas áreas geográficas. Em 1999, as regiões Sudeste e Centro Oeste se destacaram com os maiores coeficientes, de 87,3 e 80,2 por 100.000 habitantes, respectivamente. Na região Sudeste, o estado de Minas Gerais apresentou o menor coeficiente (50,9 por 100.000 habitantes), seguido por São Paulo (95,2), Espírito Santo $(97,7)$ e Rio de Janeiro $(110,1)$. Esses dois últimos encontram-se dentre os mais violentos do país, perdendo somente para o Estado de Roraima, com 148,7 óbitos por 100 mil habitantes. ${ }^{16}$

Corteleti ${ }^{29}$ demonstrou que, em Minas Gerais, na década que compreende o período de 1986 a 1997, houve um aumento dos crimes violentos em quase $100 \%$, principalmente na região metropolitana de Belo Horizonte, no Triângulo Mineiro, no Vale do Rio Doce e em cidades com mais de 100 mil habitantes. Em seus estudos, o autor procura associar alguns fatores que podem justificar a alteração da criminalidade, como: a modernização da sociedade brasileira nos últimos anos, a legislação penal deficiente, o descaso do Estado em investir na segurança pública, a diminuição do poder aquisitivo dos policiais e o sucateamento do aparato da Policia Militar. Recomenda também que, caso não haja medidas pontuais, 
dentro de dez anos o estado de Minas Gerais estará se igualando ao do Rio de Janeiro, com gangues de traficantes controlando bairros e favelas.

Camargo et al ${ }^{30}$ concluíram que, de um modo geral, em algumas capitais brasileiras, o risco de morte por causas externas é de três a cinco vezes mais alto na população do sexo masculino. Em 1989, a maior taxa para o sexo masculino ocorreu no Rio de Janeiro, com 200 óbitos por 100.000 homens, seguida das de São Paulo, Porto Alegre e Recife, com taxas acima de 100 óbitos por 100.000 homens, com tendência ascendente. As mulheres se destacam nas cidades do Rio de Janeiro e Curitiba, com 40 óbitos por 100.000 mulheres. Segundo Yunes, ${ }^{31}$ na medida em que as mulheres atingem mais alto grau de escolaridade e se inserem nas atividades laboriosas, competindo no mercado de trabalho com os homens, suas taxas de mortalidade por causas externas tendem a exacerbar-se com novos fatores de risco. Para Minayo, ${ }^{21}$ Mello Jorge et al, ${ }^{16}$ até 1995 , a taxa de mortalidade por causas externas aumentou em torno de $30 \%$ para o sexo masculino e em $10 \%$ para o sexo feminino. A razão de mortalidade para os homens era de 3:1 em relação às mulheres, porém, há um indicativo de maior proporção de óbitos em mulheres acima de 60 anos, provavelmente vítimas de quedas e acidentes.

Os acidentes e a violência constituem o principal grupo de causa definida responsáveis pela mortalidade de indivíduos entre as faixas etárias de 5 aos 39 anos de idade, em todas as capitais do país. Desde a década de 1980, os estudos apontam um deslocamento dos coeficientes de mortalidade por causas externas para faixas etárias mais jovens. As cidades do Rio de Janeiro e São Paulo revelam um aumento dos óbitos em jovens de 15 a 24 anos, especificamente nas causas referentes aos acidentes de transporte e homicídios. A partir de 2001, passam a se expandir para grupos etários de 5 aos 39 anos, havendo acréscimos nos valores referente aos Anos Potenciais de Vida Perdidos (APVP). Para os serviços de saúde, 
altera-se seu perfil, com uma sobrecarga de custos para o atendimento na urgência, tratamento dos feridos e das seqüelas geradas em uma população estritamente jovem. ${ }^{\text {5, 21, } 32}$

No que se refere à notificação da causa do óbito, por causas externas, por muitas vezes os legistas não conseguem identificar a causa básica e então essa é notificada como: "lesões em que se ignora se foram acidentais ou intencionalmente infligidas", restando, portanto, um contingente de casos que permanecerão na categoria dos ignorados. Necessário se faz comentar também o incontrolável número de lesões não tratadas nos serviços de saúde, portanto, não notificadas e que proporcionam uma subnotificação de casos prejudicando a análise das taxas globais de morbidade e mortalidade e ocasionado um sério problema para a organização e planejamento dos serviços de saúde. ${ }^{16,33,34}$

\subsubsection{Grupos de Causas}

\subsubsection{Homicídios}

Os Homicídios, evento denominado na CID-10, como Agressões, apresentam os códigos X85 a Y09 e na CID-9, como Homicídios e Lesões Provocadas Intencionalmente por Outras Pessoas, com os códigos E960 a E969 OMS. ${ }^{19,20}$

Esse grupo é considerado por muitos autores como o de mais difícil na prevenção e controle. Suas causas determinantes estão, geralmente, associadas às desigualdades sociais e econômicas pelas quais têm passado alguns países, mormente os latino-americanos, nos quais parcialmente "se permite" o crime organizado em torno do narcotráfico, do excessivo abuso de bebidas alcoólicas e do uso de drogas. O perfil dos indivíduos mortos por Homicídios, geralmente é de origem de famílias que apresentam sérios conflitos domésticos, sofrem maus tratos, fazem uso de álcool e substâncias tóxicas, associados a comportamentos violentos Minayo. $^{21}$ 
Segundo a OPAS, ${ }^{27}$ os Homicídios estão crescendo praticamente em todos os países e, em alguns, vêm assumindo características de pandemia, gerando graves problemas de saúde pública. No Brasil, ao longo dos anos, apresenta alterações significativas na transição epidemiológica, com tendência crescente, sendo suas taxas mais elevadas que a dos Estados Unidos, Canadá e alguns países europeus. Os estudos de Camargo, et al ${ }^{30}$ demonstram que a mortalidade por Homicídio nas cidades de São Paulo e Recife excede em mais de cinqüenta vezes a mortalidade na Grã-Bretanha e Japão. No Brasil, no início da década de 1980, suas taxas apresentavam valores inferiores aos dos Acidentes de Transporte. A partir da década de 1990, ultrapassam esse grupo de causa, mantendo uma tendência crescente de aproximadamente $100 \%$, em quase todas as unidades da federação.

Dentre as regiões brasileiras, em 1999, a Sudeste apresentou a mais alta taxa, com 37,4 óbitos por 100.000 habitantes, em seguida a região Centro Oeste, com 25,9 por 100.000 habitantes. Para os estados como Roraima $(57,6)$, Pernambuco $(55,6)$, Rio de Janeiro $(52,6)$ e Espírito Santo $(51,9)$ os coeficientes eram mais elevados, bem acima da média nacional, qual sejam, 25,4 por 100.000 habitantes. Com referência às capitais, Vitória surgiu como pólo de violência, com o mais elevado índice de morte por homicídios, seguida de Recife, São Paulo, Rio de Janeiro e Cuiabá. 16, 35

A Tabela 1 apresenta as mudanças na mortalidade por Homicídios no Brasil, no período de 1996 a 1999. Os dados demonstram que no decorrer dos anos, os coeficientes da mortalidade tornaram-se mais intensos, ano a ano, o que retrata, de uma forma incipiente, o crescimento da violência no país. 
Tabela 1 - Número absoluto, proporção de óbitos e taxa de mortalidade para 100.000 habitantes, por Homicídios, Brasil, 1996 a 1999

\begin{tabular}{ccccc}
\hline Valores & $\mathbf{1 9 9 6}$ & $\mathbf{1 9 9 7}$ & $\mathbf{1 9 9 8}$ & $\mathbf{1 9 9 9}$ \\
\hline \hline Número & 38.929 & 40.531 & 41.940 & 42.947 \\
$\%$ & 32,7 & 33,9 & 35,7 & 36,7 \\
Taxa & 24,8 & 25,4 & 25,9 & 26,2 \\
\hline Fonte: Mello Jorge et al ${ }^{36}$ & & & &
\end{tabular}

Segundo Laurenti et al, ${ }^{32}$ nos anos próximos a 1988, na Colômbia, Brasil, México e Porto Rico encontram-se as taxas de mortalidade mais extremas para o sexo masculino e as maiores diferenças entre os sexos, evidenciando uma média de 10 homens para 1 mulher. Nos Estados Unidos e Canadá, proporcionalmente, as taxas são menores, o que diminui também a razão entre os sexos.

Para Minayo, ${ }^{21}$ Andrade e Mello Jorge, ${ }^{37}$ o Homicídio é a causa de mortalidade com maior taxa de crescimento no Brasil, tendo como principal grupo de risco a população jovem, entre 10 e 39 anos, de baixa renda, sem qualificação profissional, sem perspectivas no mercado de trabalho formal e que residem nas regiões metropolitanas em áreas de risco, sob as piores condições sócio-ambientais. As causas se relacionam às extremas desigualdades sociais, às contradições urbanas, à organização do crime em torno do narcotráfico e do uso de drogas nos grandes perímetros urbanos, fenômeno que atrai jovem, envolve policiais, autoridades governamentais e empresários, incluindo todas as camadas sociais. A prevenção do Homicídio depende de mudanças no Estado em adotar políticas sociais básicas, num processo de democratização política, social, econômica e cultural, onde o setor saúde participa de forma secundária. 


\subsubsection{Acidentes de Transporte}

Os Acidentes de Transporte, assim denominados na CID-10 apresentam os códigos V01 a V89. Anteriormente, na CID-9 eram classificados como Acidentes de Trânsito de veículos a motor com os códigos entre E810 a E819. ${ }^{19,20}$

Souza e Minayo, ${ }^{26}$ defendem a tese de que os Acidentes de Transporte não se produzem ao acaso ou ao azar. Afetam os diferentes grupos da população, em determinada área geográfica ou pontos críticos, com diferenças na sua incidência em áreas urbanas ou rurais. Caracterizam-se como atos violentos, sendo que seus indicadores determinam o nível de civilidade e de coesão social de uma sociedade, por estarem diretamente associados ao desenvolvimento sócio-econômico, político e cultural de cada país.

Mccarroll e Haddon, ${ }^{38}$ em seus estudos, demonstraram que os condutores responsáveis pelos acidentes de transporte encontravam-se na sua maioria, alcoolizada, outros eram condutores de veículos roubados que tentavam fugir e, um menor grupo, por apresentar alguma doença ou achar-se em tratamento clínico.

Minayo, ${ }^{21}$ ao comparar os tipos de Acidentes de Transporte nos países desenvolvidos e em desenvolvimento concluiu que, nos primeiros, as pessoas morreram por colisões de veículos e, nos segundos, as vítimas, na maioria pedestre, morreram por atropelamento.

No Brasil, entre 1977 e 1994, os Acidentes de Transporte exibiram coeficientes de mortalidade considerados altos, com um crescimento de 17,4\%. Nos países desenvolvidos, apresentaram tendência inversa, devido aos investimentos na segurança dos carros, nas estradas e demais obrigatoriedades, como o uso do cinto de segurança, limitação de velocidade e fiscalização mais rígida quanto ao uso do álcool Mello Jorge. ${ }^{39}$

A evolução da mortalidade por Acidentes de Transporte, no Brasil, no período de 1996 a 1999 - Tabela 2 - apresentou um decréscimo gradativo. Alguns autores justificam esse decréscimo pelo aumento excessivo de veículos que vêm congestionando as grandes cidades, 
resultando num fluxo lento, diminuindo, portanto, as colisões fatais e os atropelamentos; pela obrigatoriedade de medidas de segurança, como o uso do cinto de segurança, implantação de lombada eletrônica; pela mais intensa fiscalização; implantação do novo Código Brasileiro de Trânsito com vigência a partir de 1998 e pela melhoria do sistema de informação de mortalidade. $^{16,40}$

Tabela 2 - Número absoluto, proporção de óbitos e taxa de mortalidade para 100.000 habitantes, por Acidentes de Transporte, Brasil, 1996 a 1999

\begin{tabular}{ccccc}
\hline Valores & $\mathbf{1 9 9 6}$ & $\mathbf{1 9 9 7}$ & $\mathbf{1 9 9 8}$ & $\mathbf{1 9 9 9}$ \\
\cline { 2 - 5 } Número & 35.545 & 35756 & 30.994 & 29.569 \\
$\%$ & 29,8 & 29,9 & 26,4 & 25,3 \\
Taxa & 22,6 & 22,4 & 19,2 & 18,0 \\
\hline Fonte: Mello Jorge et al & & & &
\end{tabular}

A mortalidade por Acidentes de Transporte é dominante nos homens. Em 1999, nas regiões brasileiras, as taxas de mortalidade para o sexo masculino apresentavam 29,3 óbitos por 100.000 habitantes e, para o feminino, 7,1 óbitos por 100.000 habitantes. A partir da década de 1980, os acidentes por motocicletas vêm sofrendo acréscimos, indicando percentuais de $11 \%$ a $20 \%$ de motociclistas homens hospitalizados por trauma, entre 15 e 24 anos de idade. ${ }^{16}$ Os estudos de Laurenti et al ${ }^{32}$ relacionam o progresso econômico social e político de uma comunidade com a mortalidade entre os sexos, ou seja, quanto mais real o desenvolvimento de uma nação, menor é a diferença de mortalidade entre os homens e mulheres. A mortalidade no sexo masculino, muitas vezes, justifica-se pelo fato de esses se movimentarem mais pelas ruas em função do trabalho e, conseqüentemente, se encontrarem mais expostos ao risco, quer como pedestres quer como motoristas.

Com relação à idade, os óbitos estão concentrados nos adultos jovens, na faixa etária de 15 a 44 anos, o que vem cada vez mais aumentando os Anos Potenciais de Vida Perdidos, gerando custos imensuráveis. Minayo, ${ }^{21}$ estimou que, para cada habitante morto em 
Acidentes de Transporte, cinco resistem, todavia, apresentam seqüelas, com gastos altíssimos em tratamentos, recuperação e reabilitação.

Souza et al $^{41}$ identificam os Acidentes de Transporte como conseqüência da aventura de uma "liberdade assassina". Além de ceifar vidas, produzem altíssimos custos relativos às despesas médico-hospitalares e psicossociais, que não atingem apenas o indivíduo afetado, mas a outros próximos, como familiares e amigos. As medidas preventivas cada vez mais se fazem necessárias, na educação do trânsito, na conservação das estradas, das ruas e dos carros, no controle e punição dos motoristas, quando alcoolizados ou em excesso de velocidade.

\subsubsection{Suicídios}

Os Suicídios são classificados na CID-10 como lesões auto provocadas intencionalmente, com os códigos X60 a X84 e na CID-9, como suicídios e lesões autoinfligidas. Seus códigos estão entre E950 a E959. ${ }^{19,20}$

No Brasil, segundo Mello Jorge, ${ }^{16}$ entre os anos de 1996 a 1999, a taxa de mortalidade por Suicídios manteve-se numa média de 4,0 óbitos por 100.000 habitantes. Em 1999, as taxas mais elevadas se encontrava na região Sul (8,5 por 100.000 habitantes), com destaque para o Rio Grande do Sul $(11,0)$, a seguir as regiões Centro Oeste, com 4,5 óbitos por 100.000 habitantes, destacando-se o estado do Mato Grosso do Sul $(7,2)$ e a região Sudeste (3,5 óbitos por 100.000 habitantes), com predominância para o estado de São Paulo, com taxa de 4,3 óbitos. O Estado de Minas Gerais, com 2,9 óbitos equiparava-se ao Rio de Janeiro, com 2,3 óbitos por 100 mil habitantes.

A Tabela 3 demonstra o comportamento da mortalidade por Suicídios, no Brasil, no período de 1996 a 1999. Nos anos apresentados, a mortalidade por suicídios, manteve-se constante, porém, por se referir a um tipo de violência autoprovocada, constitui um grupo de 
causa preocupante para os profissionais e o sistema de saúde, no entendimento de seus fatores determinantes.

Tabela 3: Número absoluto, proporção de óbitos e taxa de mortalidade para 100.000 habitantes, por Suicídios, Brasil, 1996 a 1999

\begin{tabular}{ccccc}
\hline Valores & $\mathbf{1 9 9 6}$ & $\mathbf{1 9 9 7}$ & $\mathbf{1 9 9 8}$ & $\mathbf{1 9 9 9}$ \\
\hline \hline Número & 6.743 & 6.923 & 6.985 & 6.530 \\
$\%$ & 5,7 & 5,8 & 5,9 & 5,6 \\
Taxa & 4,3 & 4,3 & 4,3 & 4,0 \\
\hline \hline Fonte: Mello Jorge et al ${ }^{36}$ & & &
\end{tabular}

Segundo a OPAS, ${ }^{27}$ no Canadá e Estados Unidos mais de 60,0\% dos Suicídios ocorrem na faixa etária entre 15 a 44 anos, preferencialmente entre homens e, a partir dos 45 anos, em mulheres.

No Brasil, em 1999, dos óbitos registrados por Suicídios, 70\% acontecem na faixa etária de 20 a 29 anos, duas vezes maior nos homens do que nas mulheres. No grupo etário acima de 60 anos ocorreram proporcionalmente em ambos os sexos e associados a quadros depressivos que evoluem para o auto-extermínio. Alguns estudos demonstram que as mulheres são mais vulneráveis às tentativas de Suicídio, pois para cada óbito masculino, três tentativas se acometem no sexo feminino. Entretanto, entre o grupo das mulheres, para cada óbito ocorrem de 25 a 30 tentativas de Suicídios. ${ }^{\mathbf{1 6}, 42}$

Os Suicídios, por se caracterizarem como lesões auto-infligidas, carregam consigo um estigma, o que desencadeia um registro precário dos óbitos. Em muitos países, por questões religiosas e hábitos culturais, existe a tendência de registrar os óbitos por Suicídios em outro grupo de causa que não se determina à intencionalidade do agravo. No Brasil, uma das justificativas para o não registro do óbito por suicídio, refere-se ao fato de os familiares da vítima fazerem jus a algum benefício pecuniário. Outras vezes, os familiares da vítima, para não divulgarem o evento, solicita ao médico o não registro real da causa básica da morte. 
Geralmente, os Suicídios são provocados por disparo de uma arma de fogo sendo, muitas vezes, notificados como Homicídios, ocasionando, em decurso, a subnotificação dos primeiros. O sub-registro de óbitos por Suicídios pode chegar a taxas duas ou três vezes menores do que a real. ${ }^{16,21,34}$

\subsection{As Estatísticas de Óbitos no Brasil}

\subsubsection{O Registro de Óbito no Brasil}

A obrigatoriedade do registro de óbito no Brasil foi regulamentada pela Lei ${ }^{\circ} 6015$ de 31 / 12 / 1973 e posteriormente, alterada pela Lei 6216 de 30 / 06 / 1975. A partir desta época, ficou determinado que, em todo território nacional, todo sepultamento deve ser efetivado após o registro do óbito, no Cartório de Registro Civil. Esse registro é lavrado à vista da apresentação da declaração de óbito, assinada pelo médico. Na falta desse profisssional, deve ser assinada por duas testemunhas, de preferência qualificadas, que tenham verificado ou presenciado a morte. Ao receber a declaração, o oficial do cartório registra o óbito e emite a certidão de óbito juntamente com a guia para o sepultamento. ${ }^{43}$

Apesar de toda a regulamentação que garante, em termos jurídicos, a prova do "desaparecimento" do indivíduo, as declarações de óbito ainda apresentam precariedades em seu preenchimento. A justificativa pode ser explicada por parte das Escolas de Medicina, que nem sempre proporcionam devida atenção à importância no ensino correto do preenchimento das devidas declarações. Muitas vezes o médico se depara, pela primeira vez, com a declaração, no momento em que se vê na contingência real de preenchê-la. Entretanto, essas dificuldades estão sendo sanadas em diversos cursos que vêm reconhecendo a real 
importância da notificação, pois é a partir delas que se geram estatísticas para elaboração e análise de vários indicadores de saúde. ${ }^{44}$

Os estudos de Mello Jorge ${ }^{45}$ assinalam que, apesar da qualidade das informações ainda serem deficientes, verifica-se gradativa e lentamente uma melhora na notificação dos dados. Segundo Laurenti, ${ }^{46}$ em 1999, os dados relativos aos óbitos por causas mal definidas, tiveram um percentual de $15,1 \%$ do total das causas, no entanto, em 2000 , esse valor decresceu para 14,3\%. Apesar desse decréscimo, continua existindo uma cobertura incompleta de dados, particularmente no norte e nordeste do país. No ano de 2000, a taxa de mortalidade geral foi de 5,5 por mil habitantes, embora estimada em 7,0 por mil habitantes o que indica, portanto, a existência de sub-registro de óbitos.

A codificação da causa básica referente às causas externas não revela o final das lesões e não expressa os conteúdos essenciais da violência ou acidentes, sequer a intencionalidade dos fatos. Mello Jorge ${ }^{44}$ cita alguns exemplos: um Acidente de Transporte pode ter decorrido de uma tentativa de Suicídio ou de um Homicídio; a morte de uma criança ou adulto pode ser registrada na declaração de óbito como queda e ocultar um Homicídio ou Suicídio. Os Homicídios, cotidiano da violência, muitas vezes não são notificados, principalmente nos casos de extermínio, quando desaparecem as vítimas sem vestígios dos corpos. Segundo Minayo, ${ }^{21}$ a subnotificação da mortalidade por Homicídio é um problema crônico de saúde coletiva, pois além de estar diretamente relacionado com informações médicas, trata-se de conflitos sociais, implicações legais e outras. Em conseqüência, grande parte dos dados se projetam num "buraco negro" de outras violências ou lesões em que se ignora se foram acidentais ou intencionalmente infligidas. 


\subsubsection{O Sistema de Informação sobre Mortalidade no Brasil}

O sistema de informação sobre mortalidade, praticamente, teve seu início na década de 1970, a partir da implementação e organização do Sistema Nacional de Vigilância Epidemiológica, que se propunha definir alguns critérios na busca das informações sobre mortalidade, para organizá-las e torná-las mais abrangentes e confiáveis.

Moraes ${ }^{47}$ destaca dois marcos que contribuíram para a atual estruturação das informações em saúde no país. Um, em 1974, através da Lei 6125 de 4 de novembro de 1974, que autorizava o poder executivo a constituir a Empresa de Processamento de Dados da Previdência Social - DATAPREV. O outro, em novembro de 1975, quando da primeira reunião nacional sobre Sistemas de Informações de Saúde, promovida pelo Ministério da Saúde e com a participação de representantes das Unidades Federadas. Nessa reunião, foram aprovados e definidos os propósitos, objetivos e metas, assim como as funções do Ministério e das Secretarias de Saúde no Sistema de Informação de Saúde (SIS). Aprovou-se o modelo único de declaração de óbito e de óbito fetal, definiram-se os fluxos e periodicidade dos dados a serem computados e, também, o primeiro subsistema a ser implantado, dentre os que comporiam o SIS, o Subsistema de Informação sobre Mortalidade (SIM).

O SIM passou então, a ser implantado em todo o país sob a responsabilidade conjugada do Núcleo de Informática da Secretaria Geral e da Divisão Nacional de Epidemiologia e Estatísticas de Saúde, com a colaboração das equipes do Centro Brasileiro de Classificação de Doenças - CBCD - e do Departamento de Estatística, ambos da Faculdade de Saúde Pública da Universidade de São Paulo. Até o final da década de 1980, o sistema foi todo processado em computadores de grande porte, sendo o Ministério da Saúde responsável por significativa parte das informações.

Em 1992, o SIM foi implantado nas Secretarias Estaduais de Saúde, desenvolvido por um sistema destinado a microcomputadores e programado para obtenção dos dados das 
declarações de óbitos digitados diretamente para uma tela de entrada, o que tornou obsoletas as planilhas para codificação da declaração de óbito. Com a evolução do sistema e a melhoria da qualidade dos dados, os técnicos do DATASUS, em 1994, desenvolveram um novo módulo que se acoplava ao SIM, chamado de Seleção de Causa Básica (SCB). Esse módulo, utilizando técnicas de Inteligência Artificial, possibilitava a automatização da codificação das causas básicas e procurava reproduzir o raciocínio de um perito, codificador de causa básica, além de configurar um facilitador do processo de descentralização do SIM para as Secretarias de Saúde. Em 1999, sob a coordenação dos técnicos do DATASUS, é desenvolvido um novo software denominado SIM, para o Windows, que minimiza as inconsistências na base de dados e facilita o processo de análise das variáveis. ${ }^{48,49,50}$

Ainda em 1999, foram publicadas, pelo Ministério da Saúde, duas portarias de grande importância para o SIM. A primeira autorizava a criação de Comitês Técnico-Consultivos para os Sistemas de Informações em Saúde, com atribuições genéricas para avaliação do desempenho dos sistemas. A segunda regulamentava as competências dos diversos níveis gerenciais na área de epidemiologia, definindo as atribuições e competências da União, Estados, Distrito Federal e Municípios. ${ }^{51}$

\subsubsection{O Sistema de Informações sobre Mortalidade por Acidentes e Violência.}

O presidente da Fundação Nacional de Saúde, considerando a necessidade de organizar as ações relativas à coleta, processamento de dados, e divulgação de informações sobre os óbitos ocorridos nos Municípios e Estados, regulamentou, através da portaria $n^{\circ} 474$ de 31 / 08 / 2000, a coleta de dados, fluxo e periodicidade de envio das informações sobre óbitos para o Sistema de Informações sobre Mortalidade (SIM). ${ }^{51}$

O processo do Sistema de Informações sobre Mortalidade começa com o formulário da declaração de óbito (DO). Esses são impressos em três vias pré-numeradas, 
seqüencialmente, pelo Centro Nacional de Epidemiologia (CENEPI) e Fundação Nacional de Saúde (FUNASA) e distribuídos às Secretarias Estaduais e Municipais de Saúde, que os repassam para as unidades notificantes: institutos médicos legais, serviços de verificação de óbitos, estabelecimentos de saúde e cartórios de registro civil.

Nos casos de óbitos por causas acidentais e / ou violentas, o médico legista do Instituto Médico Legal (IML) ou o perito designado para tal finalidade, nas localidades onde não existir o IML, deverá preencher as três vias DO com a seguinte destinação:

$\mathbf{1}^{\text {a }}$ via: Secretaria Municipal de Saúde.

$2^{\mathbf{a}}$ via: Representante ou responsável da família do falecido, para ser utilizada no registro da Certidão do Óbito junto ao Cartório de Registro Civil.

$3^{\text {a }}$ via: Instituto Médico Legal.

Na instituição de saúde cabe ao codificador certificar-se do correto preenchimento das categorias contidas na DO e buscar soluções para as devidas correções.

Através do SIM, obtém-se a coleta dos dados e, ao mesmo tempo, a emissão de relatórios que serão submetidos a um programa de crítica, que têm como rotina à avaliação dos possíveis erros, referentes ao preenchimento, à seleção da causa básica, à codificação e à digitação dos dados.

Posteriormente, eles são enviados às Secretarias Estaduais de Saúde, que disponibilizarão os dados para a FUNASA, que os submetem a uma nova crítica na base de dados e, só então, são liberados à Coordenação de Informações em Saúde do DATASUS e disponibilizados para os usuários, através das "home page" do CENEPI, DATASUS e em CD-ROM - BRASIL. ${ }^{43}$ 


\subsubsection{O Fluxo do Sistema de Informação de Mortalidade por Causas Externas e Violências no Município e Região Metropolitana de Belo Horizonte.}

Os serviços de estatísticas de Minas Gerais, desde seu começo, foram transferidos com vultosa freqüência para vários órgãos administrativos, sofrendo, portanto, alterações nas suas metodologias, nos dados estatísticos, na composição das equipes e outras.

Durante o século XX o serviço de estatísticas passou por vários setores estaduais ${ }^{52}$ :

Em 1901 pelo "Decreto n ${ }^{\circ}$ 1443" foi regulamentado o Serviço de Estatística do Estado que compreendia o recenseamento da população, com dados sobre nascimentos, casamentos e óbitos.

Em 1939 através do "Decreto - Lei n 650", criou-se o Departamento Estadual de Estatística (DEE) que tinha como atribuições à organização, sistematização e execução de todos os trabalhos estatísticos do Estado. Além de colaborar com o Instituto Brasileiro de Geografia e Estatística (IBGE) na coleta, apuração e divulgação dos dados de interesse geral.

Em Janeiro de 1946, pelo "Decreto - Lei $\mathrm{n}^{\circ}$ 2201" incorporou-se ao Departamento Estadual de Estatística (DEE) o Serviço de Estatística Vital e a seção de Estatística Médico-Social que deveriam ser chefiados por médicos com as seguintes atribuições: proceder à coleta e apurar os dados referentes à natalidade, nupcialidade e mortalidade; levantar as estatísticas das doenças de notificação compulsória.

Em fevereiro de 1972, pelo "Decreto n 14323 ", foi regulamentado o Conselho Estadual de Desenvolvimento (CED) dando competência ao Instituto Estadual de Estatística (IEE), em gerenciar todo o sistema que se referia aos dados demográficos, econômicos, sociais, culturais e políticos administrativos.

Em 1977 pelo "Decreto no 18404" reorganizou-se a Secretaria de Estado e Planejamento e Coordenação Geral, criando-se a Superintendência de Estatística e Informação (SEI), que assumia as atribuições do antigo Instituto Estadual de Estatística (IEE). 
Em 1992 através da Lei $n^{\circ} 10827$ art. $^{\circ}$ 33, transferiram-se as atividades e competências centrais de estatística e informações para a Fundação João Pinheiro que implantou, em sua estrutura organizacional, o Centro de Estatística e Informações (CEI)

Em 1995, a implantação da terceira via da Declaração de Óbitos possibilitou o setor de Epidemiologia da Secretaria Municipal de Saúde a criação de seu próprio banco de dados.

A partir de 1999, os serviços de estatísticas vitais fixam-se nas Secretarias Municipais de Saúde, coordenados pelo Setor de Gerência e Informação que se responsabilizam formalmente pela criação de seu próprio banco de dados, com as seguintes atividades:

1) Distribuição dos formulários das declarações de óbitos a serem preenchidos para todas as Unidades Notificantes;

2) Busca ativa diária das primeiras vias das declarações de óbitos nos Cartórios de Registro Civil;

3) Recolhimento das declarações de óbitos de residentes em outros municípios e codificação da causa básica das mesmas;

4) Contato semanal com o Instituto Médico Legal (IML) para esclarecimento das mortes violentas, quando necessário;

5) Leitura diária de jornais do município para esclarecimento e identificação de mortes violentas;

6) Organização e consolidação dos dados provenientes de unidades notificantes;

7) Envio dos relatórios para a Diretoria Regional de Saúde de Belo Horizonte;

8) Análise dos dados e divulgação das informações.

Compete à Diretoria Regional de Saúde de Belo Horizonte consolidar os dados dos municípios por meio de processamento eletrônico, remetê-los ao nível federal, analisá-los, divulgá-los e publicar as análises epidemiológicas. 


\subsection{Caracterização do Município e Região Metropolitana de Belo Horizonte}

O município e região metropolitana de Belo Horizonte situam-se na região Sudeste, no Estado de Minas Gerais que equivalente a 7\% da área total do Brasil e 63\% da região Sudeste. É o quarto estado de maior área no país e devido à sua posição geográfica possui a maior malha rodoviária, cerca de $300.000 \mathrm{~km}$. de rodovias que se entrelaçam em todas as direções, tornando-se importante ponto estratégico de apoio rodoviário, ligando-se às Regiões Sul, Centro-Oeste, Nordeste e Norte. Sua população, pelos dados do DATASUS ${ }^{\mathbf{1 0}}$ é de 18.553.335 habitantes, sendo que 15.213.735 situam-se na área urbana e 3.339.600 na rural, o que significa urbanização de $82 \%$. A densidade demográfica estadual de 30,5 habitantes por quilômetro quadrado indica má distribuição da população, havendo uma maior concentração de pessoas no sul do estado, região mais industrializada. Quanto a sua contribuição dos setores na geração do PIB, deve ser registrada a sistemática deterioração da agropecuária, não por entrar em estagnação ou retrocesso, mas pelo extraordinário avanço da tecnologia. ${ }^{53,54}$

Do ponto de vista econômico, as áreas com intensa produtividade agrícola ou industrializada ocasionam um alto crescimento populacional, principalmente nas grandes cidades. Nas regiões estagnadas e improdutivas, há um fenômeno migratório crescente, que decorre de seu próprio subdesenvolvimento. Muitos trabalhadores estão à mercê de empregos temporários, sujeitos a ilegalidades na sua contratação, ou pior ainda, submetidos ao trabalho escravo e infantil. Os homens normalmente se arriscam e migram para outras regiões, outros, continua sobrevivendo em condições precárias, sem benefícios sociais e infra-estrutura urbana básica para sua sobrevivência e de sua família. ${ }^{53,54}$

No estado de Minas Gerais, normalmente a população imigra para Belo Horizonte, capital do Estado, com 105 anos e uma população estimada em 2.305.812 habitantes. Tem como municípios limítrofes ao sul: Novo Lima, Brumadinho e Ibirité, ao norte: Ribeirão das Neves, Santa Luzia e Vespasiano, a oeste: Contagem e a leste: Sabará. Dispõe de fácil acesso 
aéreo, com dois aeroportos em funcionamento e, por via terrestre, as principais rodovias nacionais que a cortam, BR 040 ligando Belo Horizonte ao Rio de Janeiro e Brasília; BR 262 ligando Belo Horizonte à Vitória e Cuiabá e a BR 381 que liga Belo Horizonte a São Paulo e à região Nordeste do país. As rodovias da malha estadual facilitam o acesso às cidades turísticas e históricas de Minas Gerais. Seu parque manufatureiro inclui a metalurgia, a têxtil, alimentícia, material elétrico / eletrônico e a construção civil. Possui uma ativa área industrial, denominada Cidade Industrial, onde predomina a metalurgia. ${ }^{53,54}$

O setor de saúde oferece uma complexa assistência nos diferentes níveis de atendimento: primário, secundário e terciário. Reconhecida como centro de excelência médica, de biotecnologia e de informática, sofreu, nas últimas décadas, um aumento descontrolado da população e, em conseqüência, seus municípios vizinhos passaram a receber o excedente de pessoas. Assim, em 18 de junho de 1973, criou-se a Rede Metropolitana de Belo Horizonte ou Grande BH, com o objetivo de melhorar a qualidade de vida das pessoas que residiam na Capital e expandir as relações sócio-econômicas entre os municípios. Atualmente, conta com 33 municípios e uma população estimada em 4.615 .191 habitantes. ${ }^{53}$

Os municípios inseridos ao processo metropolitano têm sua área geográfica cada vez mais procurada, valendo-se de seus serviços e cada vez mais pressionados à incorporação de seu espaço. As atividades econômicas estão ligadas ao setor terciário e se expandem rapidamente ao eixo industrial junto às rodovias BR-382 e BR-040, que ligam ao município de Betim, onde se encontram a fábrica de automóveis FIAT, a Refinaria Gabriel Passos da Petrobrás e várias indústrias fornecedoras de peças. Destaca-se o Cinturão Verde, formado por pequenas propriedades agrícolas, onde seus produtos são comercializados na Central de Abastecimento de Minas Gerais (CEASA), na rodovia BR-040 e distribuídos para a população, através de mercados, feiras livres, supermercados e mercearias. Essa 
disponibilidade de bens de consumo nas diversas rodovias aumenta o trânsito de veículos e a circulação de pedestres.

Figura 3: Mapa da região Metropolitana de Belo Horizonte, 2000.

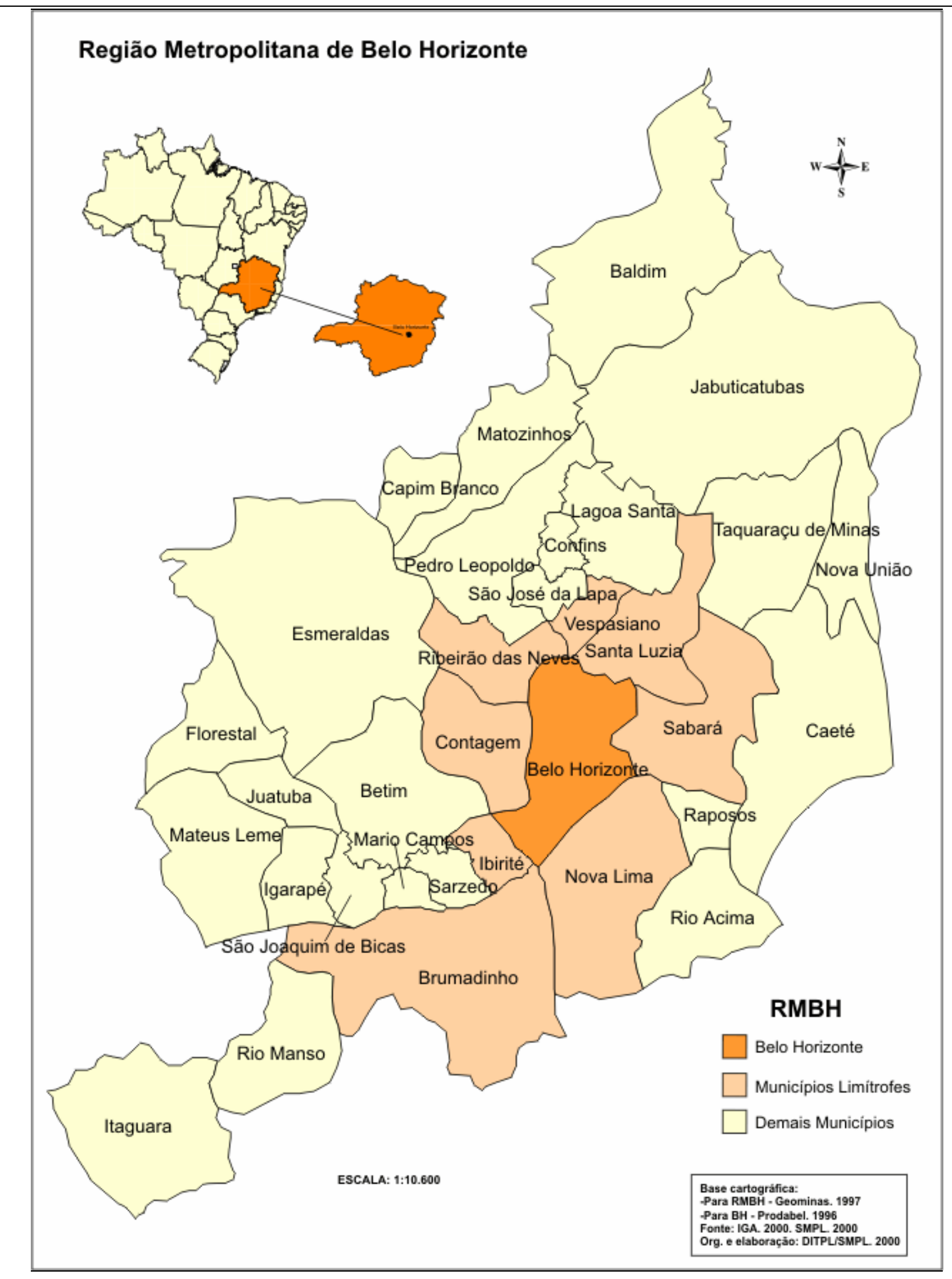

Fonte: Sann $^{55}$ 


\subsubsection{Aspectos Demográficos e Epidemiológicos}

As mudanças demográficas ocorridas na estrutura etária da população do estado de Minas Gerais, da Região Metropolitana e do município de Belo Horizonte são apresentadas nas figuras 4, 5 e 6, através de suas pirâmides populacionais referentes aos anos 2000, 1991 e 1980. Nestas figuras observou-se um decréscimo da população infantil e de um aumento gradativo da população referente aos jovens, adultos e idosos. As pirâmides populacionais referentes ao ano 2000 revelam com bastante nitidez essa transição populacional, mediante um estreitamento da base e o alargamento do ápice da pirâmide. Quanto mais se desagregam as regiões, mais se tornam evidentes as mudanças no perfil demográfico, que se deduz, naturalmente, pelas possíveis influências do processo histórico, econômico, social, político e cultural.

Em Belo Horizonte, as mudanças demográficas ocorreram pelas proclamadas virtudes de seu clima, tornando a cidade atrativa, principalmente para atender indivíduos que necessitavam de tratamento das doenças pulmonares, o que implicou um aumento progressivo de hospitais, pensões e hotéis para abrigar pessoas enfermas e/ ou moribundas. Outra influência que se tornou bastante evidente na dinâmica populacional da capital, refere-se ao intenso número de pessoas jovens e adultas que imigravam do interior do Estado à procura de estudos universitários, de empregos e de melhores condições de vida, que em excesso, resultaram no fenômeno da explosão populacional. Em consequência desse fenômeno, foi implantada a Região Metropolitana de Belo Horizonte que recebeu a influência da imigração de indivíduos e familias que residiam na capital. 
Figura 4: Pirâmides Populacionais, Minas Gerais, 1980, 1991, 2000

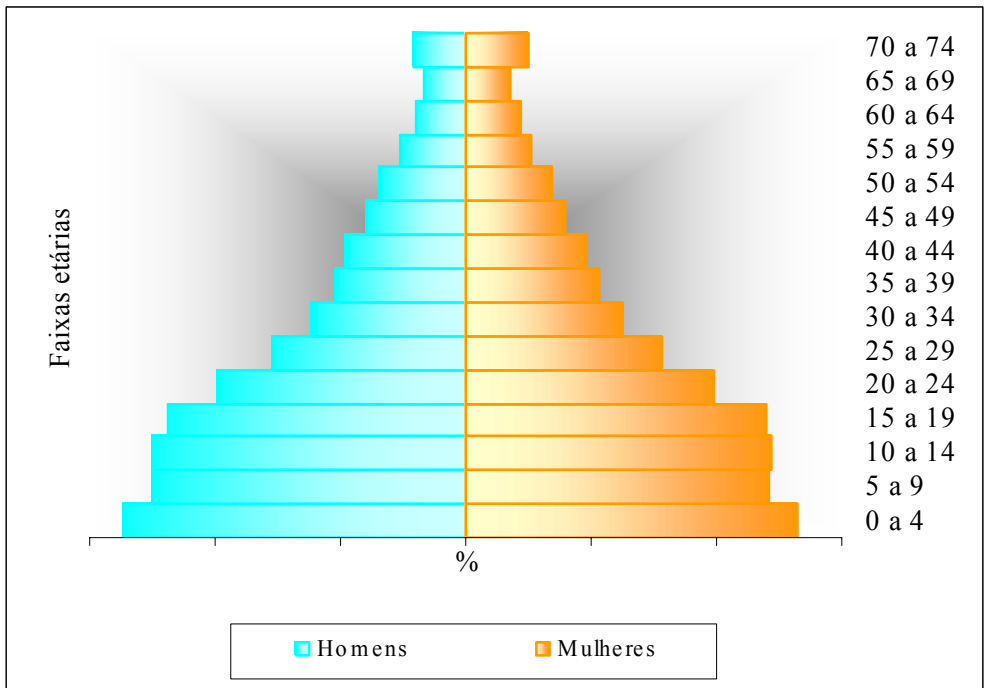

Pirâmide relativa a 1980

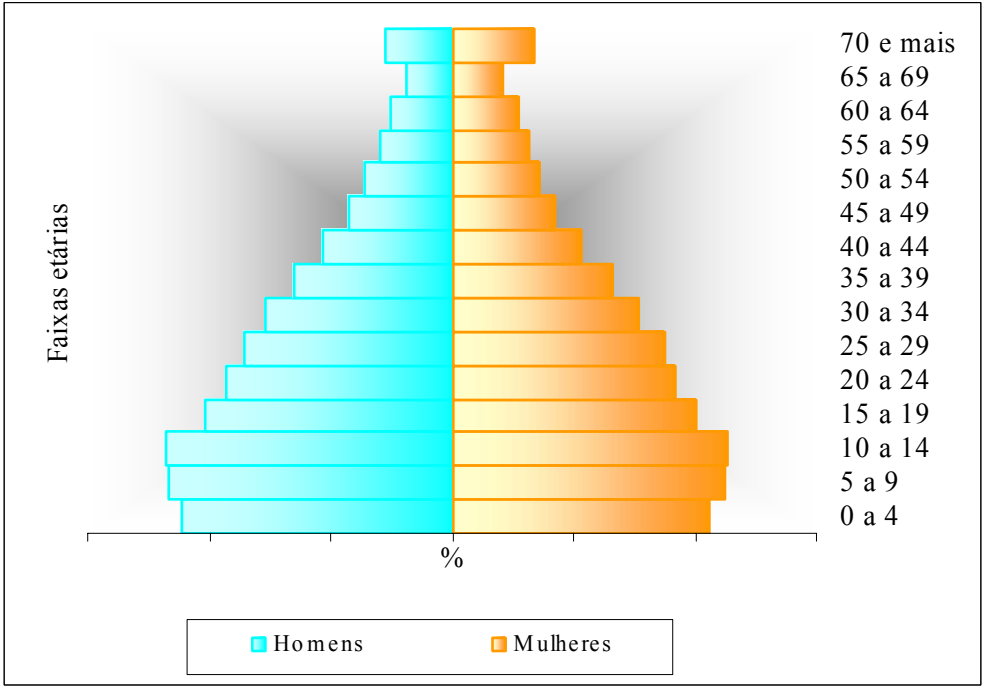

Pirâmide relativa a 1991

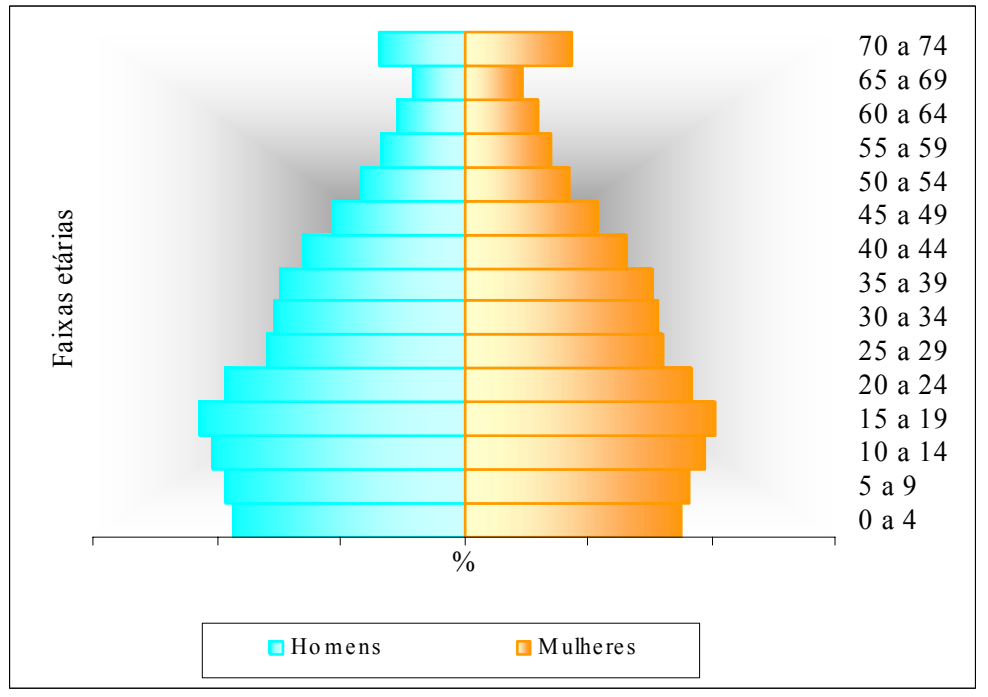

Pirâmide relativa a 2000

\footnotetext{
Fonte: Ministério da Saúde / DATASUS ${ }^{10}$
} 
Figura 5: Pirâmides populacionais, Região Metropolitana de Belo Horizonte, 1980, 1991, 2000

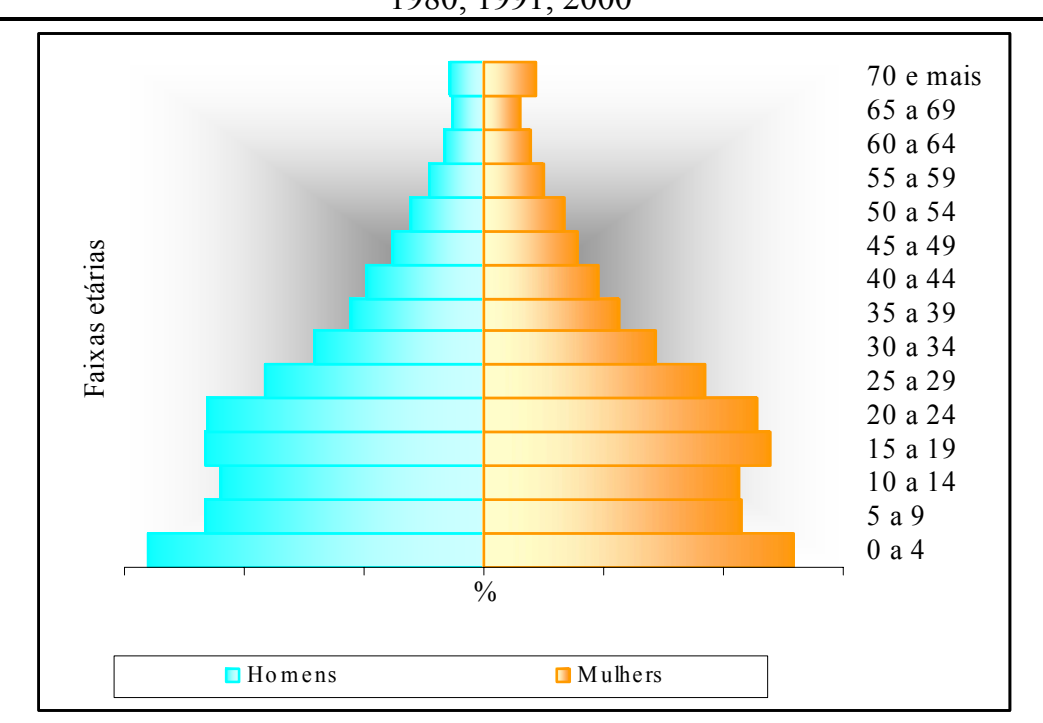

Pirâmide relativa a 1980

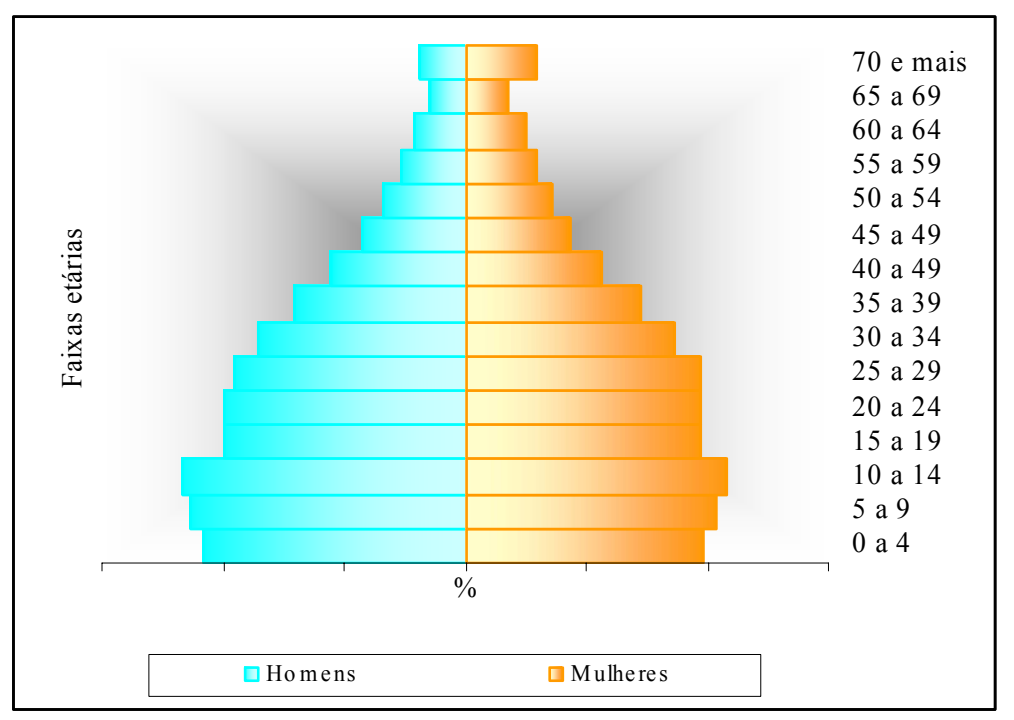

Pirâmide relativa a 1991

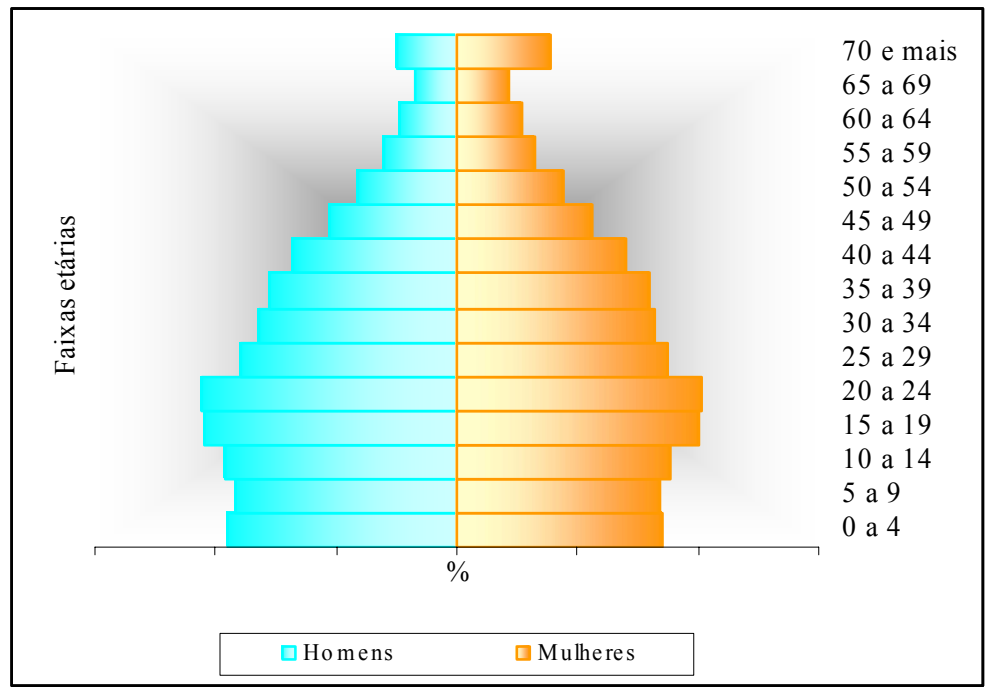


Fonte: Ministério da Saúde / DATASUS ${ }^{\mathbf{1 0}}$

Figura 6: Pirâmides Populacionais, Belo Horizonte, 1980, 1991, 2000

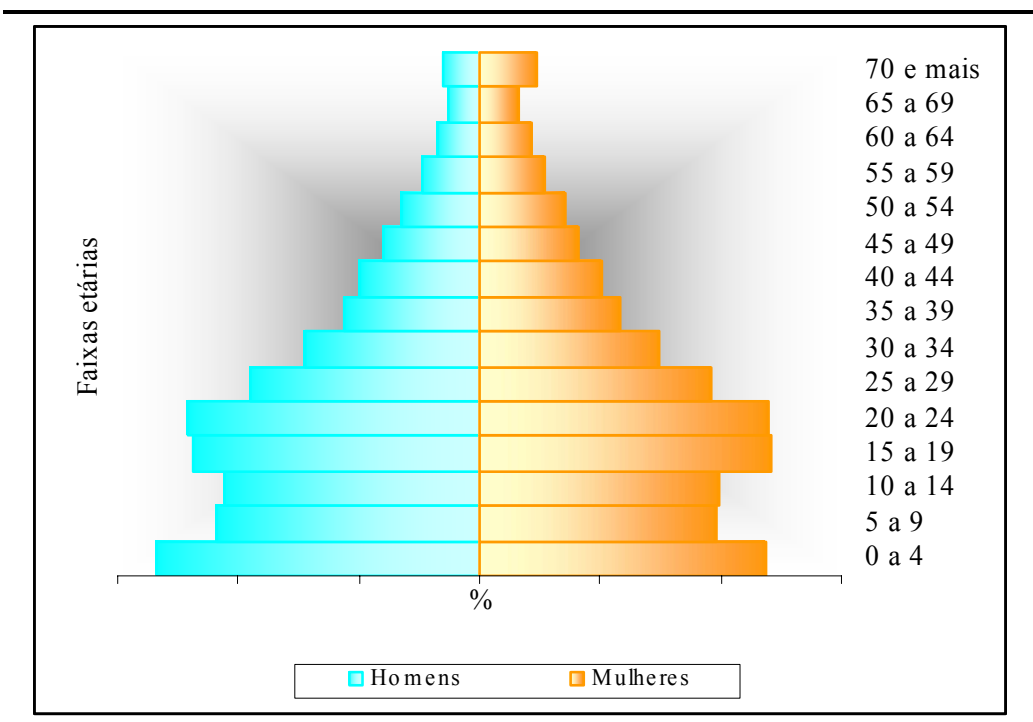

Pirâmide relativa a 1980

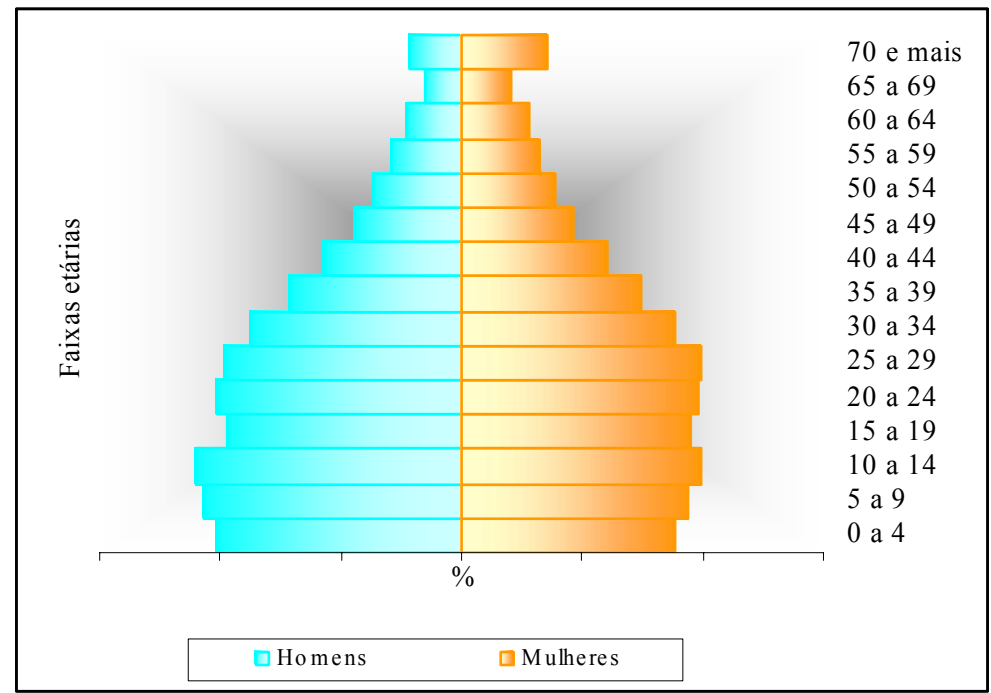

Pirâmide relativa a 1991

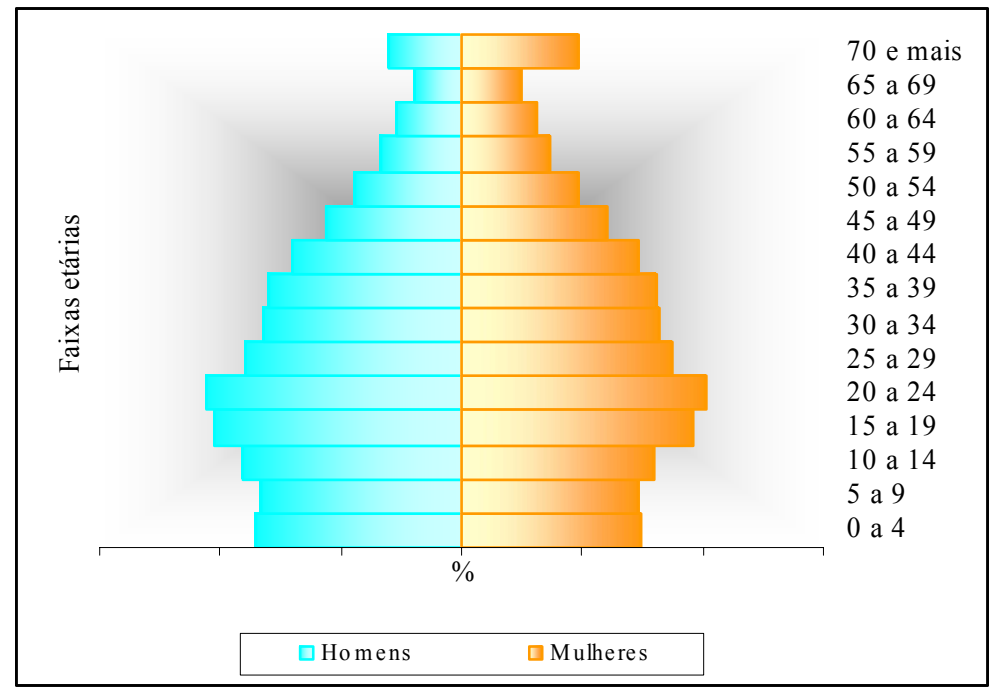

Pirâmide relativa a 2000 
Fonte: Ministério da Saúde / DATASUS ${ }^{10}$

Maletta, ${ }^{52}$ ao estudar a transição epidemiológica em Belo Horizonte, com base nas teorias de Omran, ${ }^{11}$ caracterizou o período das décadas de 40 a 90, como a fase das doenças degenerativas e a das causadas pelo homem. Ressaltou em 1970, a primeira notificação na classificação das causas externas com a seguinte especificação: “Acidentes por Causas não Especificadas Ambientais e Naturais" e, em 1980, pela primeira vez a notificação de “Acidentes de Trânsito de Veículos a Motor de Natureza não Especificada”.

Um estudo da mortalidade por acidentes e violência, elaborado pelos técnicos da Fundação João Pinheiro, ${ }^{56}$ mencionaram que em Belo Horizonte, em 1995, as causas principais sucederam-se, em ordem decrescente: acidentes de transporte de veículo a motor não especificado, homicídios, atropelamentos, quedas acidentais, suicídios e afogamentos.

Na Região Metropolitana de Belo Horizonte, em 1995, a mortalidade por homicídios se comparava com os padrões nacionais, com tendência de crescimento, priorizando a faixa entre 30 e 49 anos, no sexo masculino. Em Belo Horizonte, atingiu uma taxa de 15 óbitos para 100.000 habitantes, com incidência maior na faixa etária entre 15 a 29 anos, também no sexo masculino. Segundo os autores, naquela época, já havia indicativo de um crescimento de assassinatos de crianças e adolescentes para esse sexo e de adultos com 30 anos e mais, para as mulheres. ${ }^{57}$

Moura ${ }^{58}$ destacou que o excesso de mortes provocado pela violência, em Minas Gerais, na década de 90, referia-se a homicídios, que afetavam os homens em proporções duas vezes maiores do que nas mulheres. Nos homens jovens a violência é considerada como uma epidemia que incidia com maior freqüência na faixa etária de 15 a 39 anos de idade, sendo que muitos faleciam antes dos 24 anos.

As Tabelas 4 e 5, a seguir, apresentam a distribuição das taxas de mortalidade pelos grupos de causas definidas, que apresentaram maior impacto epidemiológico e contribuíram com o aumento da violência e dos acidentes em Belo Horizonte e Região Metropolitana. Em 
ambas Tabelas os dados demonstraram que, independentemente do local de residência e da faixa etária, tornou-se evidente uma maior incidência da mortalidade nos homicídios e no sexo masculino.

Os Homicídios apresentaram maiores coeficientes na Região Metropolitana, em ambos os sexos. Preferencialmente a faixa etária mais atingida foi a de 20 a 29 anos, em seguida, a faixa de 30 a 39 anos, para ambos os sexos e regiões (Tabelas 4 e 5).

Os Acidentes de Transporte destacaram-se na região metropolitana no sexo masculino e em Belo Horizonte no feminino. Em ambas regiões, no sexo masculino, o grupo etário que apresentou maior magnitude foi de 80 e mais, logo a seguir, o grupo de 20 a 29 anos. Entretanto, no sexo feminino, a região metropolitana, apresentou maior magnitude na faixa etária de 70 a 79 e a seguir, de 60 a 69 anos, enquanto, em Belo Horizonte ocorreram na faixa de 60 a 69 anos, seguida de 80 anos e mais. Observa-se que os Acidentes de Transporte ocorreram com maior freqüência no sexo feminino, a partir de 60 anos de idade (Tabelas 4 e 5).

Os Suicídios apresentaram maior incidência em Belo Horizonte, no sexo masculino e feminino. Em ambas regiões, no sexo masculino, atingiu inicialmente a faixa de 70 a 79 anos, logo após a de 50 a 59 anos e de 40 a 49 anos. Em Belo Horizonte, no sexo feminino, priorizou a faixa de 50 a 59 anos e de 30 a 39 anos, enquanto, na região metropolitana, inicialmente, ocorreu na faixa etária mais jovem de 30 a 39 anos e logo a seguir a de 50 a 59 anos de idade. Observou-se que em ambas regiões, nas tabelas 4 e 5, não se notificou nenhum caso de óbito por suicídio, no sexo feminino, no grupo etário de 60 anos e mais de idade. 
Tabela 4 - Distribuição das taxas de mortalidade para 100.000 habitantes, por Homicídios, Acidentes de Transporte e Suicídios, segundo faixa etária e sexo, Região Metropolitana de Belo Horizonte, 2001.

\begin{tabular}{|c|c|c|c|c|c|c|}
\hline \multirow{2}{*}{ Faixa Etária } & \multicolumn{2}{|c|}{ Homicídios } & \multicolumn{2}{|c|}{ Acidentes de transporte } & \multicolumn{2}{|c|}{ Suicídios } \\
\hline & Masculino & Feminino & Masculino & Feminino & Masculino & Feminino \\
\hline$<<10$ & 0,7 & 3,6 & 3,0 & 2,0 & - & 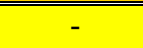 \\
\hline $10 \dashv 19$ & 56,2 & 8,1 & 12,7 & 1,4 & 3,9 & 0,5 \\
\hline $20 \dashv 29$ & 129,1 & 16,8 & 29,0 & 3,7 & 9,8 & 1,8 \\
\hline $30-39$ & 76,5 & 15,5 & 23,3 & 4,0 & 7,9 & 3,5 \\
\hline $40-49$ & 46,9 & 11,0 & 21,5 & 4,1 & 11,1 & 1,7 \\
\hline $50 \dashv 59$ & 34,0 & 6,8 & 26,2 & 6,8 & 11,1 & 3,4 \\
\hline $60 \dashv 69$ & 26,3 & 12,5 & 22,9 & 12,5 & 6,9 & - \\
\hline $70 \dashv 79$ & 10,1 & 14,7 & 22,7 & 14,7 & 17,7 & - \\
\hline 80 e mais & - & 7,2 & 59,2 & 7,2 & 7,4 & - \\
\hline Total & 58,2 & 10,8 & 18,6 & 4,1 & 6,7 & 1,5 \\
\hline
\end{tabular}

Tabela 5 - Distribuição das taxas de mortalidade para 100.000 habitantes, por Homicídios, Acidentes de Transporte e Suicídios, segundo faixa etária e sexo, Belo Horizonte, 2001.

\begin{tabular}{ccccccc}
\hline \hline \multirow{2}{*}{ Faixa Etária } & \multicolumn{2}{c}{ Homicídios } & \multicolumn{2}{c}{ Acidentes de transporte } & \multicolumn{2}{c}{ Suicídios } \\
& Masculino & Feminino & Masculino & Feminino & Masculino & Feminino \\
\hline \hline$<10$ & 1,1 & 0,6 & 2,2 & 2,8 & - & - \\
$10-19$ & 56,3 & 2,9 & 11,7 & 1,4 & 5,3 & 1,0 \\
$20-29$ & 128,7 & 7,1 & 28,2 & 4,4 & 10,1 & 1,8 \\
$30-39$ & 76,4 & 5,7 & 20,3 & 3,6 & 10,4 & 4,1 \\
$40-49$ & 42,5 & 4,4 & 17,2 & 2,5 & 12,7 & 1,9 \\
$50-59$ & 31,2 & 3,9 & 25,2 & 8,8 & 16,8 & 4,9 \\
$60-69$ & 26,2 & 1,5 & 20,1 & 13,3 & 4,0 & - \\
$70-79$ & - & - & 12,9 & 7,7 & 17,1 & - \\
80 e mais & - & - & 59,9 & 10,8 & 11,9 & - \\
Total & 57,7 & 3,9 & 17,3 & 4,4 & 8,2 & 1,8
\end{tabular}


A magnitude da mortalidade por Homicídios, Acidentes de transporte e Suicídios, oscilando entre crianças, adolescentes, jovens e idosos, transformou-se em problemas graves de saúde coletiva, na medida em que as chances de sobrevivência da população diminuem por causas violentas e acidentais. Na população mais jovem e em idade produtiva, a situação é mais problemática, na medida em que aumentam os Anos Potenciais de Vida Perdidos (APVP) e os custos sociais das vidas prematuramente interrompidas.

Para minimizar esses agravos, é preciso que se intensifiquem ações governamentais intervencionistas e preventivas, no sentido de evitar e prevenir os danos, tendo em vista a ocorrência em distintas áreas geográficas. Necessário se faz para o setor saúde, melhorar os serviços de epidemiologia, tendo em vista a qualidade dos dados para a construção de efetivos modelos de informação, confiáveis e comparáveis, que possibilitem a manutenção de um sistema de gerenciamento de dados; propor projetos de parceria com outros setores da sociedade tendo como referência os direitos do cidadão, com o objetivo de efetivar ações de políticas públicas voltadas para a segurança e vigilância, de preferência para os segmentos mais jovens da sociedade para que se possa minimizar, evitar os agravos e, na medida do possível, alterar para melhor, o quadro estatístico da violência e acidentes no país.

Minayo ${ }^{60}$ discute que a contribuição mais importante para minimizar esse problema é o reconhecimento de que a violência não é um problema pontual, mas sim um tema central que deve ser acrescido na agenda da saúde da sociedade brasileira. 
2 JUSTIFICATIVA 


\section{JUSTIFICATIVA}

No Brasil, desde as últimas décadas, o crescimento dos acidentes e violências configuram um problema de saúde coletiva de grande magnitude e transcendência, que tem causado forte impacto na morbidade e mortalidade e provocado grandes alterações do perfil epidemiológico e demográfico da população brasileira.

Ainda que a violência e os acidentes sejam uma das maiores preocupações dos dias atuais, não se trata de um fato novo, pois existem relatos e informações que os identificam em várias épocas, nas mais diferentes civilizações e nas mais variadas formas de agressões. Esses agravos são prioritariamente uma questão social e, portanto em si, não é uma questão própria do setor saúde. Eles se tornam um tema desse setor, pelo impacto que provoca na qualidade de vida dos indivíduos, pelas alterações negativas na integridade corporal, orgânica e emocional, que na maioria das vezes evolui para o óbito e, principalmente, pelas exigências de cuidados e dos insumos dos serviços médico-hospitalares, no custo para o governo de cerca de 43 bilhões (reais), anuais. ${ }^{\mathbf{6 0}, 61}$

Entre a violência e os acidentes encontram-se os Homicídios, os Acidentes de Transporte e os Suicídios, grupos, que têm sido responsáveis pelas principais causas de óbitos por causas externas, no Brasil e muitas regiões do mundo, tanto nas áreas desenvolvidas como nas que se encontram em desenvolvimento.

No Brasil, a partir da década de 1980, as causas externas tornaram-se mais importantes como causa de morte e se posicionou como a segunda causa na mortalidade geral. Faz-se necessário destacar que os Homicídios e os Acidentes de Transporte são os principais responsáveis pelas mudanças dos coeficientes de mortalidade por causas externas, nos grandes centros urbanos. ${ }^{26,40}$

Os Homicídios, a partir da década de 1990, tornaram-se mais intensos e passaram a representar o primeiro grupo responsável pela mortalidade por causas externas, cujas taxas, se 
expandiram com tendência de crescimento, em todo o Brasil, principalmente nos homens jovens. As causas são complexas, pois se correlacionam com as extremas desigualdades sociais, com a densidade populacional e, muitas vezes, se associam ao perfil da criminalidade do país e à organização do narcotráfico, essencialmente nos jovens. Os marginais e bandidos dos morros e periferias engrossam as estatísticas de Homicídios (homens de 15 a 39 anos), geralmente de cor negra ou mulata, baixa escolaridade e renda, sem qualificação profissional. Outros, que não estão engajados na criminalidade também são vítimas dos acidentes e violências e às vezes são eliminados no anonimato. ${ }^{26,40,60}$

Os acidentes de transporte que apareciam como principal causa de óbito por causas externas, na década de 1980, declinaram para a segunda posição, na década de 1990. Seus indicadores retratam a violência no trânsito e o nível de civilidade e de coesão social de uma determinada região que, por sua vez, se relacionam com seu nível de desenvolvimento sócioeconômico, político e cultural. O perfil dos indivíduos vitimados por esse grupo de causa consiste, sobretudo, do grupo etário de 20 a 39 anos, que se movimentam pelas vias de grande fluxo, no trajeto para o trabalho. Posteriormente, encontram-se as crianças e adolescentes, do grupo etário de 5 a 14 anos e os idosos, que também transitam pelas ruas, enquanto pedestres, e muitas vezes, são atropelados, elevando as estatísticas dos Acidentes de Transporte. Esses atrpopelamentos, na maioria das vezes, ocorrem pela inexistência de semáforos ou por eles não estarem regulados com o tempo suficiente para os indivíduos completarem sua travessia. Por outro lado, o perfil dos condutores dos veículos se caracteriza, por sua vez, por alcoólatras, drogados, enfermos ou condutores de veículos roubados.

Os Suicídios que se colocam em terceira posição na mortalidade por causas externas, apresentam maior magnitude no sexo masculino, na faixa etária de 40 a 64 anos, coincidindo com o fato de que é nesse grupo etário que ocorre maior incidência de quadros depressivos, mudanças ou perdas nas condições sociais e econômicas. 
A magnitude do problema nesses grupos de causas se destaca, quando os dados acusam a perda da população economicamente ativa, indivíduos jovens, em idade produtiva, limitando, desnecessariamente, o almejado aumento da esperança de vida no país. Acentuamse, na medida em que expandiram a complexidade, a demanda dos serviços de saúde e a reabilitação dos indivíduos. Isto contribuiu para diminuir a possibilidade de responder efetivamente a outros tipos de emergência, na medida em que se ampliaram os gastos para o tratamento dos feridos e das seqüelas deixadas em uma população fundamentalmente jovem.

Considerando que os Homicídios, Acidentes de Transporte os Suicídios configuram um problema de grande magnitude e que a sociedade brasileira visivelmente sofre cada vez mais, pelas perdas precocesa de vidas, faz-se necessário cada vez mais, investigar os dados com mais precisão para a elaboração de diagnósticos regionalizados dos principais agravos à saúde da população. O estudo em série histórica da mortalidade por esses grupos de causas, no município e na Região Metropolitana de Belo Horizonte possibilitará reconhecer e avaliar seu impacto epidemiológico, ao longo do tempo, permitindo identificar o sexo e as faixas etárias mais vulneráveis.

Por essas considerações e pela inexistência de outros estudos em séries temporais, ao lado da fidedignidade das bases de dados utilizados para a presente pesquisa, justifica-se o desenvolvimento da mesma, no intuito de subsidiar políticas públicas capazes de minimizar e alterar esses agravos, que tanto aterrorizam a população, proporcionando-lhes o novo caminho da longevidade, há tanto tempo esperado.

A análise de tendência da mortalidade por causas externas, em áreas geográficas distintas, tornar-se-á de extrema importância para o monitoramento do comportamento e da prevenção dos riscos à saúde de indivíduos e grupos. Em relação ao sistema de saúde, poderá contribuir para a definição de ações, para a reorganização dos serviços e para uma adequada qualificação dos profissionais. Por outro lado, espera-se que possa sensibilizar a coletividade 
no intuito de formar novos sujeitos que se mobilizarão pelas transformações das condições sociais e do estilo de vida que, por sua vez, refletirão no perfil da mortalidade e morbidade de sua comunidade. 
3 OBJETIVOS 


\section{3 - OBJETIVOS}

\subsection{Objetivo Geral}

Estudar o perfil epidemiológico da mortalidade por Homicídios, Acidentes de Transporte e Suicídios no município de Belo Horizonte e Região Metropolitana, na série histórica compreendida entre 1980 e 2000, com o propósito de subsidiar o planejamento de estratégias que possam favorecer a implementação de políticas públicas de promoção e prevenção em saúde, relacionadas com estes agravos.

\subsection{Objetivos Específicos}

3.2.1. Conhecer a magnitude dos coeficientes específicos de mortalidade por Homicídios, Acidentes de Transporte e Suicídios, segundo sexo e faixa etária em Belo Horizonte e Região Metropolitana, no período de 1980 a 2000.

3.2.2. Investigar o padrão de mortalidade por Homicídios, Acidentes de Transporte e Suicídios no município de Belo Horizonte e Região Metropolitana, no período de 1980 a 2000.

3.2.3. Avaliar a tendência dos coeficientes específicos de mortalidade pelos três grupos de causas nas regiões consideradas e no período de 1980 a 2000.

3.2.4. Avaliar a tendência dos coeficientes gerais padronizados de mortalidade por Homicídios, Acidentes de Transporte e Suicídios, no município de Belo Horizonte e Região Metropolitana, no período de 1980 a 2000. 
4 MATERIAL E MÉTODOS 


\section{MATERIAL E MÉTODOS}

\subsection{Delineamento do Estudo}

O presente estudo apresenta um desenho ecológico do tipo série histórica, correspondente ao período de 1980 a $2000 .{ }^{\mathbf{6 1 ,}} \mathbf{6 2}$

\subsection{Local e Prazo do Estudo}

O desenvolvimento de todas as etapas do estudo ocorreu no município de Ribeirão Preto, entre maio de 2003 e dezembro de 2004.

\subsection{População de Estudo}

4.3.1 Óbitos: Foram considerados os óbitos referentes a três grupos de causas externas: Homicídios, Acidentes de Transporte e Suicídios, ocorridos na população residente no município de Belo Horizonte e Região Metropolitana, no período de 1980 a 2000. Estes dados foram extraídos do Sistema de Informação de Mortalidade da Secretaria de Vigilância em Saúde (SIM / VS), disponibilizados na Base de Dados do DATASUS / Informações de saúde / Mortalidade. ${ }^{59}$

Os óbitos foram classificados segundo sexo, faixa etária, ano de ocorrência e local de residência. Os óbitos com idade ignorada foram excluídos e constituem-se para estes grupos de causas um pequeno contigente.

Os óbitos foram definidos segundo a causa básica de morte e classificados com base na Classificação Internacional das Doenças - Nona (IX) Revisão ${ }^{19}$ e Décima (X) Revisão. ${ }^{20}$ Para o período de 1980 a 1995, os óbitos foram codificados segundo a IX Revisão. A partir de 1996, os óbitos foram codificados segundo a X Revisão da CID.

Os três subgrupos de causas, definidos para o estudo e classificados segundo códigos das CID 9 e CID 10 foram os seguintes:

a) Homicídios: “Homicídios e Lesões Provocadas Intencionalmente por Outras Pessoas” (E960-E969) da IX Revisão e “Agressões” (X85-Y09) da X Revisão. 
b) Acidentes de transporte: “Acidentes de Trânsito de Veículos a Motor” (E810-E819) da IX Revisão e “Acidentes de Transporte” (V01-V89) da X Revisão.

c) Suicídios: “Suicídios e Lesões Auto-infligidas” (E950-E959) da IX Revisão e "Lesões Auto-provocadas Intencionalmente” (X60-X84) da X Revisão.

No presente estudo não foram considerados os óbitos classificados como “Intervenções Legais”.

\subsubsection{População}

Os dados populacionais necessários para o cálculo dos coeficientes segundo sexo, faixa etária, ano de ocorrência e região geográfica foram fornecidos pela Fundação Instituto Brasileiro de Geografia e Estatística (FIBGE), disponibilizados na Base de Dados do DATASUS / Informações demográficas e sócio econômicas. ${ }^{10}$

As informações da população, por região geográfica, são as provenientes dos censos de 1980, 1991 e 2000, contagem populacional de 1996 e estimativas para os anos intercensitários, desagregadas por sexo e faixa etária.

Para os dados populacionais referentes ao município de Belo Horizonte excluiu-se a população residente na Região Metropolitana, assim como, para a Região Metropolitana excluiu-se aquela residente no município de Belo Horizonte.

\subsection{Definição dos grupos etários específicos:}

Os grupos etários de interesse foram agrupados em categorias, com intervalos de 10 anos. Para os Acidentes de Transporte todas as faixas etárias foram consideradas.

Para os Homicídios e os Suicídios os óbitos foram considerados no intervalo de 5 anos, no estrato de 15 a 49 anos, não sendo considerados os óbitos por essas causas em crianças. 
As estimativas populacionais com idade ignorada foram excluídas do estudo.

Para o presente estudo, foram excluídas as faixas etárias com óbitos iguais a zero, no decorrer do período.

\subsection{Indicadores de Mortalidade:}

Coeficientes: Foram calculados os coeficientes específicos de mortalidade por Homicídios, Acidentes de Transporte e Suicídios. Tais coeficientes foram calculados segundo o sexo, faixa etária, ano de ocorrência e local de residência, expressos por 100.000 habitantes. Além dos coeficientes específicos, foram calculados os coeficientes gerais padronizados, utilizando-se como população padrão a do ano de 1980, sendo tais coeficientes, também, expressos por 100.000 habitantes.

Mortalidade proporcional: Calculou-se a mortalidade proporcional por subgrupo de causas, em cada ano da série histórica e para cada região estudada. Para o cálculo destas proporções utilizou-se como denominador o total de óbitos relativos ao conjunto dos três subgrupos de causas externas, em questão.

Razão de mortalidade segundo sexo e idade: A razão de mortalidade foi calculada a partir dos coeficientes específicos de mortalidade por subgrupo de causas, segundo sexo e faixa etária, ano de ocorrência e local de residência. Para o cálculo desse indicador, utilizou-se como numerador, o coeficiente específico de mortalidade para o sexo masculino e como denominador o coeficiente específico de mortalidade para o sexo feminino.

Incrementos / Decrementos Percentuais: Esse indicador é uma medida que resulta de um quociente em que, no numerador coloca-se a subtração entre dois coeficientes específicos de mortalidade por subgrupo de causas e no denominador, o valor de um dos dois coeficientes específicos, obtendo-se o resultado em porcentagem. Para o cálculo 
desse indicador, foram utilizados os coeficientes específicos de mortalidade segundo sexo e faixa etária, ano de ocorrência e local de residência.

\subsection{Processamento dos dados:}

O processamento dos dados foi efetuado mediante a construção de planilhas eletrônicas de cálculo, para os grupos referentes aos Homicídios, Acidentes de Transporte e Suicídios, no município de Belo Horizonte e Região Metropolitana, para a série histórica entre o período de 1980 a 2000.

Para o cálculo dos coeficientes específicos e dos coeficientes gerais padronizados foram estruturadas 21 planilhas para cada região geográfica, referentes ao período de 1980 a 2000. Considerando-se os três grupos de causas (Homicídios, Acidentes de Transporte e Suicídios), obtiveram-se 63 planilhas para cada região. Desse modo, para as duas regiões (Belo Horizonte e Região Metropolitana) foram obtidas 126 planilhas. Tais planilhas foram construídas no software MICROSOFT EXCEL OFFICE, versão 8.0. ${ }^{63}$ (ANEXOS de 1 - 6).

\subsection{Análise dos dados}

A análise descritiva na série histórica estudada incluiu a distribuição da mortalidade proporcional segundo a região estudada e dos coeficientes específicos de mortalidade, classificados segundo sexo, faixa etária, região e ano de ocorrência. Foram também utilizadas as variações percentuais ao longo do período e a razão de coeficientes, segundo sexo e faixa etária, para todos os grupos de causas estudados. Para essas análises foi utilizado o software EXCELL, versão 8.0. ${ }^{63}$

Para a análise da tendência dos coeficientes utilizou-se a técnica estatística de regressão linear simples e testes de hipóteses com um nível de significância < <,05. O estudo 
de tendência foi desenvolvido no software STATISTICAL PACKAGE FOR SOCIAL SCIENCE (SPSS). ${ }^{64}$

\subsection{Considerações éticas}

Embora as informações dos bancos de dados fornecidas pelo SIM / CENEPI / MS sejam de domínio público e não apresentem variáveis relacionadas à identificação de indivíduos, o projeto foi submetido e aprovado pelo Comitê de Ética em Pesquisa, envolvendo seres humanos, da Escola de Enfermagem de Ribeirão Preto / Universidade de São Paulo (ANEXO 7). 
5 RESULTADOS 


\section{RESULTADOS}

\subsection{HOMICÍDIOS}

\subsubsection{Mortalidade Proporcional por Homicídios}

No decorrer da série histórica, em Belo Horizonte e Região Metropolitana, ocorreu um crescimento da mortalidade proporcional por Homicídios. As curvas de mortalidade proporcional mantiveram um padrão que se mostrou similar, em ambas as regiões. Entre 1980

a 1994 (Figuras 7 e 8) foram observadas pequenas oscilações nas curvas de mortalidade, sendo que a partir de 1995, apresentaram um crescimento contínuo da mortalidade, por Homicídios, até o final do período estudado.

Figura 7. Mortalidade proporcional por Homicídios, Belo Horizonte, 1980 a 2000.

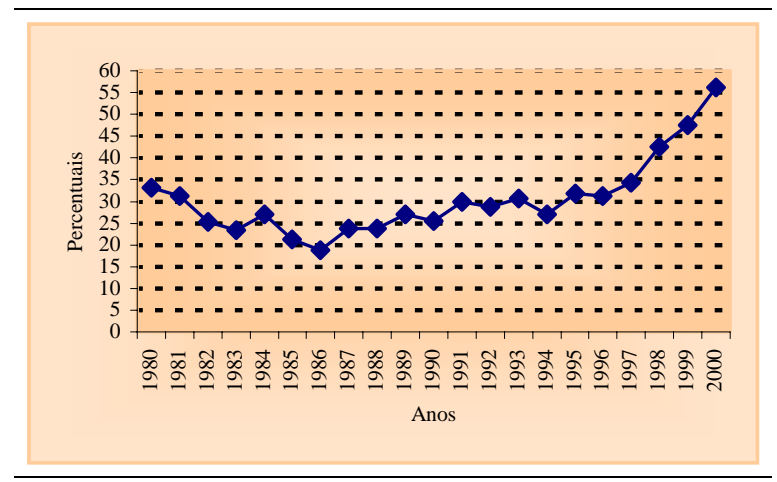

Fonte: Ministério da Saúde / DATASUS ${ }^{59}$
Figura 8. Mortalidade proporcional por Homicídios, Região Metropolitana de Belo Horizonte, 1980 a 2000.

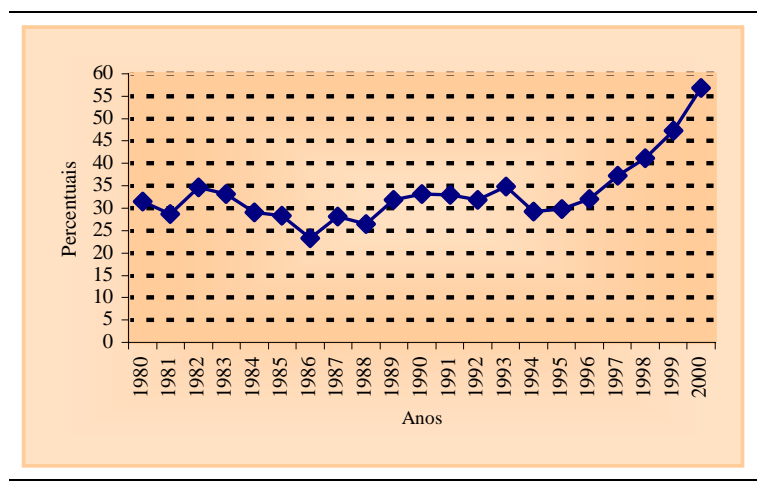

\subsubsection{Coeficientes Específicos de Mortalidade por Homicídios}

As Tabelas 6 e 7, a seguir, apresentam a distribuição dos coeficientes específicos de mortalidade por Homicídios, segundo sexo e faixa etária em Belo Horizonte e Região Metropolitana, no período de 1980 a 2000.

Nas regiões geográficas em toda a série histórica ocorreu uma ascensão dos coeficientes de mortalidade por homicídios em todas as faixas etárias, destacando-se por sua magnitude os indicadores do sexo masculino na Região Metropolitana. 
No município de Belo Horizonte, os coeficientes específicos na faixa etária de "20 a 29 anos” no sexo masculino e na faixa etária de “30 a 39 anos” no sexo feminino se sobressaíram pela sua magnitude e pelo crescimento contínuo, principalmente na década de 90. No ano de 2000, expandiram-se para a faixa etária de "15 a 19 anos", em ambos os sexos, apresentando um acréscimo nos seus coeficientes e aumentando progressivamente os grupos de risco de mortalidade por Homicídios.

Na Região Metropolitana, os coeficientes de mortalidade na faixa etária de "20 a 29 anos”, em ambos os sexos, apresentaram maior magnitude, mantendo um crescimento, até o final do período. Para as demais idades, incluindo a faixa etária de “20 a 29 anos”, os indicadores tiveram maior magnitude no sexo masculino. 


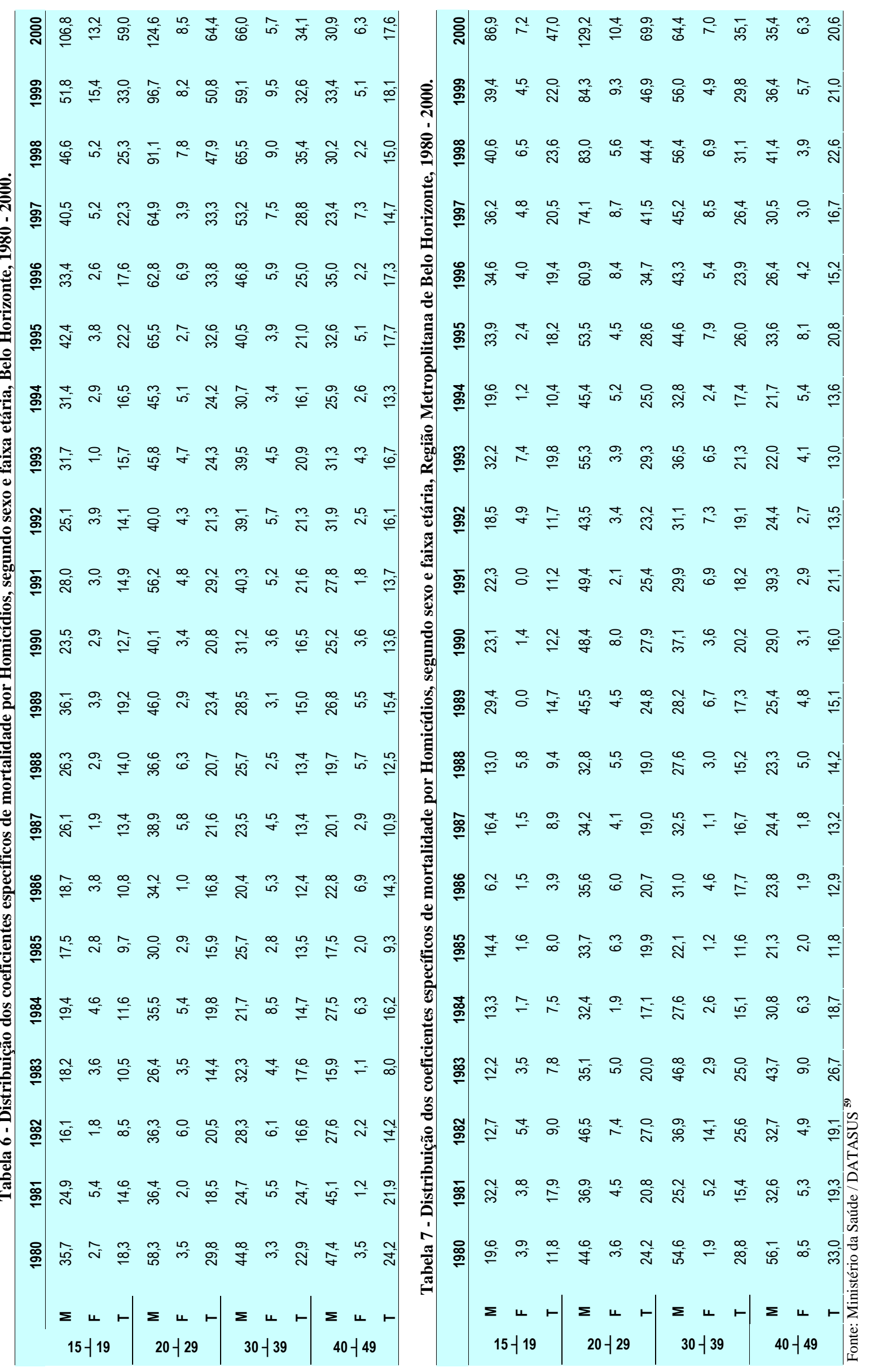




\subsubsection{Razão de Mortalidade por Homicídios Segundo Sexo.}

As Tabelas 8 e 9 apresentam os coeficientes específicos de mortalidade por Homicídios e a razão de coeficientes, segundo sexo e faixas etárias, no município de Belo Horizonte e Região Metropolitana, nos anos de 1980, 1990 e 2000.

No município de Belo Horizonte (Tabela 8) em 1980, a razão de mortalidade dos coeficientes se destacou com maiores valores nas faixas etárias de "30 a 39 anos” e de "40 a 49 anos”. A partir de 1990, a maior razão de mortalidade ocorreu na faixa etária de "20 a 29 anos”, com um aumento em seus coeficientes de mortalidade até o final do período.

Tabela 8 - Coeficientes específicos de mortalidade, por homicídios e razão de coeficientes segundo sexo e faixas etárias. Belo Horizonte, 1980, 1990, 2000.

\begin{tabular}{|c|c|c|c|c|c|c|c|c|c|}
\hline \multirow[b]{2}{*}{ Idade } & \multicolumn{3}{|c|}{1980} & \multicolumn{3}{|c|}{1990} & \multicolumn{3}{|c|}{2000} \\
\hline & $M^{*}$. & $\mathrm{F}^{*}$ & Razão M / F & $M^{*}$. & F. & Razão M / F & $M^{*}$. & $F^{*}$. & Razão M / F \\
\hline $15-19$ & 35,7 & 2,7 & 13,2 & 23,5 & 2,9 & 8,1 & 106,8 & 13,2 & 8,1 \\
\hline $20-29$ & 58,3 & 3,5 & 16,7 & 40,1 & 3,4 & 11,8 & 124,6 & 8,5 & 14,7 \\
\hline $30-39$ & 44,8 & 3,3 & 13,6 & 31,2 & 3,6 & 8,7 & 66,0 & 5,7 & 11,6 \\
\hline $40-49$ & 47,4 & 3,5 & 13,5 & 25,2 & 3,6 & 7,0 & 30,9 & 6,3 & 4,9 \\
\hline
\end{tabular}

*Coeficientes por 100000 habitantes

Fonte: Ministério da Saúde / DATASUS ${ }^{59}$

Na região metropolitana (Tabela 9) em 1980, a razão de coeficientes específicos se sobressaiu na faixa etária de “30 a 39 anos”, em 1990 na faixa etária de “15 a 19 anos” e em 2000 nas faixas etárias de “15 a 19 anos” e de “20 a 29 anos”. 
Tabela 9 - Coeficientes específicos de mortalidade por homicídios e razão de coeficientes segundo sexo e faixas etárias, Região Metropolitana de Belo Horizonte, 1980, 1990, 2000.

\begin{tabular}{|c|c|c|c|c|c|c|c|c|c|}
\hline \multirow[b]{2}{*}{ Idade } & \multicolumn{4}{|c|}{1980} & \multicolumn{2}{|r|}{1990} & \multicolumn{3}{|r|}{2000} \\
\hline & $M^{*}$. & $F^{*}$. & Razão M / F & $M^{*}$. & $F^{*}$. & Razão M / F & $M^{*}$. & $F^{*}$. & Razão M / F \\
\hline $15-19$ & 19,6 & 3,9 & 5,0 & 23,1 & 1,4 & 16,5 & 86,9 & 7,2 & 12,1 \\
\hline $20-29$ & 44,6 & 3,6 & 12,4 & 48,4 & 7,9 & 6,1 & 129,2 & 10,4 & 12,4 \\
\hline $30-39$ & 54,6 & 1,9 & 28,7 & 37,1 & 3,6 & 10,3 & 64,4 & 6,9 & 9,3 \\
\hline $40-49$ & 56,1 & 8,5 & 6,6 & 28,9 & 3,1 & 9,3 & 35,4 & 6,4 & 5,5 \\
\hline
\end{tabular}

* Coeficientes / 100.000 habitantes.

Fonte: Ministério da Saúde / DATASUS 59

\subsubsection{Variação Percentual dos Coeficientes Específicos de Mortalidade por Homicídios.}

As Figuras 9 a 12 apresentam a variação percentual dos coeficientes de mortalidade, segundo sexo e faixa etária para o município de Belo Horizonte e Região Metropolitana entre os anos de 1980 e 2000.

Em Belo Horizonte (Figura 9) no sexo feminino, em todas as faixas etárias, os coeficientes de mortalidade apresentaram os maiores incrementos percentuais. A faixa etária de "15 a 19 anos" se sobressaiu por apresentar uma variação percentual dos coeficientes de 396\%. A seguir, observou-se as faixas etárias com suas variações percentuais: de "20 a 29 anos” (143\%), “40 a 49 anos” (80\%) e “30 a 39 anos” (75\%).

No sexo masculino (Figura 10) a faixa etária de “15 a 19 anos” se destacou por apresentar um incremento percentual dos coeficientes de mortalidade por Homicídios com uma variação de 199\% e a faixa etária de “40 a 49 anos”, por apresentar um decréscimo com uma variação percentual de (-35\%). Na faixa etária de “20 a 29 anos” verificou-se um incremento percentual de $114 \%$ que se aproxima do valor encontrado no sexo feminino, também na faixa etária de “20 a 29 anos”. 
Figura 9 - Variação percentual dos coeficientes de mortalidade por homicídios entre 1980 e 2000, segundo faixa etária - sexo masculino -

Belo Horizonte.

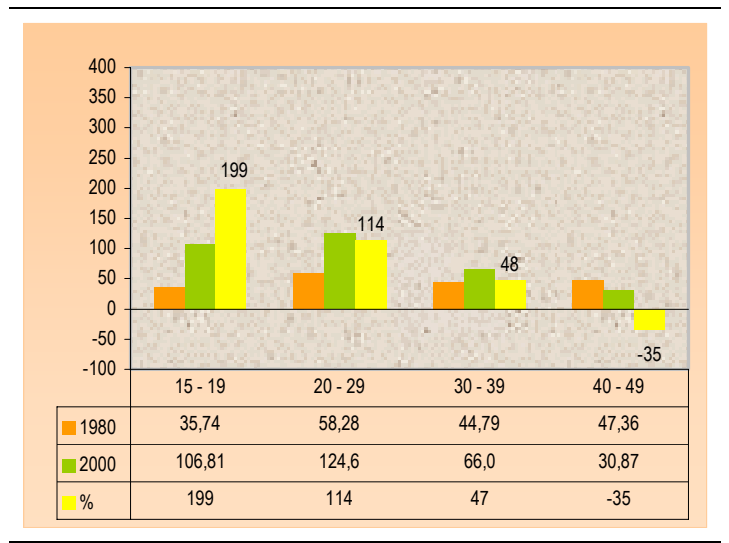

Fonte: Ministério da Saúde / DATASUS ${ }^{59}$
Figura 10 - Variação percentual dos coeficientes de mortalidade por homicídios entre 1980 e 2000, segundo faixa etária - sexo feminino Belo Horizonte.

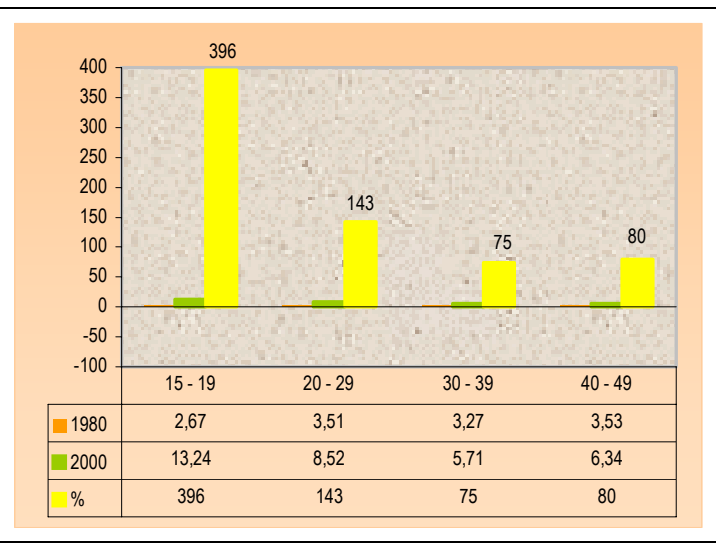

$\mathrm{Na}$ região metropolitana (Figuras 11 e 12) os coeficientes de mortalidade por Homicídios em todas as faixas etárias e em ambos os sexos, apresentaram incrementos, exceto na faixa de “40 a 49 anos”.

No sexo masculino (Figura 11) a faixa etária de "15 a 19 anos" se sobressaiu por apresentar um incremento percentual de 343\%. No sexo feminino (Figura 12) o maior incremento percentual foi observado na faixa etária de “30 a 39 anos”, com uma variação percentual de 267\%. Em ambos os sexos, a faixa etária de “20 a 29 anos” apresentou incremento percentual de 190\%. A faixa etária de “40 a 49 anos” se destacou por apresentar decrementos, com uma variação percentual para o sexo masculino (-37\%) e para o feminino $(-34 \%)$ 
Figura 11 - Variação percentual dos coeficientes de mortalidade por homicídios entre 1980 e 2000, segundo faixa etária - sexo masculino Região Metropolitana de Belo Horizonte.

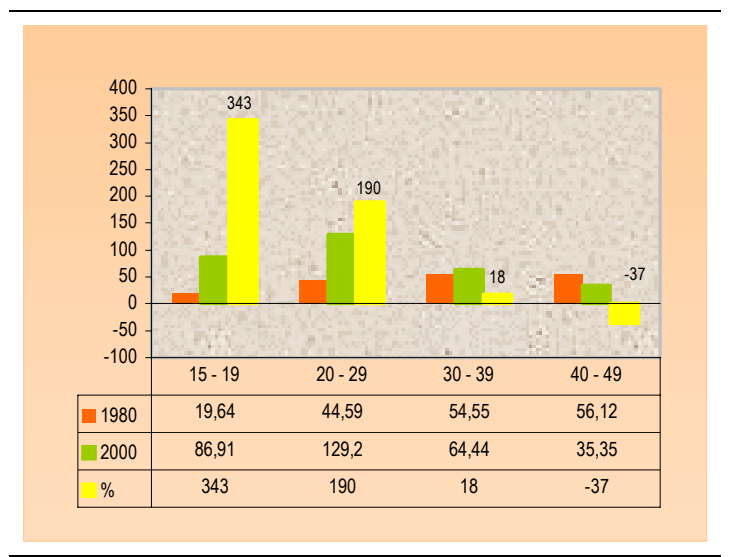

Fonte: Ministério da Saúde / DATASUS ${ }^{59}$
Figura 12 - Variação percentual dos coeficientes de mortalidade por homicídios entre 1980 e 2000, segundo faixa etária - sexo feminino Região Metropolitana de Belo Horizonte.

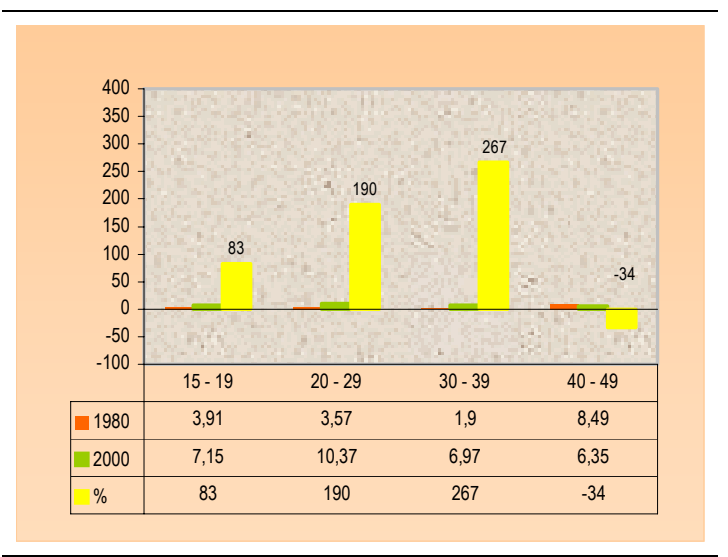

\subsubsection{Tendências dos Coeficientes Específicos de Mortalidade por Homicídios.}

As Figuras de número 13 a 20 apresentam as tendências dos coeficientes específicos de mortalidade por Homicídios, segundo sexo e faixa etária, no município de Belo Horizonte e Região Metropolitana.

Em ambas as regiões geográficas, as tendências dos coeficientes de mortalidade por Homicídios, em todas as faixas etárias, apresentaram ascensão ao longo da série histórica, com exceção da faixa etária de “40 a 49 anos”, destacando-se por sua magnitude, os indicadores do sexo masculino. Para todas as faixas etárias, regiões e para o sexo masculino, as tendências apresentaram significância estatística $(\mathrm{p}<0,05)$, exceto para a faixa de "40 a 49 anos”. No sexo feminino ocorreu uma estabilização ao longo do período.

Na faixa etária de “15 a 19 anos” (Figuras 13 e 14) verificou-se uma tendência de ascensão dos coeficientes específicos de mortalidade por Homicídios, em ambos os sexos. A Região Metropolitana se destacou por apresentar maior magnitude dos indicadores, porém, o município de Belo Horizonte apresentou maiores coeficientes angulares. Os testes de 
hipóteses não apresentaram significância estatística para o sexo feminino na Região Metropolitana.

Na faixa etária de “20 a 29 anos” (Figuras 15 e 16), os coeficientes específicos de mortalidade por homicídios se sobressaíram pela maior magnitude em relação às outras faixas etárias, com destaque para a Região Metropolitana. Para ambos os sexos as tendências foram de ascensão, observando-se em Belo Horizonte os maiores coeficientes angulares, principalmente para o sexo masculino. Os testes de hipóteses apresentaram significância estatística $(\mathrm{p}<0,05)$.

Nas Figuras 17 e 18, na faixa etária de “30 a 39 anos”, os coeficientes específicos de mortalidade por Homicídios apresentaram uma tendência de crescimento em ambos os sexos. O sexo masculino se destacou por sua magnitude em ambas as regiões, embora os respectivos coeficientes angulares apresentaram significância estatística apenas para o município de Belo Horizonte $(p<0,05)$.

Os coeficientes específicos de mortalidade por homicídios na faixa etária de “40 a 49 anos” (Figuras 19 e 20) apresentaram uma estabilização ao longo do período. 

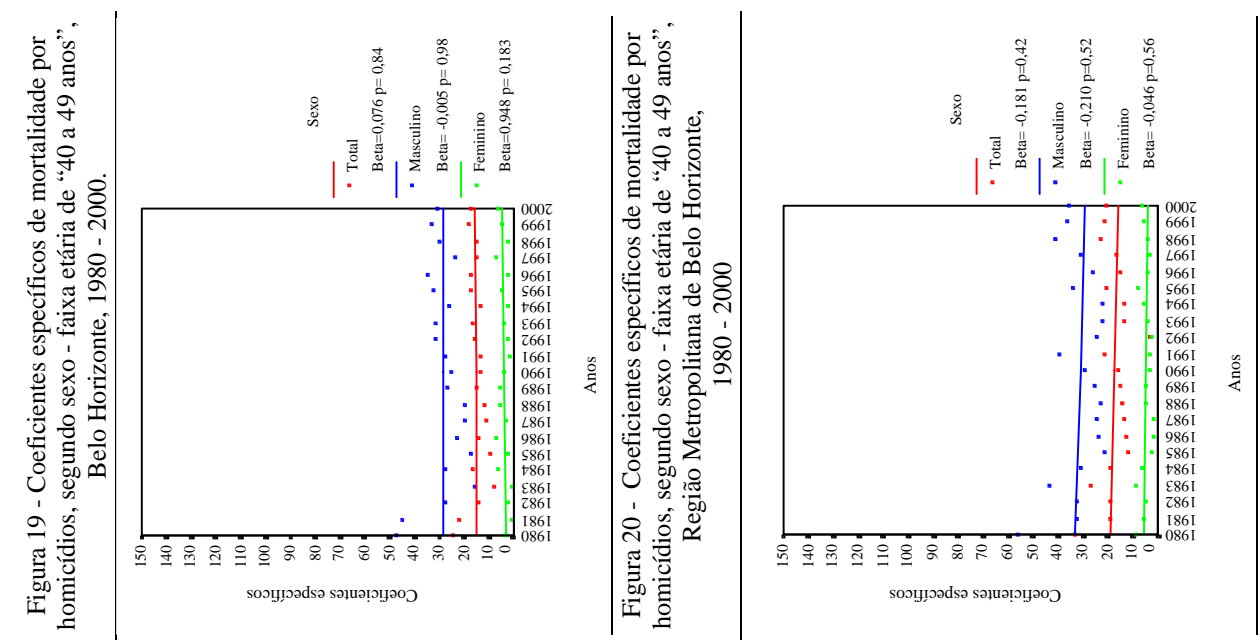

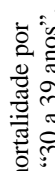
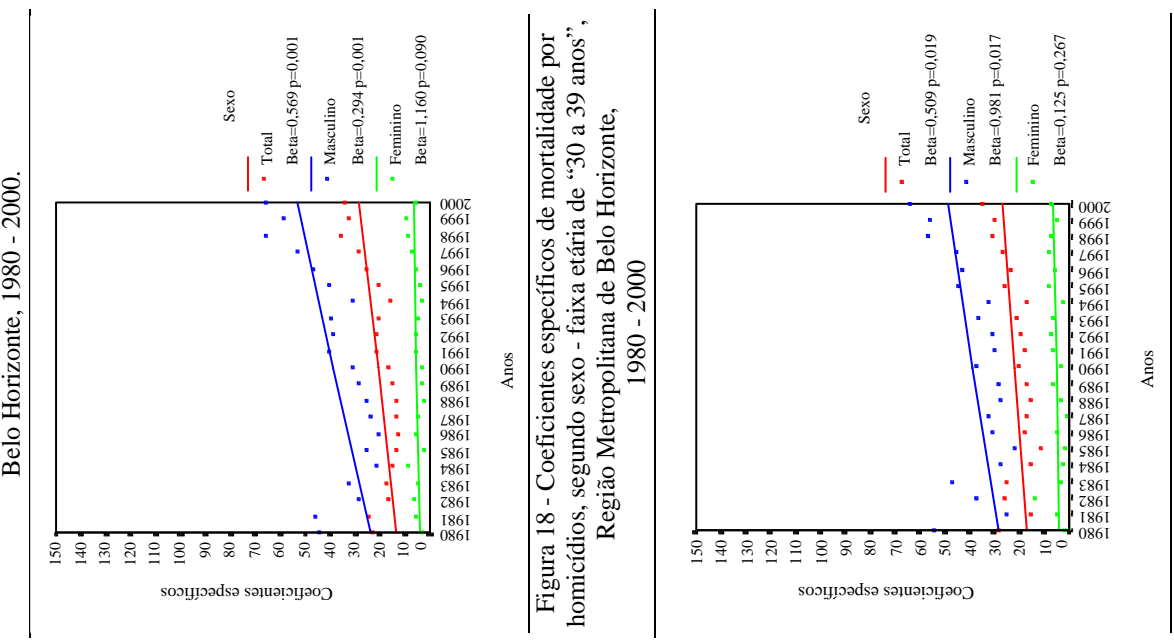

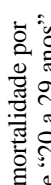
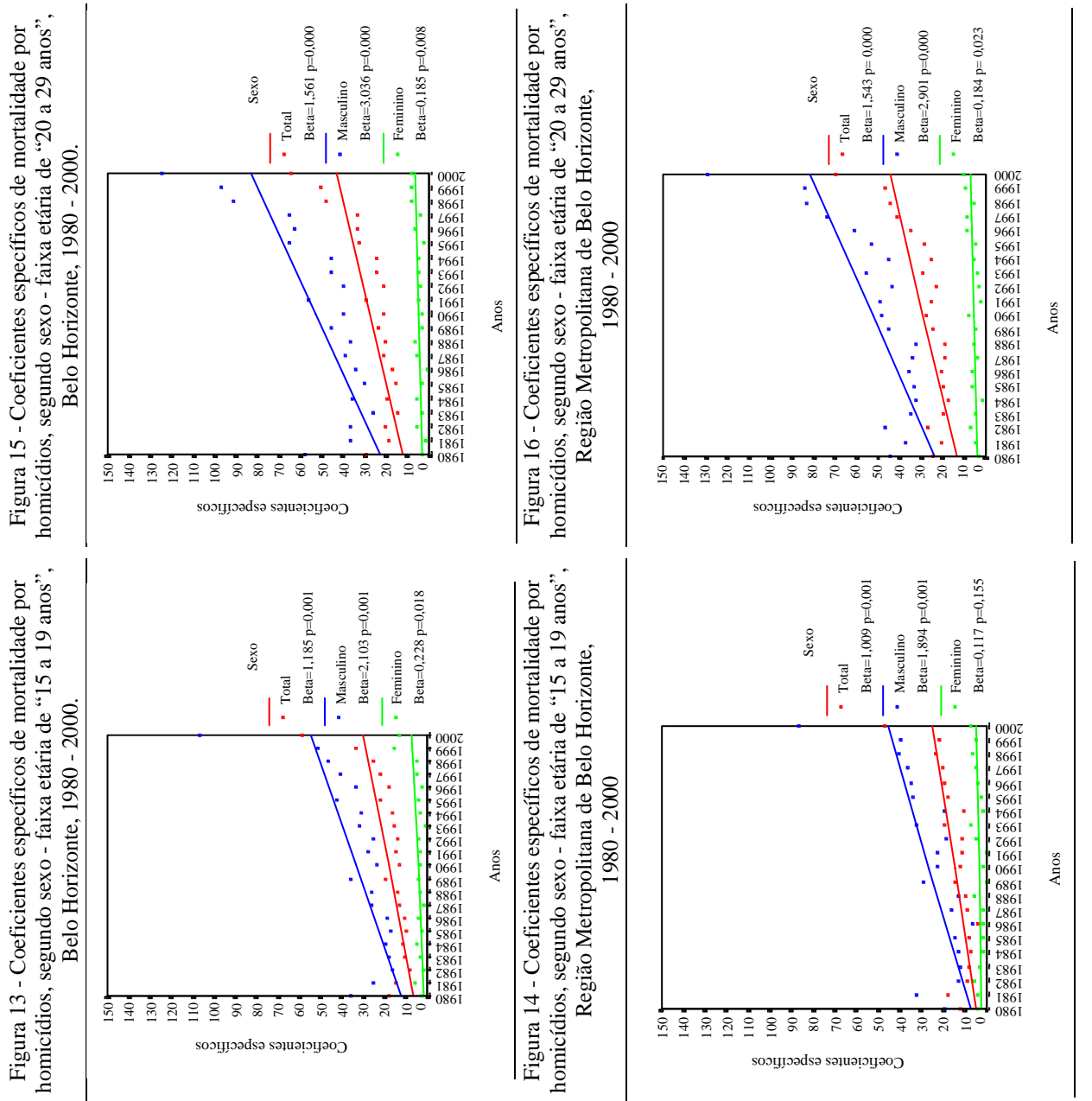

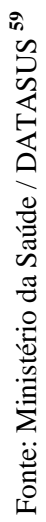




\subsubsection{Tendências dos Coeficientes Gerais Padronizados de Mortalidade por Homicídios.}

As Figuras 21 e 22 apresentam as tendências dos coeficientes gerais padronizados de mortalidade por homicídios no município de Belo Horizonte e Região Metropolitana. Em ambas regiões, observou-se uma magnitude elevada dos coeficientes para o sexo masculino, com uma tendência de ascensão, estatisticamente significante. Para o sexo feminino, verificou-se uma tendência de estabilização ao longo do período, embora, com indicação de ascensão estatisticamente significante no município de Belo Horizonte $(\mathrm{p}<0,05)$.

Figura 21 - Coeficientes gerais padronizados de mortalidade por Homicídios, segundo sexo, Belo Horizonte, 1980 - 2000.

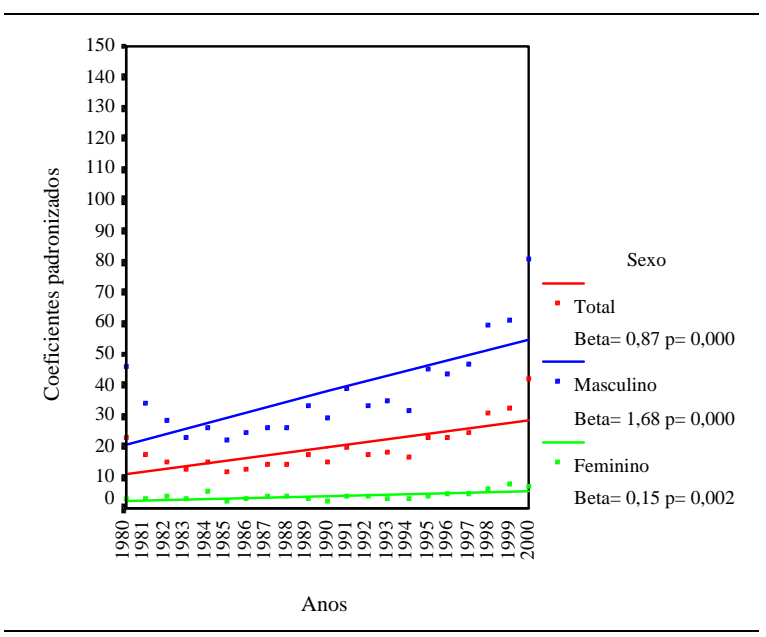

Fonte: Ministério da Saúde / DATASUS ${ }^{59}$
Figura 22 - Coeficientes gerais padronizados de mortalidade por Homicídios, segundo sexo, Região Metropolitana de Belo Horizonte, 1980 - 2000.

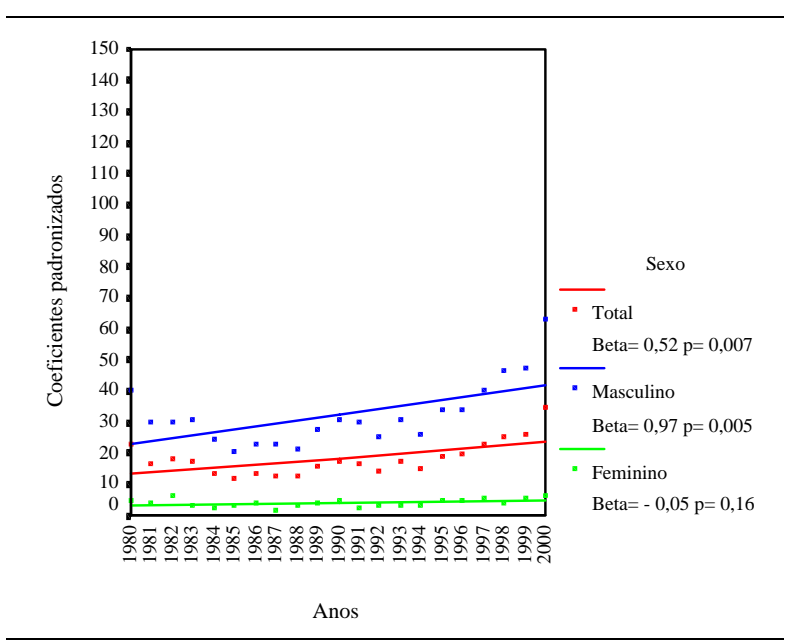




\subsection{ACIDENTES DE TRANSPORTE}

\subsubsection{Mortalidade Proporcional por Acidentes de Transporte}

Na série histórica estudada, em Belo Horizonte e Região Metropolitana, ocorreu um decréscimo da mortalidade proporcional por Acidentes de Transporte. Em ambas regiões geográficas (Figuras 23 e 24) as curvas de mortalidade proporcional mantiveram um padrão similar. Entre 1980 e 1986, observou-se um aumento dos percentuais e um crescimento nas curvas de mortalidade proporcional. A partir de 1987, ocorreu um decréscimo contínuo dos percentuais de mortalidade alterando o desenho das curvas de mortalidade proporcional.

Figura 23 - Mortalidade proporcional por Acidentes de Transporte, município de Belo Horizonte, 1980 a 2000.

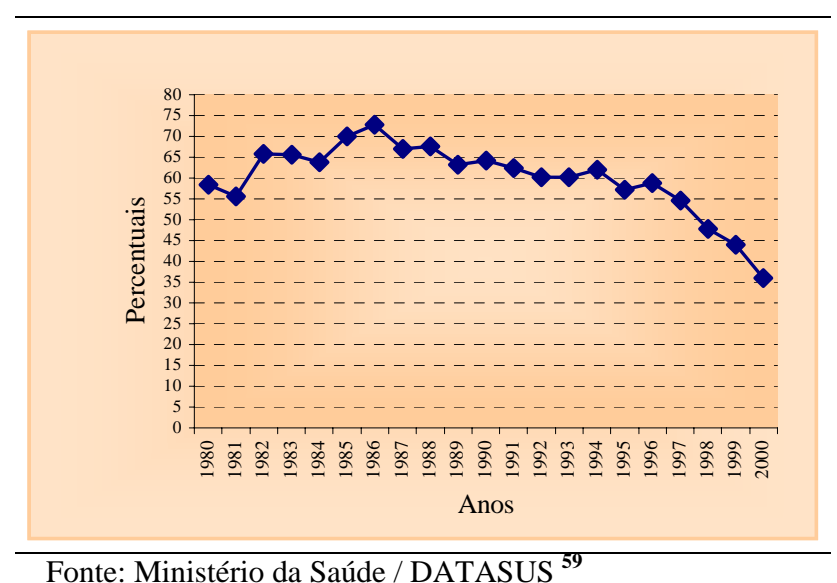

Figura 24 - Mortalidade proporcional por Acidentes de Transporte, Região Metropolitana de Belo Horizonte, 1980 a 2000.

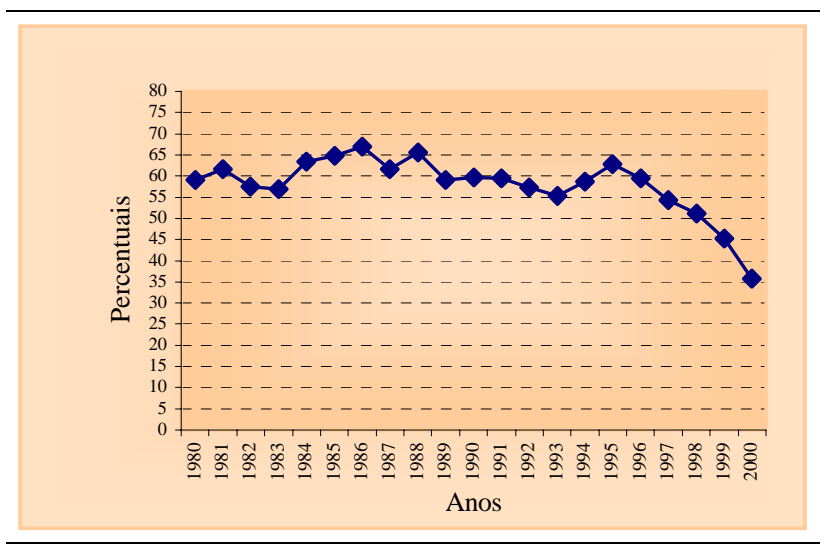

\subsubsection{Coeficientes Específicos de Mortalidade por Acidentes de Transporte}

As Tabelas 10 e 11 apresentam a distribuição dos coeficientes específicos de mortalidade por Acidentes de Transporte, segundo sexo e faixa etária em Belo Horizonte e Região Metropolitana, no período de 1980 a 2000. 
Em ambas regiões, os coeficientes específicos para o sexo masculino e as faixas etárias de “70 anos e mais” se sobressaíram por sua magnitude na mortalidade por Acidentes de Transporte, com destaque para Belo Horizonte.

Em Belo Horizonte (Tabela 10) os coeficientes específicos de mortalidade no sexo masculino apresentaram maior magnitude na faixa etária de “60 a 69 anos” (década de 1980) e na faixa de “50 a 59 anos” (década de 1990).

Na Região Metropolitana (Tabela 11), nas décadas de 1980 e 1990, os coeficientes de mortalidade por Acidentes de Transporte, com maior magnitude, foram observados no sexo masculino na faixa etária de "50 a 59 anos” e no sexo feminino na faixa etária de “60 a 69 anos”. 


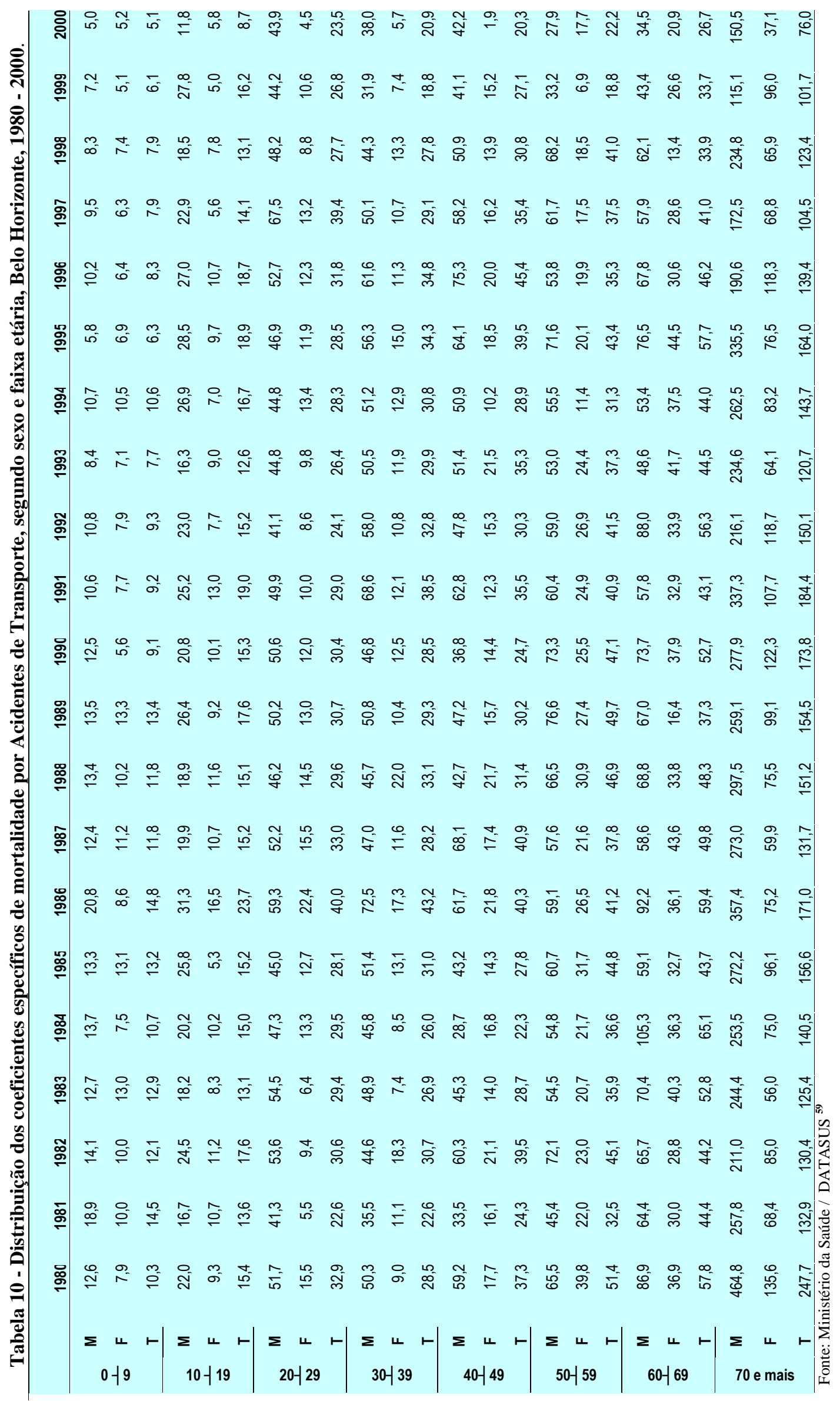




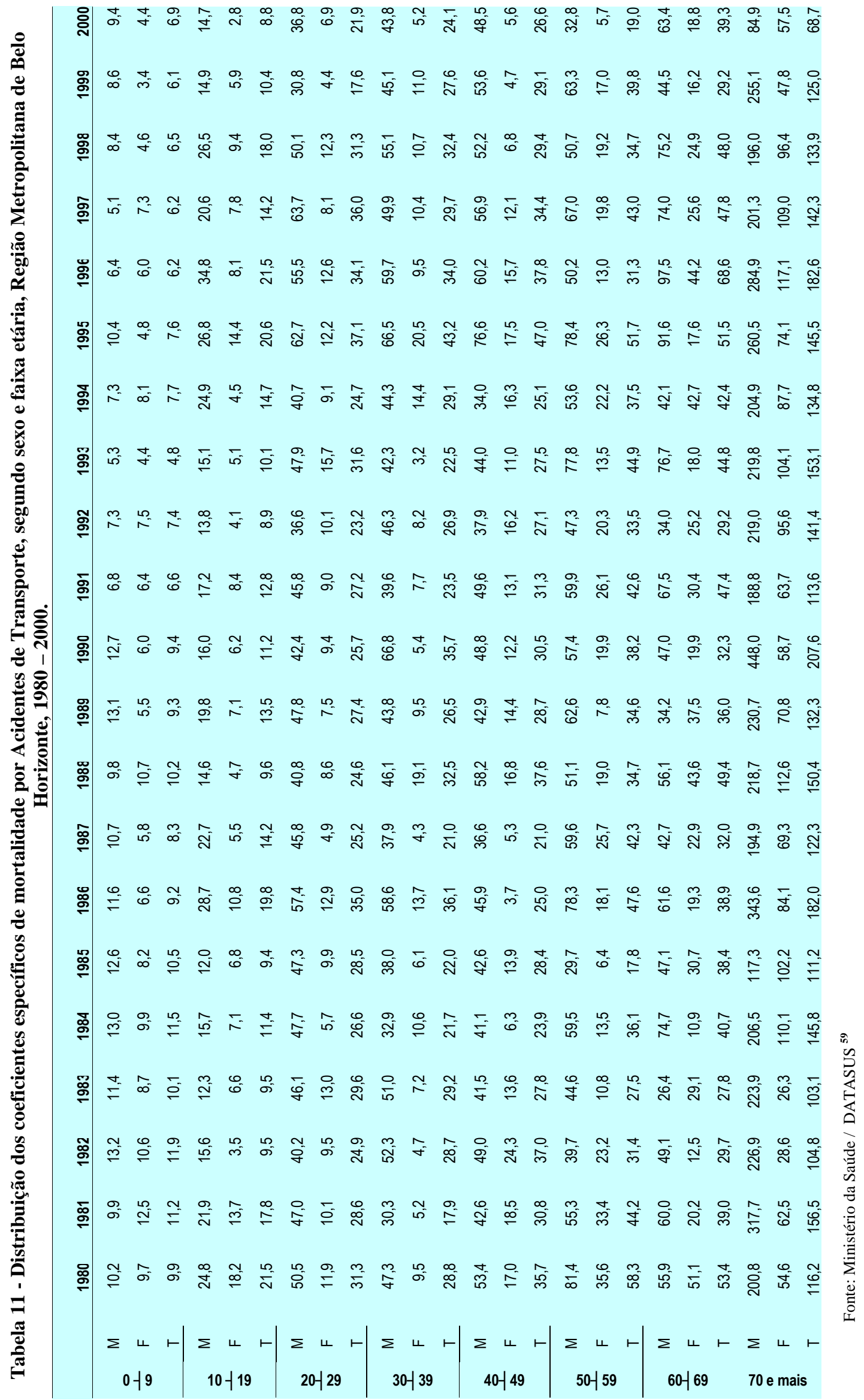




\subsubsection{Razão de Mortalidade por Acidentes de Transporte, Segundo Sexo.}

As Tabelas 12 e 13 apresentam a distribuição dos coeficientes de mortalidade por Acidentes de Transporte e a razão de coeficientes segundo sexo e faixas etárias em Belo Horizonte e Região Metropolitana.

Na Tabela 12 - município de Belo Horizonte - em 1980, a razão de mortalidade dos coeficientes apresentou maior valor na faixa etária de “30 a 39 anos”. Em 1990, a maior razão deslocou-se para a faixa de “20 a 29 anos”, enquanto, em 2000 essa razão apresentou uma elevada magnitude na faixa etária de “40 a 49 anos” que se sobressaiu com um valor de 22,2::1, indicando a maior diferença entre os sexos, na mortalidade por Acidentes de Transporte entre os sexos.

Tabela 12: Coeficientes específicos de mortalidade, por Acidentes de Transporte e razão de coeficientes segundo sexo e faixas etárias, Belo Horizonte, 1980, 1990, 2000.

\begin{tabular}{|c|c|c|c|c|c|c|c|c|c|}
\hline \multirow[b]{2}{*}{ Idade } & \multicolumn{3}{|c|}{1980} & \multicolumn{3}{|c|}{1990} & \multicolumn{3}{|c|}{2000} \\
\hline & $M^{*}$ & $F^{*}$. & Razão M / F & $M^{*}$ & $F^{*}$. & Razão M / F & $M^{*}$ & $F^{*}$ & Razão M / F \\
\hline $0-19$ & 12,6 & 7,9 & 1,6 & 12,5 & 5,6 & 2,2 & 5,0 & 5,2 & 0,9 \\
\hline $10-19$ & 22,1 & 9,3 & 2,4 & 20,8 & 10,1 & 2,1 & 11,8 & 5,8 & 2,0 \\
\hline $20-29$ & 51,7 & 15,5 & 3,3 & 50,6 & 11,9 & 4,3 & 43,9 & 4,5 & 9,7 \\
\hline $30-39$ & 50,3 & 8,9 & 5,7 & 46,8 & 12,5 & 3,7 & 37,9 & 5,7 & 6,6 \\
\hline $40-49$ & 59,2 & 17,7 & 3,3 & 36,8 & 14,4 & 2,6 & 42,2 & 1,9 & 22,2 \\
\hline $50-59$ & 65,5 & 39,8 & 1,6 & 73,3 & 25,5 & 2,9 & 27,9 & 17,7 & 1,6 \\
\hline $60-69$ & 86,9 & 36,9 & 2,3 & 73,7 & 37,9 & 2,9 & 34,5 & 20,9 & 1,7 \\
\hline $70 \mathrm{e}+$ & 464,8 & 135,6 & 3,4 & 277,9 & 122,3 & 2,3 & 150,5 & 37,1 & 4,1 \\
\hline
\end{tabular}

*Coeficientes por 100000 habitantes

Fonte: Ministério da Saúde / DATASUS ${ }^{59}$

Na Tabela 13 - Região Metropolitana - entre os anos de 1980 e 2000, a razão de mortalidade de coeficientes se destacou na faixa etária de “30 a 39 anos”. Em 2000 deslocouse ligeiramente para a faixa de “40 a 49 anos”. 
Tabela 13: Coeficientes específicos de mortalidade, por Acidentes de Transporte e razão de coeficientes, segundo sexo e faixas etárias, Região Metropolitana de Belo Horizonte, 1980, 1990, 2000.

\begin{tabular}{|c|c|c|c|c|c|c|c|c|c|}
\hline \multirow[b]{2}{*}{ Idade } & \multicolumn{3}{|c|}{1980} & \multicolumn{3}{|c|}{1990} & \multicolumn{3}{|c|}{2000} \\
\hline & $M^{*}$ & F. & Razão M / F & $M^{*}$. & $F^{*}$. & Razão M / F & $M^{*}$. & $F^{*}$. & Razão M / F \\
\hline 어 9 & 10,2 & 9,7 & 1,1 & 12,4 & 5,9 & 2,1 & 9,4 & 4,4 & 2,1 \\
\hline $10-19$ & 24,9 & 18,2 & 1,4 & 16,0 & 6,2 & 2,6 & 14,7 & 2,8 & 5,3 \\
\hline $20-29$ & 50,5 & 11,9 & 4,2 & 42,4 & 9,4 & 4,5 & 36,8 & 6,9 & 5,3 \\
\hline 30- 39 & 47,3 & 9,5 & 5,0 & 66,8 & 5,4 & 12,4 & 43,8 & 5,2 & 8,4 \\
\hline $40-49$ & 53,5 & 16,9 & 3,2 & 48,8 & 12,2 & 4,0 & 48,5 & 5,6 & 8,7 \\
\hline $50-59$ & 81,4 & 35,6 & 2,3 & 57,4 & 19,9 & 2,9 & 32,8 & 5,7 & 5,8 \\
\hline $60-69$ & 55,9 & 51,1 & 1,1 & 46,9 & 19,9 & 2,4 & 63,4 & 18,8 & 3,4 \\
\hline $70 \mathrm{e}+$ & 200,8 & 54,6 & 3,7 & 448,0 & 58,7 & 7,6 & 84,9 & 57,5 & 1,5 \\
\hline
\end{tabular}

*Coeficientes por 100000 habitantes

Fonte: Ministério da Saúde / DATASUS ${ }^{59}$

\subsubsection{Variação Percentual dos Coeficientes Específicos de Mortalidade por Acidentes de}

\section{Transporte}

Nas Tabelas 14 e 15 estão apresentadas as variações percentuais dos coeficientes de mortalidade por Acidentes de Transporte, segundo sexo, faixa etária em Belo Horizonte e Região Metropolitana, entre os anos de 1980 a 2000.

Em Belo Horizonte - Tabela 14 - em ambos os sexos e faixas etárias, verificaram-se decrementos dos coeficientes de mortalidade por Acidentes de Transporte, com destaque para o sexo feminino, na faixa de “40 a 49 anos”, que apresentou a maior variação percentual da série histórica (- 828\%). Ainda no sexo feminino, destacaram os decrementos percentuais nas faixas etárias de “70 anos e mais” com uma variação percentual de (- 266\%) e na faixa de “20 a 29 anos” com uma variação de (- 246\%).

No sexo masculino, o maior decremento foi observado na faixa de "70 anos e mais" com uma variação percentual de (- 209\%). 
Tabela 14: Variação percentual dos coeficientes de mortalidade por Acidentes de Transporte entre 1980 e 2000, segundo faixa etária - sexo masculino e feminino, Belo Horizonte.

\begin{tabular}{|c|c|c|c|c|c|c|}
\hline \multirow[b]{2}{*}{ Faixa etária } & \multicolumn{3}{|c|}{ Masculino } & \multicolumn{3}{|c|}{ Feminino } \\
\hline & 1980 & 2000 & $\%$ & 1980 & 2000 & $\%$ \\
\hline $0 \nmid 9$ & 12,6 & 5,1 & -150 & 8,0 & 5,2 & -54 \\
\hline $10-19$ & 22,1 & 12,0 & -87 & 9,3 & 5,7 & -61 \\
\hline $20 \dashv 29$ & 51,7 & 44,0 & -18 & 15,5 & 4,5 & -246 \\
\hline $30 \nmid 39$ & 50,3 & 38,0 & -32 & 8,9 & 5,7 & -57 \\
\hline $40 \dashv 49$ & 59,2 & 42,2 & -40 & 17,6 & 1,9 & -828 \\
\hline $50 \dashv 59$ & 65,5 & 28,0 & -135 & 39,8 & 17,7 & -125 \\
\hline $60 \dashv 69$ & 87,0 & 34,5 & -152 & 37,0 & 21,0 & -77 \\
\hline 70 e + & 464,8 & 150,5 & -209 & 136,0 & 37,1 & -266 \\
\hline
\end{tabular}

Fonte: Ministério da Saúde / DATASUS ${ }^{59}$

Na Região Metropolitana - Tabela 15 - em ambos os sexos e faixas etárias, observaram-se decrementos dos coeficientes de mortalidade por Acidentes de Transporte, exceto, no sexo masculino na faixa etária de "60 a 69 anos” e no sexo feminino nas faixas etárias de "20 a 29 anos" e de "70 anos e mais".

O sexo feminino revelou os maiores decrementos da série histórica estudada, nas faixas etárias de "10 a 19 anos” e de "50 a 59 anos”, com variações percentuais de (- 554\%) e (- 523\%), respectivamente.

No sexo masculino, os maiores decrementos foram observados na faixa de "50 a 59 anos” com uma variação percentual de (-148\%) e na faixa de “70 anos e mais” com uma variação de (- 136\%). 
Tabela 15: Variação percentual dos coeficientes de mortalidade por Acidentes de Transporte entre 1980 e 2000, segundo faixa etária - sexo masculino e feminino, Região Metropolitana de Belo Horizonte.

\begin{tabular}{|c|c|c|c|c|c|c|}
\hline \multirow[b]{2}{*}{ Faixa etária } & \multicolumn{3}{|c|}{ Masculino } & \multicolumn{3}{|c|}{ Feminino } \\
\hline & 1980 & 2000 & $\%$ & 1980 & 2000 & $\%$ \\
\hline $0 \nmid 9$ & 10,2 & 9,4 & -9 & 9,7 & 4,4 & -122 \\
\hline $10-19$ & 24,9 & 14,7 & -69 & 18,2 & 2,8 & -554 \\
\hline $20 \dashv 29$ & 50,5 & 36,8 & -37 & 12,0 & 6,9 & 72 \\
\hline $30 \nmid 39$ & 47,3 & 43,8 & -8 & 9,5 & 5,2 & -82 \\
\hline $40 \dashv 49$ & 53,5 & 48,5 & -10 & 17,0 & 5,6 & -206 \\
\hline $50 \nmid 59$ & 81,4 & 32,8 & -148 & 35,6 & 5,7 & -523 \\
\hline $60-69$ & 55,9 & 63,4 & 13 & 51,1 & 18,8 & -172 \\
\hline $70 \mathrm{e}+$ & 200,8 & 84,9 & -136 & 54,6 & 57,5 & 5 \\
\hline
\end{tabular}

Fonte: Ministério da Saúde / DATASUS ${ }^{59}$

\subsubsection{Tendências dos Coeficientes de Mortalidade por Acidentes de Transporte}

As tendências dos coeficientes de mortalidade por Acidentes de Transporte, em Belo Horizonte e Região Metropolitana, estão apresentadas nas Figuras 25 a 40.

Ao longo do período, no município de Belo Horizonte e Região Metropolitana, em todas as faixas etárias, os coeficientes específicos de mortalidade por Acidentes de Transporte apresentaram tendências de declínio ou estabilização. Em ambos os sexos, a elevação da magnitude dos coeficientes de mortalidade está relacionada com o aumento da idade. O sexo masculino se destacou por sua magnitude, em ambas regiões e em todas as faixas etárias.

A partir dos “50 anos” houve uma tendência de declínio para ambos os sexos, no município de Belo Horizonte. Entretanto, esse declínio apresentou significância estatística para o sexo feminino $(\mathrm{p}<0,05)$ na faixa etária de “50 a 59 anos” e para o sexo masculino na faixa “60 a 69 anos” e “70 anos e mais”. Embora, na faixa etária de “70 anos e mais”, o padrão de mortalidade tenha sido similar para ambas regiões, na faixa etária de “60 a 69 anos” no sexo masculino observou-se um padrão inverso na tendência da mortalidade ao se comparar o município de Belo Horizonte com a Região Metropolitana. 

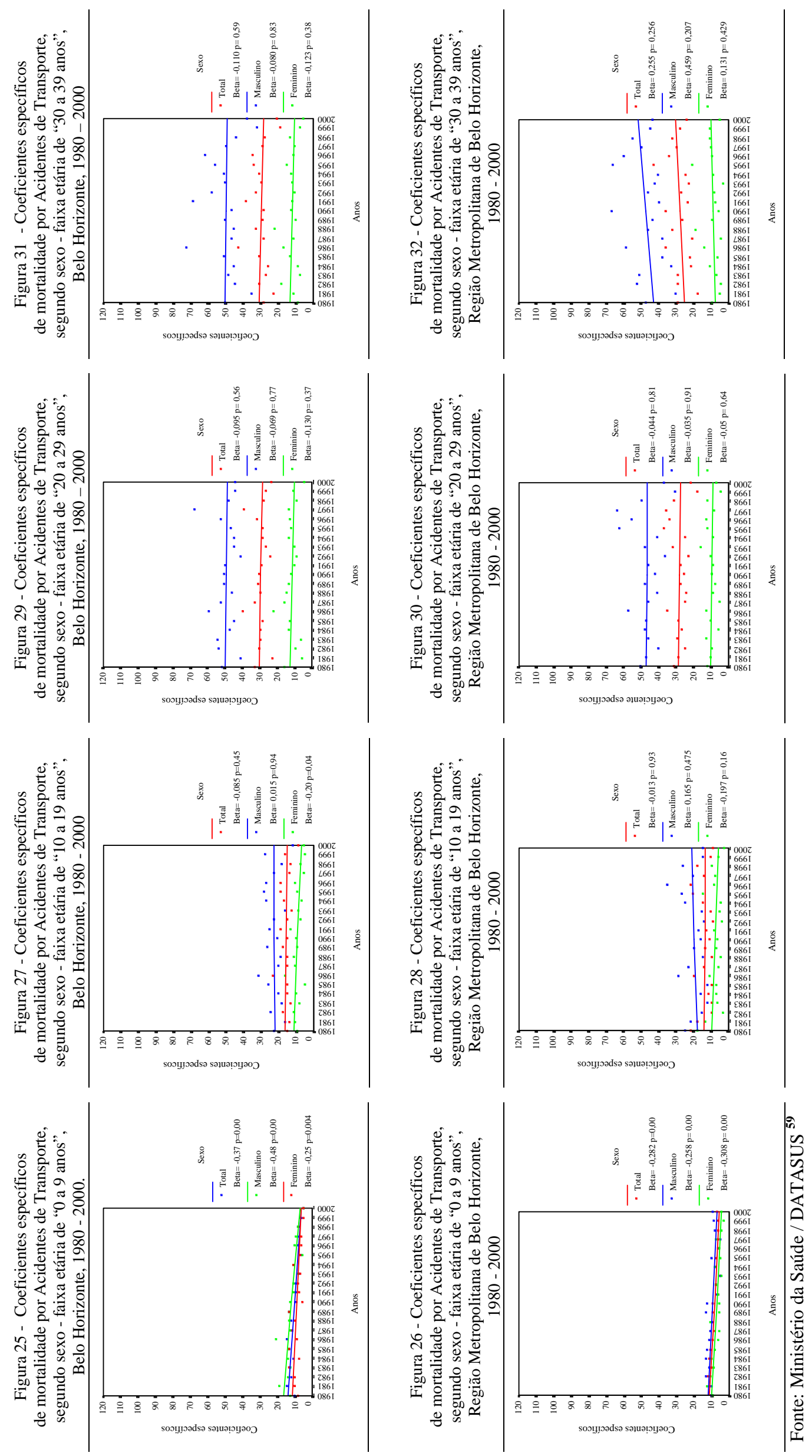

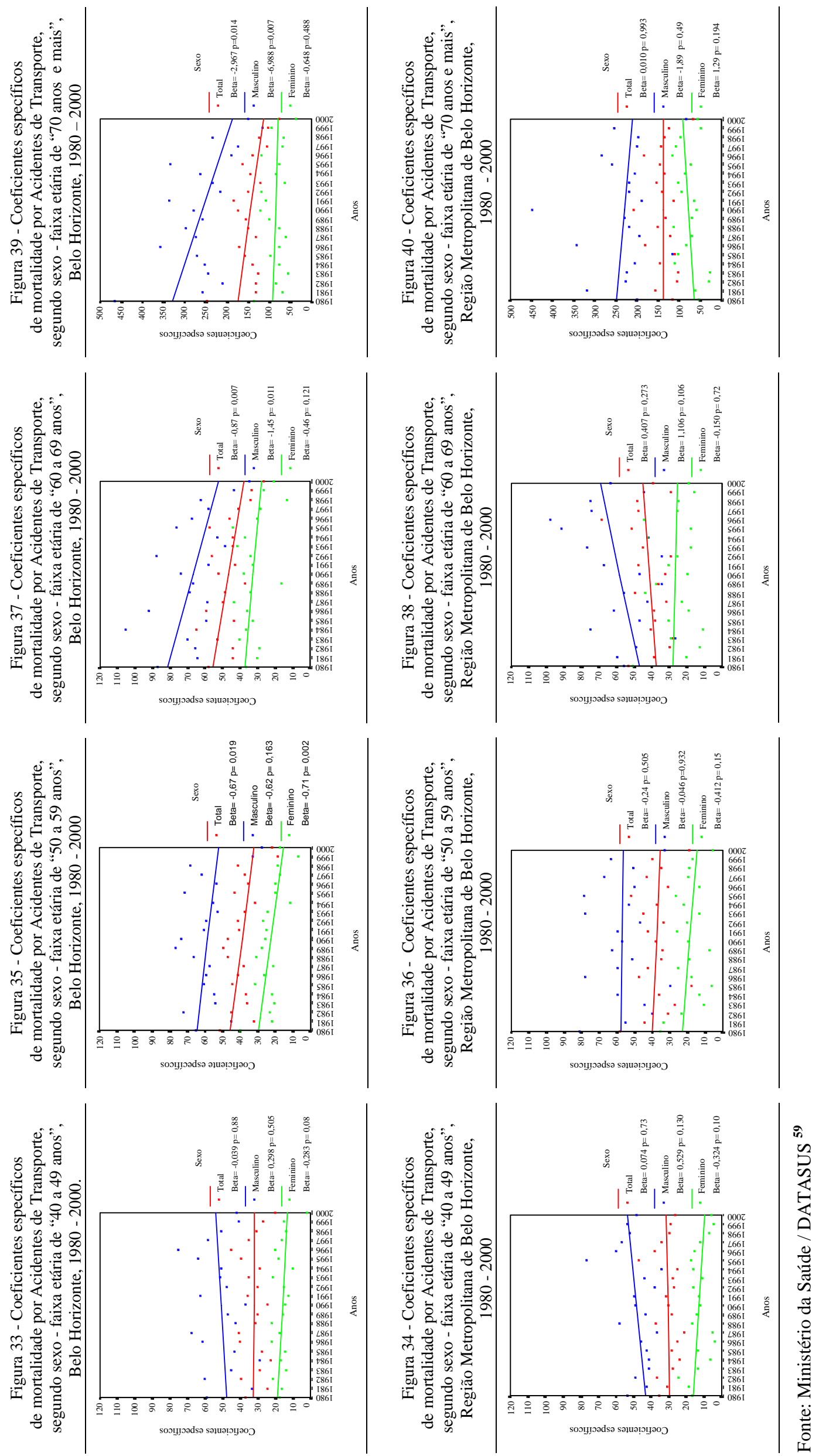


\subsubsection{Tendências dos Coeficientes gerais padronizados da mortalidade por Acidentes de}

\section{Transporte}

As Figuras 41 e 42, a seguir, apresentam as tendências dos coeficientes gerais padronizados de mortalidade por Acidentes de Transporte, segundo sexo, no município e Região Metropolitana de Belo Horizonte.

Ao longo do período, em ambas as regiões geográficas, observou-se uma estabilização dos coeficientes gerais padronizados, embora tenham apresentado uma discreta tendência de declínio para o sexo feminino com significância estatística $(\mathrm{p}<0,005)$.

Figura 41 - Coeficientes gerais padronizados de mortalidade por Acidentes de Transporte, por sexo, Belo Horizonte, 1980-2000.

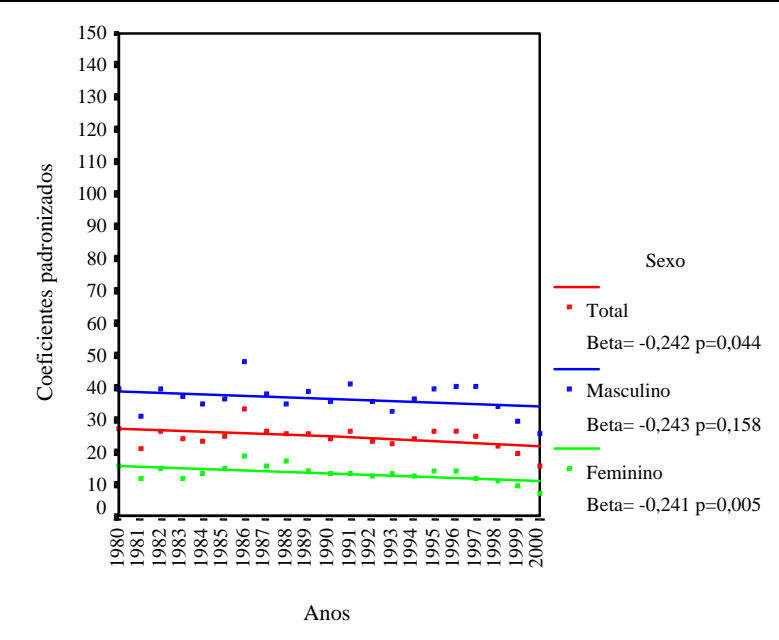

Figura 42 - Coeficientes gerais padronizados de mortalidade por Acidentes de Transporte, por sexo, Região Metropolitana de Belo Horizonte, 1980-2000.

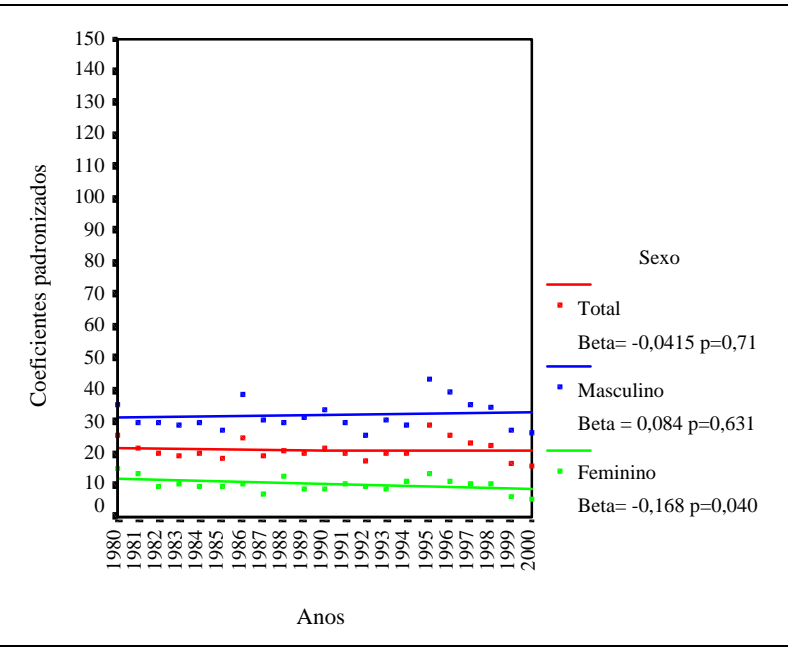

Fonte: Ministério da Saúde / DATASUS ${ }^{59}$ 


\subsection{SUICÍDIOS}

\subsubsection{Mortalidade Proporcional por Suicídios}

As Figuras 43 e 44 apresentam a mortalidade proporcional por Suicídios no município de Belo Horizonte e Região Metropolitana, durante o período de 1980 a 200.

Nas duas regiões geográficas (Figura 43 e 44) as curvas de mortalidade proporcional apresentaram oscilações no decorrer da série histórica com uma maior proporção de óbitos no município de Belo Horizonte. A partir de 1998, em ambas regiões foram observados decréscimos nos percentuais de mortalidade, que se tornaram mais acentuados em Belo Horizonte, sendo que a partir de 2000, tais percentuais se equipararam em ambas as regiões.

Figura 43 - Mortalidade proporcional por Suicídios, município de Belo Horizonte, 1980 a 2000.

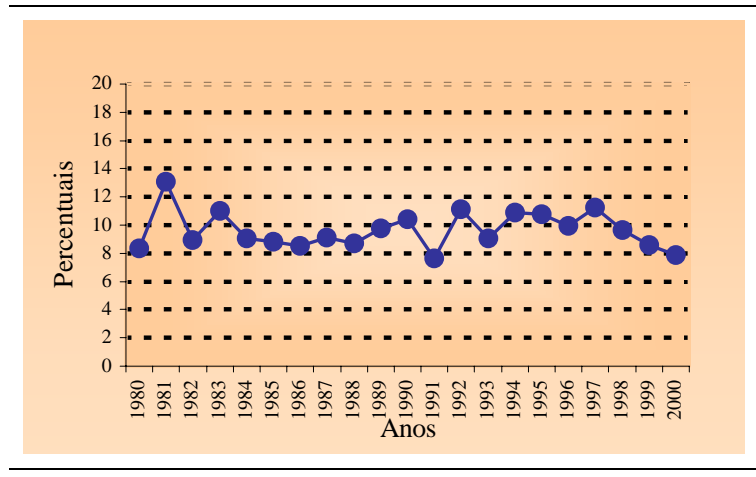

Fonte: Ministério da Saúde / DATASUS ${ }^{59}$
Figura 44 - Mortalidade proporcional por Suicídios, Região Metropolitana de Belo Horizonte, 1980 a 2000.

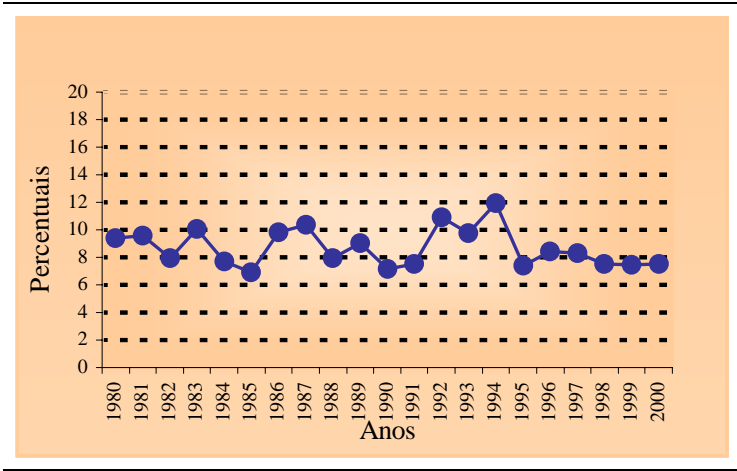

\subsubsection{Coeficientes Específicos de Mortalidade por Suicídios}

A distribuição dos coeficientes específicos de mortalidade por Suicídios, segundo sexo e faixa etária no município de Belo Horizonte e Região Metropolitana, está apresentada nas Tabelas 16 e 17, destacando-se os indicadores para o sexo masculino pela elevada magnitude em relação ao sexo feminino. 
No município de Belo Horizonte (Tabela 16) no decorrer do período, os coeficientes que apresentaram maior magnitude, no sexo masculino, se destacaram nas faixas etárias de “20 a 29 anos” e de “30 a 39 anos” e no sexo feminino na faixa etária de “30 a 39 anos”.

Na Região Metropolitana (Tabela 17) no decorrer da série histórica, em ambos os sexos, os coeficientes que apresentaram maior magnitude, se destacaram na faixa de "30 a 39 anos". 


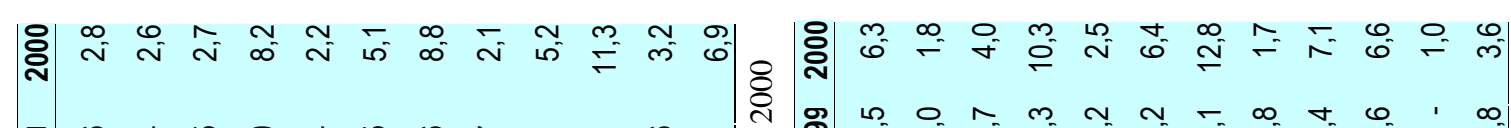
ஓ

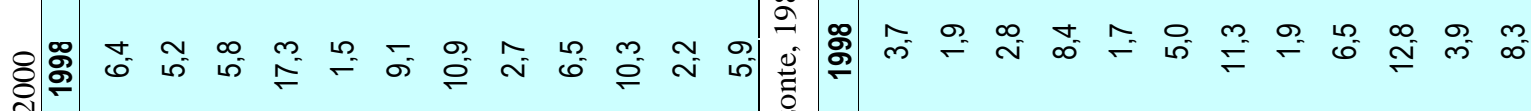
过离

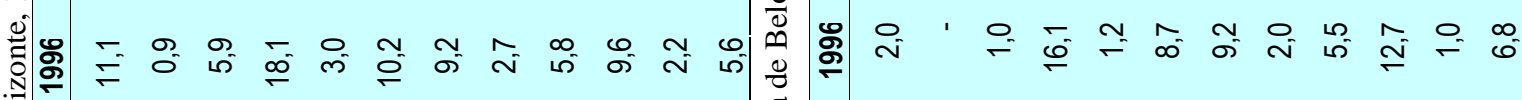
产兽 预

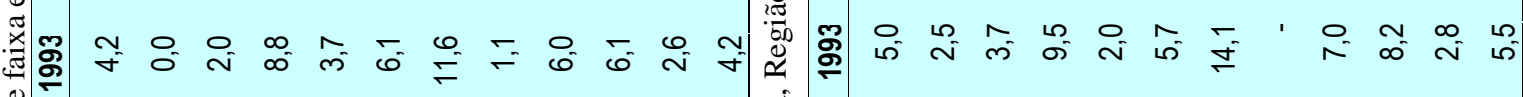

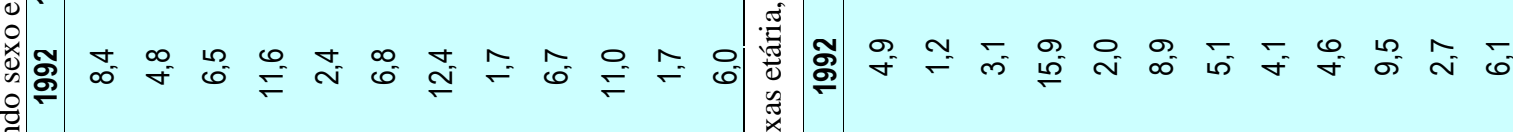

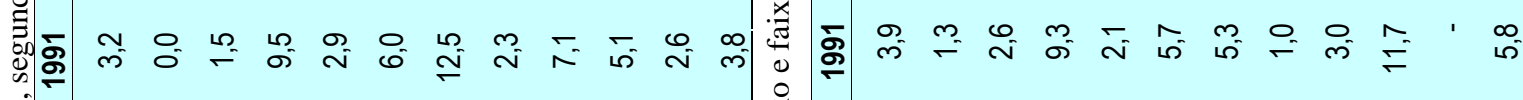

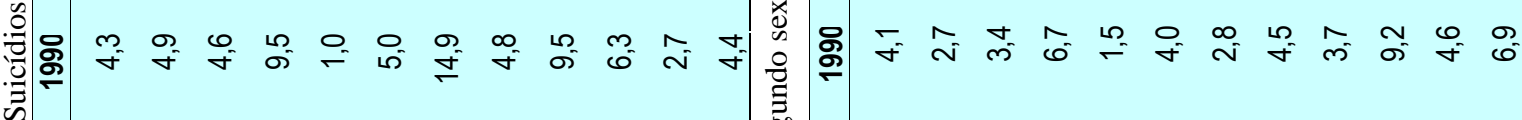

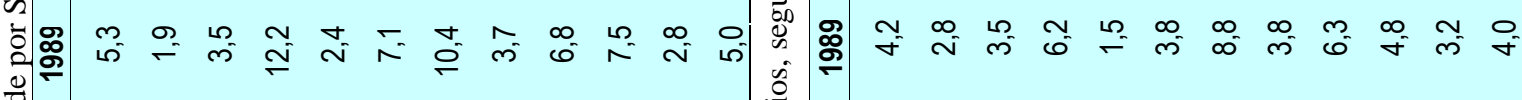
莺哭

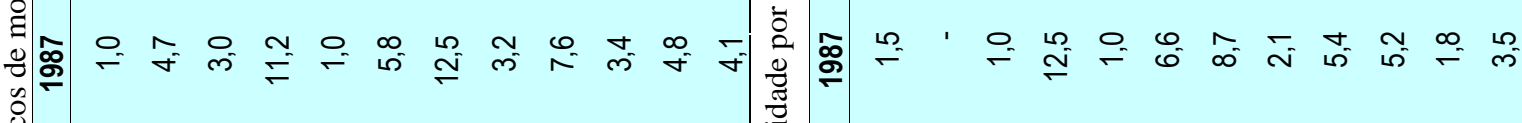

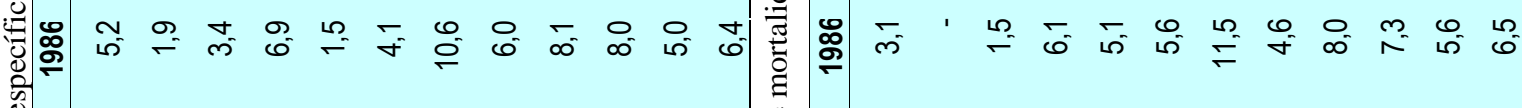

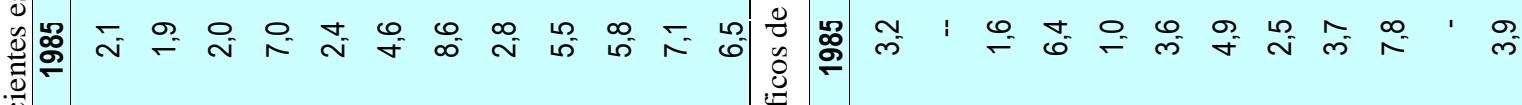

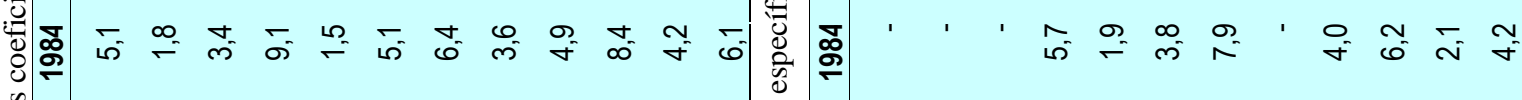

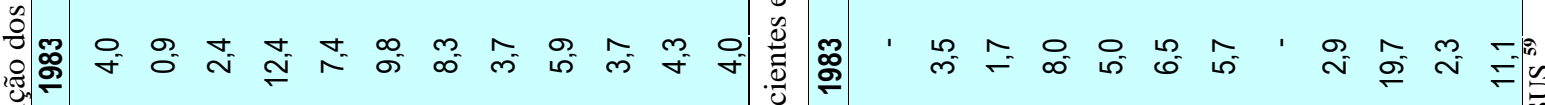

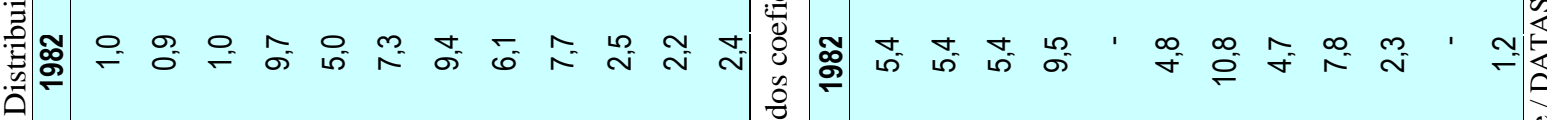
光完

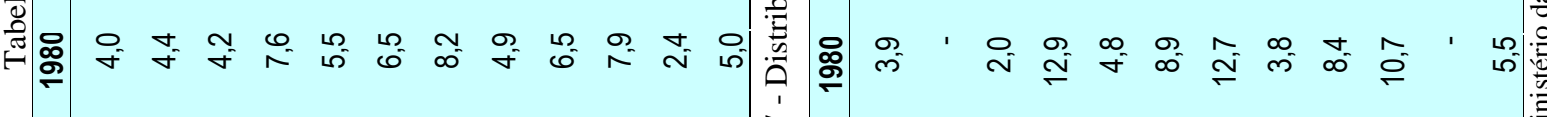

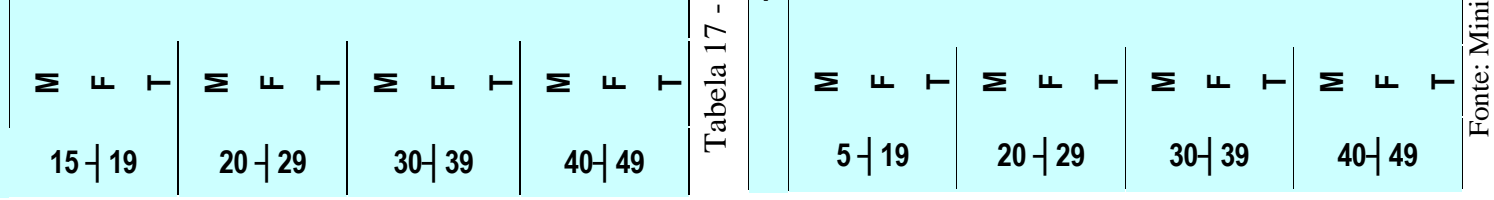




\subsubsection{Razão de Mortalidade por Suicídios segundo Sexo.}

As Tabelas 18 e 19 apresentam a distribuição dos coeficientes específicos de mortalidade por Suicídios e a razão de coeficientes, segundo sexo e faixas etárias, no município de Belo Horizonte e Região Metropolitana, nos anos de 1980, 1990 e 2000.

Na Tabela 18 - município de Belo Horizonte - em 1980, a razão de coeficientes de mortalidade por Suicídios se destacou na faixa etária de “40 a 49 anos”. Em 1990, a maior magnitude da razão de mortalidade ocorreu na faixa etária de “20 a 29 anos”, enquanto, que no ano 2000, a maior magnitude da razão dos coeficientes foi verificada na faixa etária de “30 a 39 anos”.

Tabela 18 - Coeficientes específicos de mortalidade, por Suicídios e razão de coeficientes segundo sexo e faixas etárias, Belo Horizonte, 1980, 1990, 2000.

\begin{tabular}{|c|c|c|c|c|c|c|c|c|c|}
\hline \multirow[b]{2}{*}{ Idade } & \multicolumn{3}{|c|}{1980} & \multicolumn{3}{|c|}{1990} & \multicolumn{3}{|c|}{2000} \\
\hline & $M^{*}$. & $\mathrm{F}^{*}$. & Razão M / F & M*. & $\mathrm{F}^{*}$. & Razão M / F & $M^{*}$. & $\mathrm{F}^{*}$. & Razão M / F \\
\hline $15-19$ & 4,0 & 4,4 & 0,9 & 4,3 & 4,9 & 0,9 & 2,8 & 2,7 & 1,0 \\
\hline $20-29$ & 7,6 & 5,5 & 1,4 & 9,5 & 1,0 & 9,5 & 8,2 & 2,3 & 3,6 \\
\hline $30-39$ & 8,2 & 5,0 & 1,6 & 14,9 & 4,8 & 3,7 & 8,8 & 2,1 & 4,2 \\
\hline $40-49$ & 8,0 & 2,4 & 3,3 & 6,3 & 2,7 & 2,3 & 11,3 & 3,2 & 3,5 \\
\hline
\end{tabular}

Fonte: Ministério da Saúde / DATASUS ${ }^{59}$

Na Tabela 19 - Região Metropolitana de Belo Horizonte - em 1980, a distribuição da razão de coeficientes de mortalidade por Suicídios apresentou similaridade com as faixas etárias que se destacaram no município de Belo Horizonte. Em 1980, o maior valor da razão de coeficientes foi observado na faixa etária de “30 a 39 anos”, em 1990 foi na faixa etária de “20 a 29 anos” e em 2000 na faixa etária de “30 a 39 anos”. 
Tabela 19 - Coeficientes específicos de mortalidade, por Suicídios e razão de coeficientes segundo sexo e faixas etárias, Região Metropolitana de Belo Horizonte, 1980, 1990, 2000.

\begin{tabular}{|c|c|c|c|c|c|c|c|c|c|}
\hline \multirow[b]{2}{*}{ Idade } & \multicolumn{3}{|c|}{1980} & \multicolumn{3}{|c|}{1990} & \multicolumn{3}{|c|}{2000} \\
\hline & $\mathrm{M}^{*}$. & $\mathrm{F}^{*}$. & Razão M / F & $\mathrm{M}^{*}$. & $\mathrm{F}^{*}$. & Razão M / F & $\mathrm{M}^{*}$. & $\mathrm{F}^{*}$. & Razão M / F \\
\hline $15-19$ & 4,0 & - & - & 4,1 & 2,7 & 1,5 & 6,3 & 1,8 & 3,5 \\
\hline $20-29$ & 13,0 & 4,8 & 2,7 & 6,7 & 1,5 & 4,5 & 10,3 & 2,5 & 4,1 \\
\hline $30-39$ & 12,7 & 3,8 & 3,3 & 2,8 & 4,5 & 0,6 & 12,8 & 1,7 & 7,5 \\
\hline $40-49$ & 10,7 & - & - & 9,1 & 4,6 & 2,0 & 6,6 & 1,0 & 6,6 \\
\hline
\end{tabular}

\subsubsection{Variação Percentual dos Coeficientes Específicos de Mortalidade por Suicídios.}

As Figuras 45 a 48 apresentam a variação percentual dos coeficientes de mortalidade, segundo sexo e faixa etária para o município de Belo Horizonte e Região Metropolitana entre os anos de 1980 e 2000.

Em Belo Horizonte (Figuras 45 e 46) os coeficientes de mortalidade por Suicídios, no sexo masculino, apresentaram incrementos percentuais em todas as faixas etárias, exceto na faixa de "15 a 19 anos”. O maior incremento percentual se destacou na faixa etária de "40 a 49 anos”, com uma variação de 43,1\%. No sexo feminino, os coeficientes de mortalidade apresentaram decrementos percentuais em todas as faixas etárias, exceto na faixa de " 40 a 49 anos”, com uma variação de 34,9\%. Em ambos os sexos, os maiores decrementos percentuais foram observados nas faixas etárias de “15 a 19 anos”, com variações percentuais de ($67,5 \%)$ para o sexo feminino e de (- 43,8\%) para o sexo masculino. 
Figura 45 - Variação percentual dos coeficientes de mortalidade por Suicídios, entre 1980 e 2000, segundo faixa etária - sexo masculino Belo Horizonte.

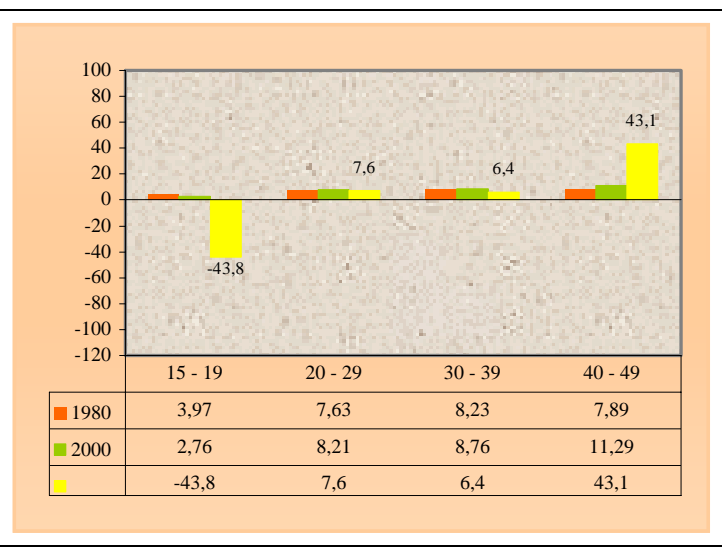

Fonte: Ministério da Saúde / DATASUS ${ }^{59}$
Figura 46 - Variação percentual dos coeficientes de mortalidade por Suicídios, entre 1980 e 2000, segundo faixa etária - sexo feminino Belo Horizonte.

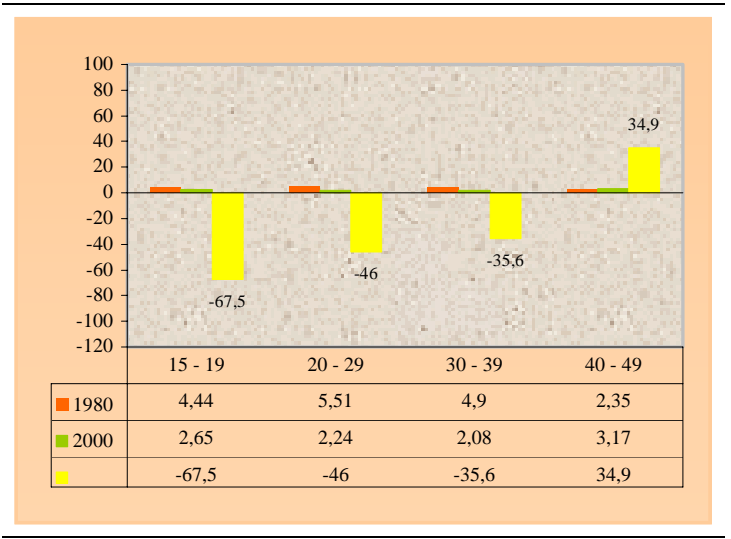

Na Região Metropolitana (Figura 47 e 48) os coeficientes de mortalidade por Suicídios, no sexo masculino, se destacaram com um incremento percentual na faixa etária de “15 a 19 anos”, com uma variação percentual de 60\% e com um decremento percentual na faixa etária de “40 a 49 anos” com uma variação de (-62,5\%). No sexo feminino, os incrementos percentuais de destaque ocorreram nas faixas etárias de " 15 a 19 anos” e de "40 a 49 anos”, ambos com uma variação percentual de 100\%. O decremento percentual se sobressaiu no sexo feminino, na faixa etária de “30 a 39 anos” com uma variação percentual de $(-117,8 \%)$. 
Figura 47 - Variação percentual dos coeficientes de mortalidade por Suicídios, entre 1980 e 2000, segundo faixa etária - sexo masculino Região Metropolitana de Belo Horizonte.

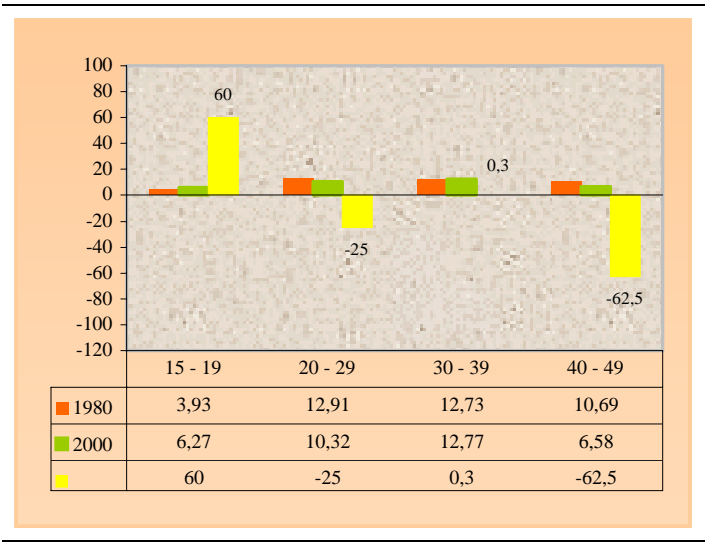

Fonte: Ministério da Saúde / DATASUS ${ }^{59}$
Figura 48 - Variação percentual dos coeficientes de mortalidade por Suicídios, entre 1980 e 2000, segundo faixa etária - sexo feminino Região Metropolitana de Belo Horizonte.

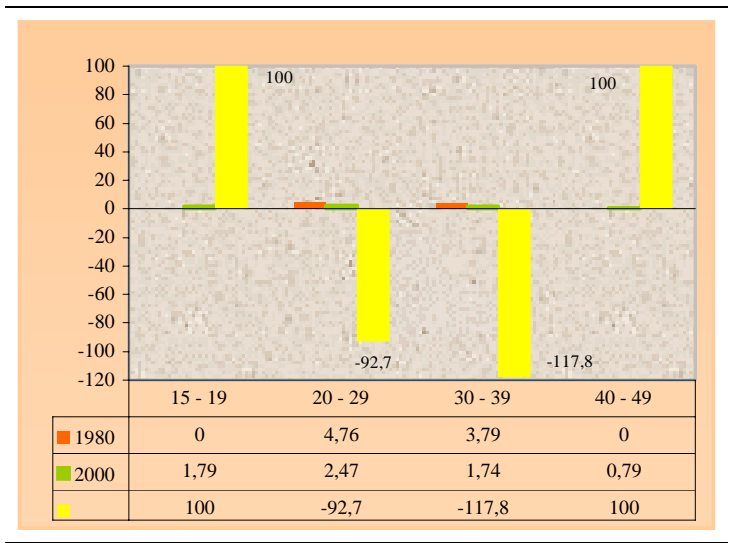

\subsubsection{Tendências dos Coeficientes Específicos de Mortalidade por Suicídios.}

As Figuras 49 a 56 apresentam as tendências dos coeficientes específicos de mortalidade por Suicídios no município de Belo Horizonte e Região Metropolitana.

Na série estudada, nas duas regiões geográficas, os coeficientes específicos de mortalidade por Suicídios, em todas as faixas etárias, no sexo masculino se sobressaíram com maior magnitude em relação ao sexo feminino.

No município de Belo Horizonte (Figuras 51 e 55) no sexo masculino, os coeficientes específicos de mortalidade revelaram uma pequena tendência de ascensão nas faixas etárias de “20 a 29 anos” e de “40 a 49 anos”, com significância estatística $(\mathrm{p}<0,005)$. No sexo feminino (Figuras 51 e 53) os indicadores de mortalidade por Suicídios apresentaram uma tendência de decréscimo nas faixas etárias de “20 a 29 anos” e de “30 a 39 anos”, com testes de hipóteses com significância estatística $(\mathrm{p}<0,05)$.

Na Região Metropolitana (Figuras 50, 52, 54, 56) em todas as faixas etárias e em ambos os sexos, foi observado uma tendência de estabilização dos coeficientes específicos de mortalidade por Suicídios. 

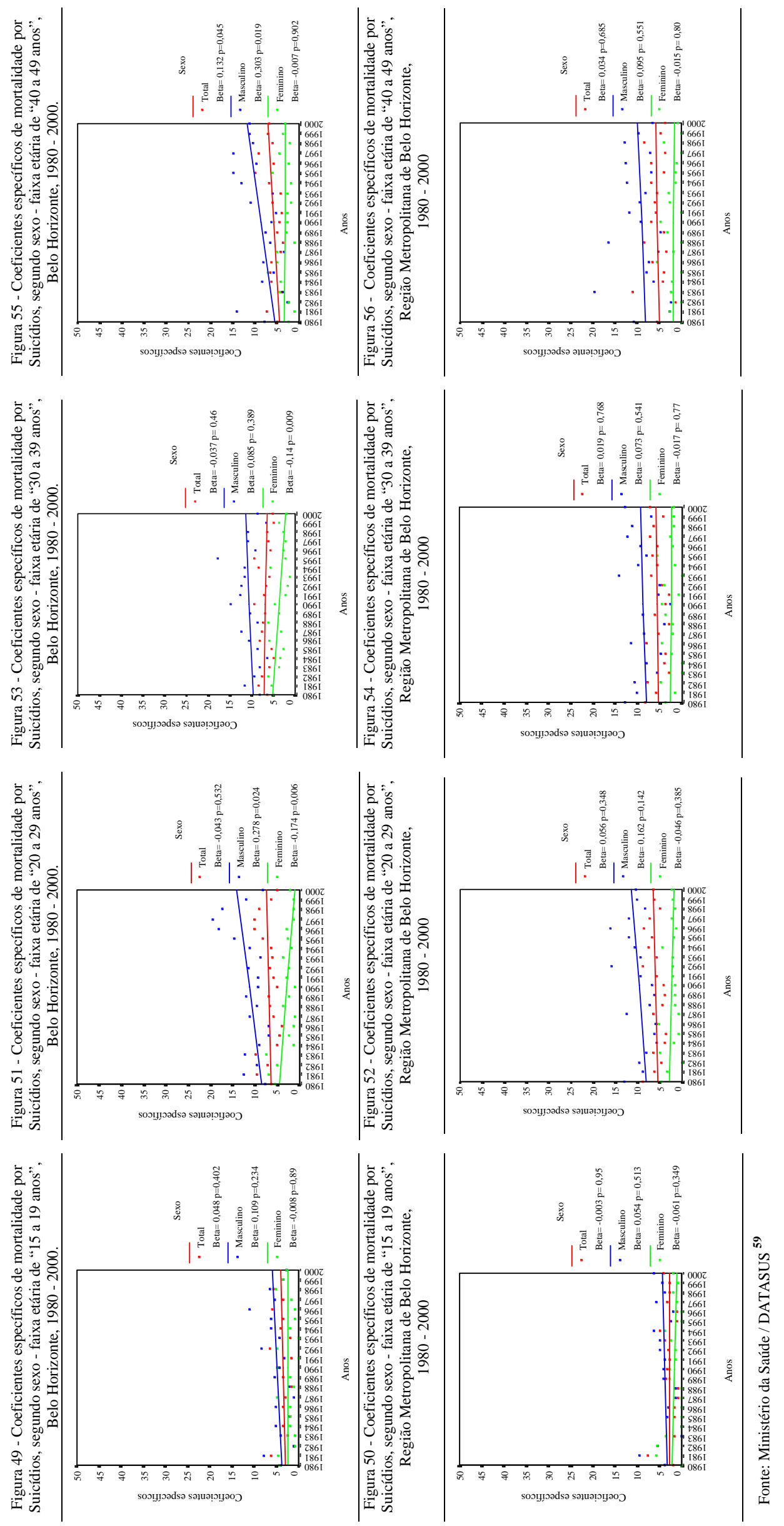


\subsubsection{Tendências dos Coeficientes Gerais Padronizados de Mortalidade por Suicídios.}

Nas Figuras 57 e 58, a seguir, estão apresentadas as tendências dos coeficientes gerais padronizados de mortalidade por Suicídios no município e Região Metropolitana de Belo Horizonte.

No município de Belo Horizonte (Figura 57), os coeficientes gerais padronizados apresentaram uma tendência de ascensão para o sexo masculino e de decréscimo para o sexo feminino. Os testes de hipóteses apresentaram significância estatística $(p<0,05)$.

Na Região Metropolitana (Figura 58) ocorreu uma tendência de estabilização dos coeficientes gerais padronizados em ambos os sexos e ao longo da série histórica.

Figura 57 - Coeficientes gerais padronizados de mortalidade por Suicídios, segundo sexo, Belo Horizonte, 1980-2000.

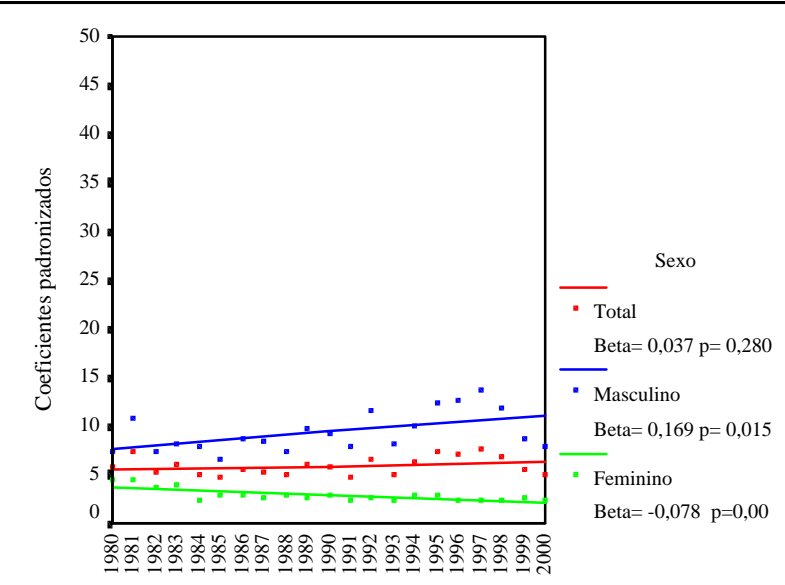

Anos
Figura 58 - Coeficientes gerais padronizados de mortalidade por Suicídios, segundo sexo, Região Metropolitana de Belo Horizonte, 1980-2000.

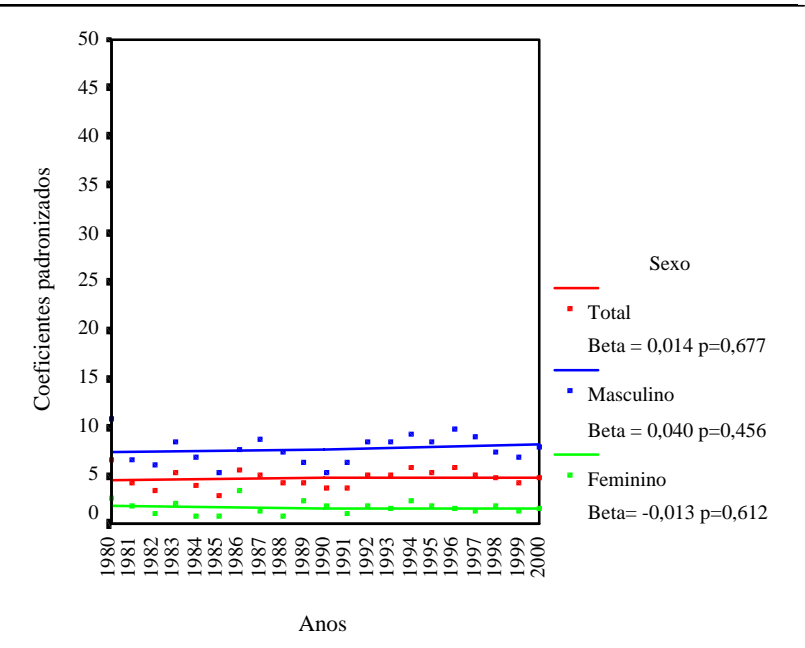

Fonte: Ministério da Saúde / DATASUS ${ }^{59}$ 
6 - DISCUSSÃO 


\section{DISCUSSÃO}

\subsection{HOMICÍDIOS}

O estudo em séries temporais, no período de 1980 a 2000, no município de Belo Horizonte e Região Metropolitana, permitiu analisar e avaliar a evolução dos coeficientes específicos e da mortalidade proporcional por Homicídios. Nas décadas de 1980 e 1990, as curvas de mortalidade proporcional apresentaram um padrão similar para ambas regiões geográficas e os coeficientes específicos mantiveram um crescimento contínuo, cada vez mais evidente, com o decorrer dos anos. A partir de 1995, esses indicadores passaram a evoluir progressivamente com maior magnitude em relação aos outros grupos de causas, se posicionando como os principais responsáveis pela mortalidade por causas externas.

Nas duas regiões estudadas, o crescimento contínuo dos indicadores de mortalidade por Homicídios corrobora com os resultados de pesquisas anteriores, que apresentaram um comportamento similar com outras áreas do Brasil. Os estudos de séries históricas, desde a década de 1980, já apontavam os Homicídios em algumas regiões do Brasil como os principais responsáveis pela mortalidade por causas externas. ${ }^{30,36}$ Na década de 1990, a mortalidade por Homicídios se agravou, nas grandes regiões metropolitanas e nas áreas urbanas, com seus coeficientes se destacando como um dos maiores do mundo. ${ }^{24,38,60,65}$ Os indicadores de mortalidade por Homicídios passaram a ocupar proporções importantes na mortalidade por causas externas, em especial nos estados de Pernambuco, Espírito Santo e Rio de Janeiro. No Estado de Minas Gerais, a partir de 1995, seus coeficientes de mortalidade apresentaram uma súbita elevação e uma magnitude muita além do esperado, o que alterou o perfil da mortalidade por causas externas em todo o Estado, indicando uma alteração no padrão de violência, principalmente em Belo Horizonte, tornando-o semelhante a de outros centros urbanos brasileiros. ${ }^{66,67,68}$ Mello Jorge et al ${ }^{16}$ quando analisaram a saúde no Brasil, 
entre 1996 a 1999, caracterizaram os Homicídios como um fenômeno urbano, com tendência de ascensão, sendo que, nos últimos anos, tal tendência deslocou-se para áreas mais periféricas e menos urbanizadas.

Nesse estudo, entre 1980 a 2000, a distribuição dos óbitos por Homicídios, segundo o local de residência, apontou desigualdades na mortalidade entre as regiões estudadas, destacando-se a população residente na Região Metropolitana de Belo Horizonte com os maiores percentuais de mortalidade e maiores situações de risco de morte por Homicídios, em relação aos residentes em Belo Horizonte.

Alguns autores estabelecem uma relação da distribuição espacial da mortalidade por Homicídios com os indicadores socioeconômicos e espaços urbanos. Segundo Barros ${ }^{69}$ e relatos do Ministério da Saúde, ${ }^{70}$ a mortalidade por Homicídios na Região Sudeste, a mais rica e urbanizada do país, apresentou, entre 1980 a 2001, o maior número de óbitos e o maior risco de morrer por causas externas, enquanto a Região Sul, o menor risco. Barata et al ${ }^{71}$ demonstraram que no município de São Paulo, no período entre 1988 a 1994, os indivíduos que residiam em regiões de baixo nível sócio econômico apresentaram um risco de morrer por Homicídios três vezes maior, do que aqueles que habitavam áreas com melhores condições. Greenberg e Scheneider ${ }^{72}$ e Carmo et al ${ }^{73}$ verificaram que os diferenciais de mortalidade no interior dos espaços urbanos associam-se fortemente ao risco de morte por Homicídios e que em áreas com piores condições sócio-econômicas há uma maior exposição à criminalidade. Macedo et al ${ }^{28}$ e Ribeiro et al ${ }^{74}$ indicaram que o processo de ocupação em determinados espaços urbanos e as desigualdades sociais podem estar associados ao maior risco de morrer por Homicídios. Duchiade ${ }^{2}$ e Vermelho e Monteiro, ${ }^{5}$ verificaram que em áreas geográficas onde se encontram os bolsões de miséria e onde o desemprego e o subemprego são aviltantes, os indicadores de mortalidade por Homicídios são mais expressivos. Ishitani ${ }^{75}$ e Villela ${ }^{76} \mathrm{em}$ suas análises sobre os diferenciais de mortalidade no interior dos espaços urbanos, na década 
de 1990, em Belo Horizonte e Região Metropolitana, identificaram que residir em favelas associava-se a um a maior risco de morrer por Homicídios (2,8 vezes) do que nos bairros, independentemente do sexo e idade.

Duarte et al ${ }^{77}$ em 1999, ao estudarem as associações dos indicadores de nível socioeconômico e demográfico com as taxas de mortalidade por Homicídios, na população brasileira, identificaram uma tendência de ascensão significativa dessas taxas em relação ao grau de urbanização. Lima et Ximenes ${ }^{78}$ justificam que o crescimento da violência nas capitais e regiões metropolitanas pode ter ocorrido devido às mudanças no comportamento da população brasileira em conseqüência da migração e da concentração populacional, da baixa escolaridade e não qualificação de mão de obra, do aumento das taxas de desemprego e da intensificação das desigualdades econômicas. Enfatizam, ainda, que as desigualdades nas condições de vida são determinantes do crescimento dos coeficientes de mortalidade por Homicídios.

Zaluar et al ${ }^{79}$ discutem que o crescimento da violência se estabelece numa relação direta entre a pobreza e as iniqüidades sociais e econômicas no território geográfico. Esses autores verificaram no Rio de Janeiro (1988) que a diminuição do poder aquisitivo ocorrida nessa população, surgiu quando as taxas de Homicídios nessa cidade já haviam duplicado. Em São Paulo, no início da década de 1980, as taxas de Homicídios duplicaram, no entanto, a proporção de pobres se manteve. Em Belo Horizonte, na década de 1980, as taxas de Homicídios e outras violências diminuíram, não ocorrendo, entretanto, variação na proporção de pobres. Para Minayo, ${ }^{21}$ o crescimento da mortalidade por Homicídios está relacionado com o contexto político e institucional de cada local e com a coesão social da sociedade. Haja vista, a estruturação do narcotráfico e do crime organizado que foram responsáveis pelo agravamento e aumento dos índices da criminalidade nas capitais e regiões metropolitanas. 
No presente estudo, a mortalidade por Homicídios, no município de Belo Horizonte e Região Metropolitana, no período de 1980 a 2000, se destacou no sexo masculino, pela sua magnitude e esteve concentrada na faixa de “20 a 29 anos”, na qual estão inseridos os adolescentes, jovens e adultos em idade produtiva. A tendência dos coeficientes específicos de Belo Horizonte e Região Metropolitana apresentou ascensão em todas as faixas etárias, em ambos os sexos, exceto na faixa de 40 a 49 anos. Os resultados se encontram em consonância com os dados do estudo em séries temporais (1981 a 2001) ${ }^{70}$ que enfatizam uma tendência de ascensão, em ambos os sexos, com maior risco para o sexo masculino.

A expansão do perfil etário de mortalidade por Homicídios, a partir da década de 1980, pode ser explicada pela crise econômica que se instalou no Brasil, quando o mercado de trabalho formal tornou-se recessivo, dando oportunidades ao mercado paralelo, com o aumento do subemprego e do desemprego, produzindo bolsões de miséria em algumas regiões. ${ }^{\mathbf{8 0},} \mathbf{8 1}$ Segundo Minayo, ${ }^{21}$ a partir da década de 1990, as taxas de mortalidade por Homicídios no Brasil aumentaram progressivamente, indicando como principais grupos de risco, a população jovem entre 10 e 39 anos, com baixa renda, sem qualificação profissional ou perspectivas no mercado de trabalho formal e que residiam nas regiões metropolitanas em áreas reconhecidas como as de piores condições de vida. A pesquisa referente à análise de saúde no Brasil, ${ }^{70}$ entre 1981 a 2001, revelou que as faixas etárias com maior risco de morrer por Homicídios se encontravam nas de “10 a 39 anos” nos homens e de “10 a 19 anos” nas mulheres.

Considerando os Anos Potenciais de Vida Perdidos (APVP), entre 1980 e 1981, o Brasil apresentou uma queda de cerca de $12 \%$ do total de APVP na mortalidade geral e um aumento de 30\% do total de APVP, quando se considerou somente os acidentes e violência. ${ }^{3}$ Ishitani ${ }^{75}$ identificou na Regional Centro Sul de Belo Horizonte que a mortalidade por Homicídios em pessoas jovens e residentes nas favelas foi responsável por 31,5\% dos APVP. 
Alguns autores apontam a vitimização de crianças, adolescentes e jovens, principalmente no sexo masculino, que residem nas regiões urbanas e em bairros onde se configura o contraste social. Na maioria das vezes, estão envolvidos com drogas, com amigos ligados às atividades criminosas e distanciados das escolas, circunstâncias estas que diminuem as oportunidades de crescimento pessoal e profissional, restringindo, cada vez mais, as garantias e os direitos de cidadão. ${ }^{45,57,82}$ As armas de fogo já se destacam como fator de risco para a mortalidade por Homicídios, pois, para cada uma vez que se usa uma arma em defesa própria, 43 vezes ela é usada para cometer o crime ou o auto-extermínio. Outros como o álcool e as drogas, especialmente o "crack", são de uso mais intenso nos homens, adolescentes e constituem um fator de risco para o sexo masculino, especificamente entre a faixa etária de 10 a 15 anos de idade, pois, dentre aqueles que morrem, a maioria são vítimas de Homicídios. ${ }^{\text {35, 83, } 84}$

Lima e Ximenes ${ }^{78}$ em estudo realizado entre 1980 a 1998, sobre a evolução temporal dos Homicídios, na população masculina de 15 a 19 anos, residentes no estado de Pernambuco, apontaram uma maior tendência da mortalidade no município de Recife (capital do estado), em relação à Região Metropolitana. Consideram que o fato da Região Metropolitana ter sido fundada posteriormente, pode ter determinado o desenvolvimento de uma população com características e hábitos diferentes dos residentes na capital. Os autores indicam que as desigualdades nas condições de vida da população e na ocupação dos espaços urbanos são determinantes do aumento progressivo dos Homicídios, enquanto, a dimensão da violência se expressa pelas necessidades da população e as ofertas sociais, econômicas e institucionais.

Na série histórica, em ambas regiões, a razão de coeficientes de mortalidade por Homicídios indicou uma elevada magnitude no sexo masculino, sobressaindo em 1990 e 2000 
na faixa etária de “20 a 29 anos” em Belo Horizonte e na faixa de “15 a 19 anos” na Região Metropolitana.

Os coeficientes específicos de mortalidade apresentaram acréscimos em ambos os sexos e faixas etárias, sendo que, o maior incremento percentual foi observado na faixa etária de “15 a 19 anos”. Em Belo Horizonte, o sexo feminino se sobressaiu com uma variação percentual de 396\% e na Região Metropolitana, o sexo masculino se destacou com uma variação percentual de 343\%.

Alguns autores enfatizam que a predominância da mortalidade por Homicídios no sexo masculino e em faixas etárias jovens é uma tendência mundial, que se justifica pelos fatores comportamentais dos homens, que usualmente se expõem aos perigos dos acidentes e violência. 16, 60 Na pesquisa sobre a saúde no Brasil, ${ }^{70}$ entre 1981 a 2001, os autores destacaram a Região Sudeste com maiores incrementos anuais do risco de morte por Homicídios entre os homens. Laurenti et al ${ }^{32}$ constataram que nos países onde há uma maior igualdade entre os sexos, a razão de coeficientes na mortalidade por Homicídios é sempre menor.

Neste estudo, a padronização dos coeficientes de mortalidade no município de Belo Horizonte e Região Metropolitana, entre 1980 a 2000, contribuiu para a adequada avaliação da "força da mortalidade”, sem o efeito da variável idade. O que resultou numa magnitude elevada dos indicadores e dos coeficientes específicos gerais padronizados para o sexo masculino, em ambas regiões, e uma indicação de ascensão para o sexo feminino em Belo Horizonte.

A maior magnitude dos indicadores e dos coeficientes angulares de tendência da mortalidade por Homicídios no sexo masculino (coeficientes específicos e gerais padronizados), estão de acordo com os achados de Laurenti et al ${ }^{32}$ e Yunes, ${ }^{31}$ que ao estudarem as causas externas nas Américas, na década de 1990 verificaram que em regiões 
onde as taxas de Homicídios foram significativamente elevadas, destacaram-se as vítimas do sexo masculino. Esses indicadores se destacaram nos países como o Brasil, Colômbia, México e Porto Rico. No entanto, em países onde há uma maior igualdade entre os sexos no que diz respeito às oportunidades de acesso à educação, que são irrestritos, a razão entre os coeficientes de mortalidade por Homicídios foi menor, como Cuba e Canadá.

A subnotificação dos dados de mortalidade por Homicídios torna-se cada vez mais um problema crônico para o setor saúde, pois depende de informações médicas e associa-se a conflitos sociais e implicações legais. Muitas vezes para se omitir um ato violento não são notificados como Homicídios, mas sim como "lesões em que se ignora se foram acidentais ou intencionalmente infligidas”. ${ }^{21,85}$ Os estudos de Njaine et al ${ }^{86}$ ressaltam que a grande maioria dos óbitos classificados nesse grupo inespecífico se relaciona com o uso de armas de fogo e estão inadequadamente inseridos nesse grupo o que pode promover a subnotificação dos Homicídios. Pereira e Castro ${ }^{87}$ ao analisarem o preenchimento das Declarações de óbitos, em Brasília, encontraram maior omissão nos atestados de óbitos referentes à morte ocasionada por violência. Justificam esse fato como sintomático, pois o esclarecimento da circunstância em que ocorreu o evento favorece a determinação da causa jurídica do óbito.

Mendonça ${ }^{83}$ defende a tese que o reforço e a melhoria do sistema educacional brasileiro podem ser uma estratégia básica para solucionar grande parte dos problemas relativos aos Homicídios. Do ponto de vista das cidades, necessário se faz um planejamento urbano e regional - que reorientem a melhoria das condições de vida, nas periferias das aglomerações urbanas, proporcionando a diminuição da delinqüência da violência e da criminalidade urbana. Para Souza, ${ }^{\mathbf{8 8}}$ a aplicação de recursos para o desenvolvimento de pesquisas, também é de fundamental importância para adequar os investimentos em programas preventivos, no sentido de minimizar a mortalidade por Homicídios. 


\subsection{ACIDENTES DE TRANSPORTE}

Na série histórica do estudo, no período entre 1980 a 2000, no município de Belo Horizonte e Região Metropolitana, a mortalidade proporcional e os coeficientes específicos de mortalidade por Acidentes de Transporte, na década de 1980, mantiveram um crescimento e se posicionaram como primeira causa de óbito entre os principais grupos de causas externas. A partir da década de 1990, apresentaram decréscimos contínuos, passando para a segunda posição. No decorrer do período estudado, os indicadores de mortalidade se destacaram por sua magnitude no município de Belo Horizonte.

Esses resultados estão em consonância com pesquisas anteriores sobre o comportamento da mortalidade por Acidentes de Transporte, que foi semelhante a algumas regiões do Brasil e outros países. Para alguns autores, ${ }^{23,40}$ os Acidentes de Transporte no Brasil representaram 13,6\% da mortalidade geral, percentual esse que se equipara a alguns países em desenvolvimento ou se encontra aquém de outros como Canadá, Alemanha e Suécia. No Brasil, na década de 1980, seus indicadores se posicionaram em primeiro lugar na mortalidade por causas externas, sendo que, a partir da década de 1990, declinaram para o segundo lugar, pois o primeiro foi ocupado pelos Homicídios.

Maletta, ${ }^{52}$ em Belo Horizonte, na década de 1980, verificou que os indicadores de mortalidade por Acidentes de Transporte começaram a se expandir, ocupando o décimo primeiro lugar entre as principais causas de óbito, sendo que, uma década após, em 1991, evoluíram para a sexta posição. Camargo et al, ${ }^{30}$ na década de 1990, incluíram Belo Horizonte entre as capitais brasileiras com as maiores taxas de Acidentes de Trânsito. Camargo ${ }^{40}$ ao descrever a mortalidade por causas externas em São Paulo, relatou um aumento substancial dessas causas, entre as décadas de 1960 e 1970, e um declínio constante entre as décadas de 1980 e 1990, cerca de 20\%. Esse declínio foi justificado principalmente pela implantação do Código Brasileiro de Trânsito (CBT). 
Outras pesquisas estabelecem uma relação da distribuição espacial da mortalidade por Acidentes de Transporte com as áreas geográficas. Para alguns autores, a região geográfica pode indicar a magnitude da mortalidade e os diferentes riscos a que a população está exposta. No caso dos Acidentes de Transporte em regiões onde a área geográfica é composta por conjuntos habitacionais, há uma maior probabilidade de que seus habitantes se envolvam em acidentes menos fatais, causados por veículos pequenos e ou bicicletas, com menor velocidade, sendo que, na maioria das vezes, a vítima é o pedestre. Em regiões periféricas, próximas aos grandes eixos rodoviários, seus habitantes se encontram mais expostos a sofrerem acidentes fatais, em decorrência de altas velocidades, veículos pesados e rodovias deficientes e mal sinalizadas. ${ }^{\text {30, 36, } 37}$ Esses estudos são capazes de subsidiar a análise dos resultados do comportamento dos coeficientes de mortalidade por Acidentes de Transporte, no município e na Região Metropolitana de Belo Horizonte, na série histórica estudada.

Na investigação sobre os coeficientes específicos de mortalidade por Acidentes de Transporte no município e Região Metropolitana de Belo Horizonte, por sexo e faixa etária, entre 1980 a 2000, evidenciou-se uma situação similar nas suas magnitudes entre os sexos. Os coeficientes específicos apresentaram uma maior incidência de óbitos nos idosos, na faixa etária de “70 anos e mais” que se despontam desde 1980, se colocando em primeira posição.

Em relação à razão de coeficientes de mortalidade por Acidentes de Transporte, os indicadores apresentaram maior magnitude em Belo Horizonte, sendo que, a razão de maior valor observou-se na faixa etária de “30 a 49 anos” (1980 e 1990), e na faixa etária de “40 a 49 anos” (2000). Na Região Metropolitana, a razão de mortalidade com maior evidência, destacou-se na faixa etária de “30 a 39 anos” (1980 e 1990), e na faixa de 40 a 49 anos (2000).

As variações percentuais dos coeficientes de mortalidade, em ambas as regiões, apresentaram decréscimos dos indicadores em todas as faixas etárias e em ambos os sexos, 
exceto na Região Metropolitana, no sexo masculino na faixa etária de “60 a 69 anos” e no sexo feminino nas faixas etárias de "20 a 29 anos" e "70 anos e mais”.

Algumas pesquisas têm demonstrado que no conjunto das causas externas, os Acidentes de Transporte se sobressaem por sua magnitude, tanto na mortalidade quanto nas seqüelas. A maior mortalidade por Acidentes de Transporte se destacou no sexo masculino, no entanto, com o decorrer dos anos, aumentou no sexo feminino. ${ }^{1,30}$ O perfil dos indivíduos que morrem por acidentes de transporte usualmente são jovens, do sexo masculino (20 a 29 anos), ainda que os coeficientes de mortalidade sejam, geralmente, maiores entre os idosos, a partir de 75 anos. Nesses últimos, a maior incidência se deve aos atropelamentos, em virtude da fragilidade física da própria idade. Nos jovens, do sexo masculino, ocorre principalmente pela sua maior exposição ao risco no trânsito e em decorrência dos determinantes sociais e culturais que os expõem a maiores riscos na condução de veículos, com maiores velocidades, manobras radicais e uso de drogas lícita e ilícitas. Por outro lado, os jovens utilizam cada vez mais as motocicletas como instrumento de trabalho, no mercado formal ou informal, o que vem aumentando o risco de se acidentar por esse veículo. A magnitude de mortalidade no sexo masculino vem se invertendo, em relação ao sexo feminino, desde a crescente participação da mulher no mercado de trabalho, em que muitas vezes, um dos critérios para se inserir no emprego, é saber dirigir o veículo, proporcionandolhes uma maior exposição ao tráfego urbano e ou às grandes rodovias, quer como pedestres, quer como motoristas. ${ }^{36,42,89,90}$

Os estudos de Gawryszewski e Mello Jorge ${ }^{82}$ sobre a mortalidade por Acidentes de Transporte em São Paulo, apresentaram uma tendência de decréscimo, a partir da década de 1980. Do período de 1975 a 1999, houve uma diminuição dos coeficientes de cerca de 55,7\%. Além das medidas de segurança, os autores justificam essa tendência, devido ao aumento da 
frota de veículos nos grandes centros, provocando constantes congestionamentos, dificultando o fluxo dos veículos, diminuindo assim, as ocorrências de colisões fatais.

No Brasil, a Região Sudeste se posicionou em terceiro lugar na mortalidade por Acidentes de Transporte. O estado de Minas Gerais apresentou taxas menores do que a de outros estados, porém, a cidade de Belo Horizonte, usualmente vem sendo apontada entre as capitais brasileiras com alto índice de violência no trânsito. ${ }^{73,91}$

Duarte et al ${ }^{77}$ ao analisarem as associações entre os indicadores de nível socioeconômico e demográfico com as taxas de mortalidade por Acidentes de Transporte no Brasil, entre 1991 e 2000, identificaram maior risco de morte associado a Estados com maior renda populacional, menor escolaridade e maiores taxas de crescimento populacional. Segundo os autores, em uma população com maiores níveis de renda, rápido crescimento populacional e aumento do número per capita de automóveis, porém, com baixa escolaridade tornam-se difícil à organização e estruturação urbanística dos espaços territoriais, favorecendo os Acidentes de Transporte. Para os autores, a associação dos níveis de prosperidade e mortalidade por Acidentes de Transporte, ao longo do tempo, se invertem. Inicialmente, o desenvolvimento econômico pode ocasionar um aumento do número de óbitos por Acidentes de Transporte, devido ao crescimento da quantidade de veículos a motor e ao tempo insuficiente, para o estabelecimento de mecanismos de adaptação à população e ao território. Com a prosperidade são criados mecanismos de proteção, gerando maior conhecimento para a população e melhoria da estruturação do território, do tráfego e dos serviços de saúde eficientes para a atenção ao cidadão. A letalidade pode estar influenciada pelas variáveis: severidade do acidente (alta velocidade, alcoolismo e condições das rodovias) e pela ineficiência dos serviços de saúde em atender adequadamente os feridos de média e alta gravidade. 
Na análise de regressão linear, do presente estudo, na série histórica, nas duas regiões geográficas, em ambas as faixas etárias e sexos, a tendência dos coeficientes da mortalidade por Acidentes de Transporte apresentou ora declínio ora tendência de estabilização. Em ambos os sexos, a elevação na magnitude está relacionada com o aumento da idade.

Os coeficientes gerais padronizados de mortalidade por Acidentes de Transporte em Belo Horizonte, e Região Metropolitana, resultaram numa estabilização dos seus indicadores, com uma tendência de declínio para o sexo feminino.

Para alguns autores, o declínio da mortalidade por Acidentes de Transporte está relacionado com as medidas preventivas, entre as quais se encontram a implantação de lombadas eletrônicas, o uso do cinto de segurança e a implantação do Código Brasileiro de Trânsito (CBT) em 1997, com vigência a partir de 1998. ${ }^{\text {36, } 92}$

O CBT, a partir de janeiro de 1998, através da Lei ${ }^{\circ} 9.503$ que tem por finalidade assegurar e preservar a vida dos indivíduos, por meio de medidas eficazes capazes de diminuir e restringir os fatores de risco tanto para o condutor do veículo como para o pedestre. Entretanto, o CBT ainda não atingiu suas metas e nem reduziu os resultados esperados, o que se justifica, pelas dificuldades encontradas para garantir sua eficácia, tais como atraso tecnológico nos serviços de trânsito, precário controle do tráfego urbano e das rodovias, precária habilitação dos futuros condutores e falta de integração com outras instituições. ${ }^{82,93}$ Segundo Mello Jorge et al, ${ }^{36}$ os investimentos no setor, ainda não foram suficientes para determinar um declínio substancial da mortalidade por Acidentes de Transporte. Relatos do Ministério da Saúde, ${ }^{70}$ indicaram que o impacto do CBT na redução da mortalidade por Acidentes de Trânsito, em curto período de tempo, tornou-se significativo somente para algumas regiões brasileiras, tais como: Sul, Sudeste e Centro Oeste.

Outro fator importante para a prevenção dos Acidentes de Transporte se encontra na organização de um sistema de informação adequado com o propósito de melhorar a qualidade 
das informações, fornecendo elementos precisos sobre os aspectos epidemiológicos, relativos à identificação do indivíduo, do tipo de acidente que ocasionou o óbito entre outros. Através desse sistema medidas de promoção e prevenção poderiam promover o controle destas ocorrências. 


\subsection{SUICÍDIOS}

Na série histórica, em estudo, a mortalidade proporcional e os coeficientes específicos de mortalidade por Suicídios, em Belo Horizonte e Região Metropolitana, apresentaram oscilações e valores mais baixos, em relação aos outros grupos de causas estudados. O município de Belo Horizonte se sobressaiu por apresentar maior magnitude, em relação à Região Metropolitana. Esses resultados estão em consonância com pesquisas socioespaciais, que procuram estabelecer uma relação da distribuição dos coeficientes de mortalidade por Suicídios com os espaços geográficos. Segundo alguns autores, a mortalidade por Suicídios se associa com o desenvolvimento econômico de uma região. O maior peso de seus indicadores de mortalidade se encontra em regiões desenvolvidas, ${ }^{82}$ o que é o caso do município de Belo Horizonte, por ser mais desenvolvido do que a Região Metropolitana. Villela, ${ }^{76}$ entre 1991 a 1996, na Regional Centro Sul de Belo Horizonte, verificou que residir em Bairros associavase a um maior risco de morte por Suicídios, independentemente do sexo.

Barros et al, ${ }^{69}$ em 1991, em seus estudos sobre a mortalidade por Suicídios, nos diferentes países, identificou a alta mortalidade nos países europeus e baixa mortalidade nos países latino - americanos. Para Camargo et al, ${ }^{30}$ nos países em desenvolvimento e em algumas cidades brasileiras, as taxas de mortalidade por Suicídios, são relativamente baixas, de 1 a 4 óbitos / 100.000 habitantes, bem próximas àquelas do México (2,2 óbitos / 100.000 habitantes) e Venezuela (4,2 óbitos / 100.000 habitantes) e bem distantes das referentes aos países desenvolvidos, como Finlândia (28,5 / 100.000 habitantes) e Hungria (39,9 / 100.000 habitantes). Segundo Camargo, ${ }^{40}$ os coeficientes de mortalidade por Suicídios no Brasil, são bem inferiores aos outros grupos de maior impacto epidemiológico, porém, apresentaram acréscimos no final da década de 1990, seus coeficientes de 4,0 / 100.000 habitantes, evoluíram para 4,4 / 100.000 habitantes. 
Os estudos dos coeficientes específicos de mortalidade por Suicídios, no município de Belo Horizonte e Região Metropolitana, entre 1980 a 2000, revelaram uma maior magnitude no sexo masculino. Em relação à faixa etária destaca-se o grupo de “20 a 39 anos” no sexo masculino e de "20 a 29 anos” no sexo feminino.

Mello Jorge et al, ${ }^{45}$ ao avaliarem a recodificação do preenchimento das declarações de óbito por causas externas em São Paulo, identificaram que os coeficientes de mortalidade por Suicídios apresentaram o dobro do encontrado anteriormente.

A subnotificação da mortalidade por Suicídios é comumente encontrada e varia de acordo com as regiões e culturas, já que esse evento traz consigo um grande preconceito na maioria dos grupos sociais. Segundo Mello Jorge e Gotlieb ${ }^{36}$ a mortalidade por Suicídios sempre foi subestimada. No entanto, nos últimos anos, seus coeficientes mostram-se crescentes principalmente no adulto jovem do sexo masculino. Esse fato é preocupante, na medida em que esse crescimento não se atribui a qualquer mudança metodológica no sistema de informação de mortalidade.

Alguns autores vêm discutindo a subnotificação dos óbitos que se destacam na mortalidade por Causas Externas. A ausência de informações adequadas nas Declarações de Óbitos pode chegar a 10\% e estar encobrindo a causa real do óbito, o tipo de agravo, a natureza da lesão e os meios específicos utilizados, especialmente, no caso dos Homicídios e Suicídios. ${ }^{\text {82, 92, } 94}$

No Brasil, a distribuição dos óbitos por Suicídios, segundo sexo e faixa etária, entre 1996 a 1999, diferentemente do que ocorreu no município de Belo Horizonte e Região Metropolitana, apresentou uma maior incidência nos idosos. ${ }^{\mathbf{1 6}}$ Os estudos de Vermelho ${ }^{\mathbf{8 1}}$ apontou um aumento da mortalidade por Suicídios nos jovens e adultos, principalmente na faixa etária de "15 a 39 anos”, o que se torna um motivo de preocupação, principalmente, para aqueles que estão sob maior risco, por apresentarem uma história anterior de Suicídio na 
família, história de depressão, de abusos físicos e ou sexuais, abuso de álcool ou outros tipos de drogas, desemprego, reprovação escolar, rejeição dos amigos e outras perdas.

No presente estudo de séries temporais, em ambas regiões, a razão de mortalidade por Suicídios indicou uma maior magnitude nos homens, sendo que, a maior razão de coeficientes ocorreu nas faixas etárias de “20 a 29 anos”, “30 a 39 anos” e “40 a 49 anos”.

A variação percentual dos coeficientes específicos por Suicídios, em ambos os sexos, apresentou oscilações, ora com incrementos ora com decrementos percentuais, em ambos os sexos. Em Belo Horizonte, em ambos os sexos e na Região Metropolitana, no sexo masculino, destacaram-se os decrementos percentuais na faixa etária de "15 a 19 anos” e os incrementos na faixa de “40 a 49 anos”. No sexo feminino, na Região Metropolitana, os incrementos se destacaram nas faixas etárias de “15 a 19 anos” e “40 a 49 anos”, enquanto, os decrementos percentuais ocorreram na faixa etária de “30 a 39 anos”.

Esse comportamento dos coeficientes de mortalidade por Suicídios se encontra em consonância com outros estudos que apresentaram uma maior incidência no sexo masculino e com uma pequena tendência de aumento no sexo feminino. Camargo, ${ }^{40}$ estudando a mortalidade por causas externas no município de São Paulo, entre 1979 a 1995, verificou que os coeficientes de mortalidade nos homens foram maiores do que mulheres, e com o transcorrer dos anos ocorreu uma tendência de aumento com a idade, especialmente nas regiões onde há uma maior incidência de mortalidade por Suicídios. Entre 1979 a 1995, verificou que os coeficientes de mortalidade para o sexo masculino apresentaram um aumento de aproximadamente de 70\%, enquanto, para o feminino não verificou mudança significativa. Outros estudos revelaram que a grande diferença entre os sexos está no desfecho do evento. Nas mulheres, predominam as tentativas de Suicídios, pois para cada óbito masculino ocorrem dez tentativas de Suicídios no sexo feminino. ${ }^{30,36}$ 
Os resultados da tendência dos coeficientes específicos de mortalidade por Suicídios, nesse estudo, revelaram em Belo Horizonte, no sexo masculino uma tendência de ascensão nas faixas etárias de “20 a 29 anos”. No sexo feminino, essa tendência ocorreu na faixa etária de "20 a 29 anos” e de “30 a 39 anos”. Na Região Metropolitana houve uma tendência de estabilização em todas as faixas etárias e em ambos os sexos.

Com a padronização dos coeficientes de mortalidade por Suicídios, Belo Horizonte apresentou uma tendência de ascensão para o sexo masculino e de decréscimo para o sexo feminino. Na Região Metropolitana ocorreu uma tendência de estabilização dos coeficientes no decorrer do período.

Os estudos de Yunes e Zubarew ${ }^{66}$ sobre a mortalidade por Suicídios no Brasil revelaram, no período de 1980 a 1995, uma certa estabilidade em suas taxas, mas com um aumento na ordem de 22\%. Mello Jorge et al ${ }^{\mathbf{1 6}}$ ao analisarem os coeficientes de mortalidade por Suicídios, no Brasil, em 1999, identificaram maior magnitude e uma tendência de ascensão em algumas áreas como a Região Sul, principalmente no Rio Grande do Sul. Meneghel et al ${ }^{95}$ identificaram um crescimento dos coeficientes de mortalidade por Suicídios e um aumento em sua magnitude, principalmente entre os agricultores no Rio Grande do Sul, entre 1980 a 1999. Gawryszewski e Mello Jorge ${ }^{82}$ ao estudarem a mortalidade por causas externas, no Estado de São Paulo, numa série histórica de 1960 a 1999, relataram uma diminuição significativa nos coeficientes específicos de mortalidade por Suicídios, até 1975, sendo que a partir de 1980, os indicadores apresentaram uma tendência de declínio, embora, menos acentuada no período anterior.

Mello Jorge ${ }^{39}$ em sua pesquisa realizada em São Paulo, de 1960 a 1980, evidenciou alguns aspectos importantes no meio utilizado para atingir-se o auto extermínio. Segundo a autora, a escolha do meio utilizado se modificou com o decorrer dos anos, entre os sexos, e em função das mudanças de comportamento da população. O envenenamento, mais utilizado 
em ambos os sexos continuou sendo o método de escolha entre as mulheres, no entanto, os homens passaram a utilizar as armas de fogo. Em segundo lugar, destacou-se entre as mulheres a precipitação de lugares mais elevados e nos homens, o enforcamento. Dessa forma, a investigação dos meios utilizados para o auto-extermínio é de fundamental importância para subsidiar medidas e ações preventivas para a prevenção desses eventos na comunidade. 
7 CONSIDERAÇÕES FINAIS 


\section{CONSIDERAÇÕES FINAIS}

\subsection{Em relação aos Homicídios}

Os coeficientes específicos de mortalidade e a mortalidade proporcional, em ambas regiões, apresentaram crescimento contínuo, sendo que, a partir da década de 1990, se posicionaram como os principais responsáveis pela mortalidade por Causas Externas. Os coeficientes apresentaram maior magnitude para o sexo masculino, principalmente na Região Metropolitana.

Na faixa etária de “20 a 29 anos”, os coeficientes apresentaram maior magnitude no sexo masculino em Belo Horizonte e em ambos os sexos, na Região Metropolitana. Na faixa etária de “30 a 39 anos”, apresentaram maior magnitude no sexo feminino no município de Belo Horizonte.

A maior razão de coeficientes de mortalidade em Belo Horizonte ocorreu na faixa etária de “20 a 29 anos”. A Região Metropolitana apresentou oscilações na faixa de “30 a 39 anos” em 1980; na de “15 a 19 anos” em 1990 e na faixa de “20 a 29 anos” em 2000.

Os coeficientes específicos de mortalidade apresentaram incrementos percentuais em Belo Horizonte no sexo masculino, exceto na faixa de “40 a 49 anos” e no sexo feminino, em todas as faixas etárias”. Na Região metropolitana verificou-se incrementos percentuais, exceto na faixa de “40 a 49 anos”. Em ambas regiões, o maior incremento ocorreu na faixa etária de “15 a 19 anos”. Em Belo Horizonte se destacou no sexo feminino com incremento de 396\% e na Região Metropolitana no sexo masculino com um incremento de 343\%.

Em ambas regiões, os coeficientes específicos de mortalidade apresentaram maior magnitude para o sexo masculino e as tendências, ao longo da série, apresentaram ascensão, que foi estatisticamente significante ( $<<0,05)$, com exceção da faixa etária de “40 a 49 anos”. 
As tendências dos coeficientes gerais padronizados de mortalidade apresentaram uma ascensão que foi estatisticamente significante para o sexo masculino em ambas as regiões $(p<0,05)$, enquanto que, para o sexo feminino a tendência foi significante apenas no município de Belo Horizonte.

\subsection{Em relação aos Acidentes de Transporte}

Os coeficientes específicos de mortalidade e a mortalidade proporcional começaram a decrescer a partir de 1980, sendo que, no final da década de 1990, esse grupo de causa foi para o segundo lugar na mortalidade por causas externas. Os coeficientes específicos de mortalidade apresentaram maior magnitude para o sexo masculino.

A faixa etária de “70 anos e mais” se destacaram por sua maior magnitude em ambos os sexos e regiões.

Em Belo Horizonte, a maior razão de coeficientes ocorreu nas faixas etárias de "30 a 39 anos” em 1980; de “20 a 29 anos” em 1990 e de “40 a 49 anos” em 2000. Na Região Metropolitana se destacou nas faixas etárias de “30 a 39 anos” nos anos de 1980 e 1990 e na faixa etária de “40 a 49 anos”, em 2000.

Em Belo Horizonte, os coeficientes específicos apresentaram decrementos percentuais em ambos os sexos. Na Região Metropolitana, ocorreram decrementos percentuais em ambos os sexos, com exceção do sexo masculino na faixa etária de “60 a 69 anos” e do sexo feminino nas faixas de “20 a 29 anos” e de “70 anos e mais”.

Em Belo Horizonte, na faixa etária de "70 anos e mais”, os decrementos foram mais evidentes, sendo que, para o sexo masculino representou (-209\%) e para o feminino (266\%). Na Região Metropolitana, os maiores decrementos ocorreram na faixa etária de “50 a 59 anos” (-148\%) no sexo masculino e na faixa de “10 a 19 anos” (-554\% ) no sexo feminino. 
As tendências dos coeficientes específicos de mortalidade, em ambas regiões em todas as faixas etárias, apresentaram ora declínio ora estabilização. A magnitude dos indicadores se destacou no sexo masculino.

As tendências dos coeficientes gerais padronizados de mortalidade, em ambas regiões apresentaram uma estabilização ao longo do período com um declínio para o sexo feminino $(\mathrm{p}<0,05)$.

\subsection{Em relação aos Suicídios}

Os coeficientes específicos de mortalidade e a mortalidade proporcional apresentaram oscilações ora aumentando, ora diminuindo. Em ambas regiões, os coeficientes de mortalidade se destacaram por sua maior magnitude no sexo masculino, com destaque para o município de Belo Horizonte.

As faixas etárias de “20 a 29 anos” e de “30 a 39 anos” no sexo masculino e a faixa de “30 a 39 anos” no sexo feminino em Belo Horizonte se destacaram pela maior magnitude dos coeficientes. Na Região metropolitana, os indicadores se sobressaíram por sua magnitude na faixa etária de “30 a 39 anos”.

Em Belo Horizonte, a maior razão de coeficientes de mortalidade foi observada na faixa etária de “40 a 49 anos” em 1980 e de “30 a 39 anos” em 1990 e 2000. Na Região Metropolitana, se destacou na faixa etária de “20 a 29 anos” em 1990 e na faixa etária de "30 a 39 anos” em 1980 e 2000.

Em Belo Horizonte, no sexo masculino, o maior incremento percentual ocorreu na faixa etária de “40 a 49 anos” e o maior decremento na faixa etária de “15 a 19 anos”. No sexo feminino e para todas as faixas etária ocorreu decremento \%, com exceção da faixa de “40 a 49 anos”. 
Na Região Metropolitana, no sexo masculino, o maior incremento ocorreu na faixa etária de “15 a 19 anos” e o maior decremento na faixa de “40 a 49 anos”. No sexo feminino, os incrementos se sobressaíram na faixa etária de "15 a 19 anos” e de "40 a 49 anos” e os decrementos nas faixas de “20 a 29 anos” e de “30 a 39 anos”.

As tendências dos coeficientes específicos de mortalidade no município de Belo Horizonte no sexo masculino apresentaram uma discreta ascensão na faixa etária de "20 a 29 anos” e na faixa etária de “40 a 49 anos”. No sexo feminino, ocorreu tendência de declínio nas faixas etárias de “20 a 29 anos” e de “30 a 39 anos” (p<0,05). Na Região metropolitana, observou-se uma tendência de estabilização dos indicadores.

As tendências dos coeficientes gerais padronizados de mortalidade no município de Belo Horizonte apresentaram uma ascensão para o sexo masculino e um declínio para o sexo feminino $(\mathrm{p}<0,05)$. Na Região Metropolitana ocorreu uma tendência de estabilização dos indicadores. 
8 REFERÊNCIAS 


\section{REFERÊNCIAS}

1. Camargo CPF. Dinâmica populacional como processo histórico-social. In: Santos JLF, Levy MSF, Szmrecsãnyi T, organizadores. Dinâmica da população: teoria, métodos e técnicas de análise. São Paulo: TA Queiroz; 1980. p.12-18.

2. Duchiade MP. População brasileira: um retrato em movimento. In: Minayo MCS, organizador. Os muitos brasis: saúde e população na década de 80. São Paulo: Hucitec; 1995. p.14-56.

3. Laurenti R. Transição demográfica e transição epidemiológica. In: Anais do $1^{\circ}$ Congresso Brasileiro de Epidemiologia, 1990; Campinas, (SP). Rio de Janeiro: Associação Brasileira de Saúde Coletiva; 1990. p.143-65.

4. Centro Latino Americano de Demografía (CELADE). Impacto de las tendencias demográficas sobre los sectores sociales en América Latina: contribución al disenõ de políticas y programas. Santiago: Chile; 1996. 297 p.

5. Vermelho LL, Monteiro MFG. Transição demográfica e epidemiológica. In: Medronho RA, Carvalho DM, Bloch KV, Luiz RR, Werneck GL, editores. Epidemiologia. São Paulo: Atheneu; 2002. p.91-103.

6. Nadalin SO. A demografia numa perspectiva histórica. São Paulo: Associação Brasileira de Estudos Populacionais; 1994. 111p.

7. Patarra NL. Mudanças na dinâmica demográfica. In: Monteiro CA, editor. Velhos e Novos males da Saúde no Brasil: a evolução do país e de suas doenças. 2a ed. São Paulo: Hucitec; 2000. p.61-78. 
8. Veras RP, Alves MIC. A população idosa no Brasil: considerações acerca do uso de indicadores de saúde. In: Minayo MCS, organizador. Os muitos brasis: saúde e população na década de 80. São Paulo: Hucitec; 1995. p.320-337.

9. Menezes ED. Estrutura da população brasileira (on line). [citado 2003 mar 23] São Paulo 2001; Disponível em: < URL:http://www.frigoletto.com.br/geopop/populbras.htm>.

10. Ministério da Saúde. Fundação Nacional de Saúde. Datasus. Informações e saúde, informações demográficas e socioeconômicas. [citado 2003 mar 23]. Brasília; FUNASA; 2000. Disponível em <http://www.datasus.gov.br/tabnet/tabnet/htm> .

11. Omran AR. The epidemiologic transation: a theory of the epidemiology of population change. In: Omran AR, editor. Milbank Memorial Fund. Washington 1971. p.509-83.

12. Omran AR. The epidemiologic transition in the Americas. Washington: Pan-American Health Organization World Health Organization University of Maryland; 1996. cap.1, p.5-28.

13. Frenk J, Freita T, Bobadilla JL, Stern C, Lozano R, Sepúlveda J, José M. La transición epidemiologica en América Latina. Bol of Sanit Panam 1991; 111:485-96.

14. Luna EJA. A emergência das doenças emergentes e as doenças infecciosas emergentes e reemergentes no Brasil. Rev Bras Epidemiol 2002; 5:229-43.

15. Medronho RA, Carvalho DM, Bloch KV, Luiz RR, Werneck GL. Estudos ecológicos. In: Medronho RA, Carvalho DM, Bloch KV, Luiz RR, Werneck GL, editores. Epidemiologia. São Paulo: Atheneu; 2002. p.191-8.

16. Mello Jorge MHP, Gotlieb SLD, Laurenti R. Análise por tipo de doença ou agravo. In: Mello Jorge MHP, Gotlieb SLD, Laurenti R, editores. A saúde no Brasil: análise do período 1996 a 1999. Brasília: Organização Pan-Americana da Saúde; 2001. p.203-20. 
17. Prata PR. A transição epidemiológica no Brasil. Cad. Saúde Pública 1992; 8:168-75.

18. Reichenheim ME, Werneck GL. Adoecer e morrer no Brasil dos anos 80; perspectivas de novas abordagens. In: Guimarães R, Tavares RAW, editores. Saúde e sociedade no Brasil - anos 80. Rio de Janeiro: Relume Dumará; 1994. p.113-130.

19. Organização Mundial da Saúde (OMS). Manual da classificação estatística internacional de doenças, lesões e causas de óbito, 9ª Rev. (CID-9) São Paulo: USP; 1975. p.559-659.

20. Organização Mundial da Saúde (OMS). Classificação estatística internacional de doenças e problemas relacionados à saúde, 10ª Rev. (CID-10) São Paulo: USP; 1993. cap. 20, p.1013-130.

21. Minayo MCS. A violência social sob a perspectiva da saúde pública. Cad Saúde Pública 1994; 10 supp1:7-18.

22. Edelman J, Satcher D. Violence prevention as a public health priority. Health Affers 1993; 4:123-5.

23. Neto JAC. Aspectos epidemiológicos dos acidentes de trânsito em Brasília, Distrito Federal, no período de 1980 - 1994. [dissertação]. Salvador: Instituto de Saúde Coletiva da Universidade Federal da Bahia; 1996.

24. Lopez AD. Disease control priorities in developing countries. In: Lopez AD, editor. Causes of death in industrial and developing countries: estimates for 1985 1990. World Bank. Oxford: Oxford University Press; 1993.

25. Mello Jorge MHP, Laurenti R. Apresentação. Rev Saúde Pública 1997; 31 supp4:1-4.

26. Souza ER, Minayo MCS. O impacto da violência social na saúde pública do Brasil: na década de 80. In: Minauo MCS, organizador. Os muitos brasis: saúde e população na década de 80. São Paulo: Hucitec: Rio de Janeiro: Abrasco; 1995. p.87-116. 
27. Organización Panamericana de la Salud (OPAS). La violencia en las Américas: la pandemia social del siglo XX. Washington 1997. 32 p.

28. Macedo AC, Paim JS, Silva LMV, Costa MCN. Violência e desigualdades sociais: mortalidade por homicídios e condições de vida em Salvador, Brasil. Rev Saúde Pública. $2001 ; 35: 515-22$.

29. Corteleti MA. Estudo revela explosão da criminalidade em Minas Gerais. Bol Informativo UFMG, Belo Horizonte 1998; 1205: 5.

30. Camargo ABM, Ortiz LP, Fonseca LAM. Evolução da mortalidade por acidentes e violências em áreas metropolitanas. In: Monteiro CA, editor. Velhos e novos males da saúde no Brasil: a evolução do país e de suas doenças. 2a ed. São Paulo: Hucitec; 2000. p.256-67.

31. Yunes J. Mortalidad por causas violentas en la región de las Américas. Bol Of Sanit Panam 1993; 114:302-16.

32. Laurenti R, Buchala CM, Mello Jorge MHP, Lebrão ML, Gotlieb SLD. Perfil epidemiológico da saúde masculina na região das Américas: uma contribuição para o enfoque de gênero. In: Laurenti R, editor. Perfil epidemiológico da saúde masculina na região das Américas: uma contribuição para o enfoque de gênero. São Paulo: Faculdade de Saúde Pública da USP/ FSP; 1998. p.99-121.

33. Iunes RF. III - Impacto econômico das causas externas no Brasil: um esforço de mensuração. Rev Saúde Pública 1997; 31supp4:38-46.

34. Mello Jorge MHP, Gawryszewski VP, Latorre MRO. I - Análise dos dados de mortalidade. Rev Saúde Pública 1997; 31 supp4: 5-25. 
35. Lima MLC, Souza ER, Ximenes R, Albuquerque MFPM, Bitoun J, Barros, M.D. Evolução de homicídios por área geográfica em Pernambuco entre 1980 e 1998. Rev Saúde Pública 2002; 36:462-9.

36. Mello Jorge MHP. Gotlieb SLD. Mortalidade. In: Mello Jorge MHP, Gotlieb SLD, editores. As condições de saúde no Brasil. Rio de Janeiro: Fiocruz; 2000. p.71-224.

37. Andrade SM, Mello Jorge MHP. Características das vítimas por acidentes de transporte terrestre em município da região Sul do Brasil. Rev Saúde Pública 2000; 34:149-56.

38. Mccarrol JR, Haddon WJ. Un estudio controlado sobre accidentes mortales de automovil en la cidad de Nueva York. In: Carol B, et al, editores. El desafio de la epidemiologia: problemas y lecturas seleccionadas. Washington (DC): Organización Panamericana de la Salud; 1998. p.598-610.

39. Mello Jorge MHP. Mortalidade por causas violentas no município de São Paulo. [tese]. São Paulo: Faculdade de Saúde Pública, Universidade de São Paulo; 1979.

40. Camargo ABM. Mortalidade por causas externas no estado de São Paulo e suas regiões. [tese]. São Paulo: Faculdade de Saúde Pública, Universidade de São Paulo, 2002.

41. Souza ER, Assis SG, Silva CMFP. Violência no Rio de Janeiro: áreas de risco e tendências da mortalidade entre adolescentes de 10 a 19 anos. Rev Panam Salud Publica 1997; 1: 389-98.

42. Berquó E. Causas externas de morte. In Berquó E, editor. Fecundidade, saúde reprodutiva e pobreza na América Latina, o caso brasileiro. São Paulo: Cebrap Nepo / Unicamp; 1997. p.112-20.

43. Ministério da Saúde. Mortalidade Brasil 2000. Brasília: Fundação Nacional de Saúde Brasil; 20031 CD (ca. 40 min.). 
44. Mello Jorge MHP, Laurenti R. Situação atual das estatísticas oficiais relativas à mortalidade por causas externas. Rev Saúde Pública 1990; 24:217-23.

45. Mello Jorge MHP, Gotlieb SLD, Laurenti R. O sistema de informações sobre mortalidade: problemas e propostas para o seu enfrentamento II - Mortes por causas externas. Rev Bras Epidemiol 2002; 5:212-23.

46. Laurenti R. Mortalidade Brasil 2000. Brasília: Fundação Nacional de Saúde Brasil; 2003 $1 \mathrm{CD}$ (ca $40 \mathrm{~min}$.$) .$

47. Moraes IHS. Informações em saúde: da prática fragmentada ao exercício da cidadania. São Paulo: Hucitec: Rio de Janeiro: Abrasco. 1994.

48. Moraes AS, Rezende MHV, Freitas ICM. Tendência da mortalidade por doenças isquêmicas do coração, no município de Goiânia-Brasil, na série histórica entre 1980 e 1994. Arq Bras Cardiol 2000; 74: 483-97.

49. Pereira MG. Transição demográfica e epidemiológica. In: Pereira MG, editor. Epidemiologia: teoria e prática. 5ª ed. Belo Horizonte: Guanabara - Koogan; 2001. p.15785.

50. Sanches KRB, Camargo Júnior KR, Coeli CM, Cascão AM. Sistemas de informação em saúde. In: Medronho RA, editor. Epidemiologia. São Paulo: Atheneu; 2002. p.337-59.

51. Ministério da Saúde. Portaria No 474, de 31 de agosto de 2000. Regulamenta a coleta de dados, fluxo e periodicidade de envio das informações sobre óbitos para o Sistema de Informações sobre Mortalidade - SIM. Diário Oficial da União, Poder Executivo, Brasília (DF). 2000. set 4; 1CD (ca. 40 min.).

52. Maletta CHM. Transição epidemiológica no município de Belo Horizonte, no período de 1890 a 1991. [tese] Ribeirão Preto: Faculdade de Medicina de Ribeirão Preto, Universidade de São Paulo, 1997. 
53. Prefeitura Municipal de Belo Horizonte. Secretaria Municipal de Planejamento / Departamento de Informações Técnicas. Anuário Estatístico de Belo Horizonte. Belo Horizonte: Centro Gráfico da PBH; 2001.

54. Instituto Brasileiro de Geografia e Estatística. Departamento de População e Indicadores Sociais. Estimativas de população do Brasil, Grandes Regiões, Unidades da Federação e Municípios. Rio de Janeiro; 2002.

55. Sann JGL. A caminho das noções básicas de geografia. Belo Horizonte: Dimensão, 2001.p.1.

56. Fundação Joao Pinheiro. Perfil de Minas Gerais. Belo Horizonte: Centro de Estatísticas e Informação. 1999. p.149-56.

57. Sapori LF, Batitucci EC. Análise descritiva da incidência de homicídios na região metropolitana de Belo Horizonte (1980-1995). [citado 2001 mar 19] Centro de Estudos Econômicos e Sociais Fundação João Pinheiro, 1998. Disponível em <http://www.est.ufmg.br/geccs2/artigos/html/adescr/adescr.html>.

58. Moura FL. Preventable excess deaths in Minas Gerais, Brasil, from 1979 to 1986: public health nursing intervention priorites. [dissertation]. Chapel Hill: University of North Carolina; 1995.

59. Ministério da Saúde. Fundação Nacional de Saúde. Datasus. Informações de saúde / Mortalidade. [citado 2003 mar 23]. Brasília; FUNASA; 2000. Disponível em < $\underline{\text { http://tabnet.datasus.gov.br }>}$.

60. Minayo MCS. A difícil e lenta entrada da violência na agenda do setor saúde. Cad Saúde Pública 2004; 20:646-647. 
61. Gordis L. From association to causation: deriving inferences from epidemiology studies. In: Gordis L, editores. From. Epidemiology. Philadelphia. W.B. Saunders; 2000. p.184203.

62. Hennekens CH, Buring JE. Epidemiology in medicine. Boston. Little, Brow; 1987.

63. Microsoft Corporation. Microsoft Excel, for Windows 2000. [computador programa] Excel vs. 8.0. Copyright: Brasil, 2000.

64. SPSS for windows. SPSS - Statistical Package in Social Science: Rellease 10.0.1 (27/outubro/1999) standarte version Copyritght - SPSS INC, 1989-1999.

65. Rocha RL. Violência e paz. Radis comunicação em saúde. 2004; 21:19.

66. Yunes J, Zubarew T. Mortalidad por causas violentas en adolescentes y jóvenes: un desafio para la región de las Américas. Rev Bras Epidemiol 1999; 2:102-71.

67. Drumond Júnior M. Homicídios e desigualdades sociais na cidade de São Paulo: uma visão epidemiológica. Saúde e Sociedade 1999; 8:63-81.

68. Simões CCS. Perfis de Saúde e de mortalidade no Brasil: uma análise de seus condicionantes em grupos populacionais específicos. Brasília: Organização PanAmericana da Saúde; 2002.

69. Barros MDA, Ximenes R, Lima MLC. Causa básica de morte por causas externas: validação dos dados oficiais em Recife, Pernambuco, Brasil. Rev Panam Salud Publica 2001; 9:84-93.

70. Ministério da Saúde. Secretaria de Vigilância em Saúde. Departamento de Análise de Situação de Saúde. Saúde Brasil 2004 - uma análise da situação de saúde - Brasília: Ministério da Saúde; 2004. 
71. Barata BR, Ribeiro MCSA, Guedes MBLS, Moraes JS. Intra-Urban differentials in death rates from homicide in the city of São Paulo, Brazil, 1988-1994. Soc Sci Med 1998; 47:19-23.

72. Greenberg M, Scheneider D. Violence in American cities: young black males is the answer, but what was the question? Soc Sci Med. 1994; 39:179-87.

73. Carmo EH, Barreto ML, Silva Júnior JB. Mudanças nos padrões de morbimortalidade da população brasileira: os desafios para um novo século. Epidemiologia e Serviços de Saúde. Brasília: Ministério da Saúde; 2003. p.63-75.

74. Ribeiro MCSA, Guedes MBL, Moraes JC. Intra-urban differentials in death rates from homicide in the city of São Paulo, Brazil, 1988-1994. Soc Sci Med 1998; 1:19-23.

75. Ishitani LH, Marislaine LM, Lopes HNRO, Souza DAP, Miranda PSC. Mortalidade por homicídios em bairros e favelas da Região Centro Sul de Belo Horizonte. Rev Médica de Minas Gerais 2001; 11:7-10.

76. Villela LCM. Diferenciais de mortalidade por causas externas na Regional Centro Sul de Belo Horizonte, Minas Gerais, 1992 a 1996. [dissertação]. Belo Horizonte: Escola de Veterinária, Universidade Federal de Minas Gerais, 1999.

77. Duarte EC, Scheneider MC, Souza RS, Ramalho WM, Sardinha LMV, Silva Júnior JB, Salgado CC. Epidemiologia das desigualdades em saúde no Brasil: um estudo exploratório. Brasília: OPAS; 2002.

78. Lima MLC, Ximenes R. Violência e morte: diferenciais da mortalidade por causas externas no espaço urbano do Recife, 1991. Cad Saúde Pública 1998; 14:829-40.

79. Zaluar A, Noronha JC, Alburqueque C. Violência: pobreza ou fraqueza institucional? Cad Saúde Pública 1994; 2410 supp 1:213-7. 
80. Fundação Oswaldo Cruz. Mortalidade por causas externas no Brasil. Radis-Dados, 1985: 8.

81. Vermelho LL. Mortalidade de jovens: análise do período de 1930 a 1991. (A transição epidemiológica para a violência). [tese]. São Paulo: Faculdade de Saúde Pública, Universidade de São Paulo, 1994.

82. Gawryszewski VP, Mello Jorge MHP. Mortalidade violenta no município de São Paulo nos últimos 40 anos. Rev Bras Epidemiol 2000; 3:50-69.

83. Mendonça F. Clima e Criminalidade: ensaio analítico da correlação entre a temperatura do ar e a incidência de criminalidade urbana. Curitiba: UFPR; 2001.

84. Souza ER. Homicídios no Brasil: o grande vilão da Saúde Pública na década de 80. Cad Saúde Pública 1994; 10 supp1:45-60.

85. Yunes J, Rajas D. Tendência de la mortalidad por causas violentas en la población y entre los adolescentes y jóvenes de la región de las Américas. Cad Saúde Pública 1994; 10 supp1:88-125.

86. Najaine K, Souza ER, Minayo MCS. A produção da (des)informação sobre violência: análise de uma prática discriminatória. Cad Saúde Pública 1997; 13:405-14.

87. Pereira MG, Castro ES. Avaliação do preenchimento de declarações de óbitos, Brasília (DF) 1977-1978. Rev Saúde Pública 1981; 15:14-9.

88. Souza ER Mortalidade por homicídios na década de 80: Brasil e capitais de regiões metropolitanas. In: Barreto ML, organizador. Epidemiologia, serviços e tecnologias em saúde. Rio de Janeiro: Fiocruz / Abrasco; 1998 p.187-205.

89. Leão I, Mandaloufas K. Direitos humanos: Observadores do respeito e da dignidade. Jornal da USP, São Paulo, 2 a 8 de dezembro de 2002. Pesquisa, p.8. 
90. Kellermamann Al. Obstacles to firearm and violence reseach. Health affairs. 1993; 4:142-53.

91. Kilsztajn SS, César RLS, Dorivaldo FS, André CM, Aissa RC, Ivan LBF. Taxa de mortalidade por acidentes de trânsito e frota de veículos. Rev Saúde Publica, 2001; 35:262-8.

92. Vasconcelos AMN, Lima DD. A mortalidade por acidentes de trânsito no Brasil. In: Anais do $11^{\circ}$ Encontro Nacional de Estudos Populacionais; 1998. out. 19-23; Caxambu-Brasil. Belo Horizonte: Abep; 1998.

93. Ministério da Saúde. Portaria MS / GM nº 737 de 16 maio 2001 nº 96 seção 1E, de 18 / 05 / 01. Política nacional de redução da morbimortalidade por acidentes e violência. Diário Oficial da União, Poder Executivo, Brasília (DF), 2001.

94. Vasconcelos AMN, Lima DD. A qualidade das estatísicas de óbitos no Brasil. Rev Bras Estudos Pop 1998; 15:115-24.

95. Meneghel SN, Victora CG, Faria NMX, Carvalho LA, Falk JW. Características epidemiológicas do suicídio no Rio Grande do Sul. Rev Saúde Pública 2004; 38:804-10. 
ANEXOS 


\section{ANEXO 1}

Taxa de Mortalidade por Homicídios.

Município de Belo Horizonte - 1990

\begin{tabular}{|c|c|c|c|c|c|c|c|}
\hline Idade & Sexo & Óbitos & P. Padrão & Pop. Ano & $\mathrm{CM} 100 \mathrm{mil}$ & ób.esp. & \\
\hline \multirow{3}{*}{ 15---19 } & $M$ & 22 & 100733 & 93548 & 23,52 & 23,69 & \\
\hline & $F$ & 3 & 112562 & 102606 & 2,92 & 3,29 & \\
\hline & $T$ & 25 & 213295 & 196154 & 12,75 & 27,18 & \\
\hline \multirow[t]{3}{*}{ 20---29 } & $M$ & 76 & 183605 & 189651 & 40,07 & 73,58 & \\
\hline & $\mathbf{F}$ & 7 & 199544 & 208940 & 3,35 & 6,69 & \\
\hline & $T$ & 83 & 383149 & 398591 & 20,82 & 79,78 & \\
\hline \multirow[t]{3}{*}{$30--39$} & $M$ & 46 & 109390 & 147394 & 31,21 & 34,14 & \\
\hline & $F$ & 6 & 122428 & 167961 & 3,57 & 4,37 & \\
\hline & $T$ & 52 & 231818 & 315355 & 16,49 & 38,23 & \\
\hline \multirow[t]{3}{*}{$40--49$} & $M$ & 24 & 76021 & 95111 & 25,23 & 19,18 & \\
\hline & $F$ & 4 & 84978 & 111025 & 3,60 & 3,06 & \\
\hline & $\mathrm{T}$ & 28 & 160999 & 206136 & 13,58 & 21,87 & \\
\hline \multirow[t]{3}{*}{ 50--59 } & $M$ & 9 & 47351 & 61383 & 14,66 & 6,94 & \\
\hline & $F$ & - & 57746 & 74456 & - & - & \\
\hline & $\mathbf{T}$ & 9 & 105097 & 135839 & 6,63 & 6,96 & \\
\hline \multirow[t]{3}{*}{$60--69$} & $M$ & 6 & 25313 & 35273 & 17,01 & 4,31 & \\
\hline & $F$ & - & 35207 & 50126 & - & - & \\
\hline & $T$ & 6 & 60520 & 85399 & 7,03 & 4,25 & \\
\hline \multirow[t]{3}{*}{70 e m } & M & - & 13203 & 20152 & - & - & \\
\hline & $\mathbf{F}$ & - & 21787 & 36037 & - & - & \\
\hline & $\mathrm{T}$ & - & 34990 & 56189 & - & - & $\begin{array}{l}\text { Coef. pad. } \\
\text { por } 100.000\end{array}$ \\
\hline \multirow[t]{3}{*}{ TOTAL } & $M$ & 183 & 555616 & 642512 & 28,48 & 161,84 & 29,13 \\
\hline & $F$ & 20 & 634252 & 751151 & 2,66 & 17,41 & 2,75 \\
\hline & $\mathrm{T}$ & 203 & 1189868 & 1393663 & 14,57 & 179,25 & 15,06 \\
\hline
\end{tabular}

Fonte: Ministério da Saúde / DATASUS ${ }^{59}$ 


\section{ANEXO 2}

Taxa de Mortalidade por Homicídios.

Região Metropolitana de Belo Horizonte 1990

\begin{tabular}{|c|c|c|c|c|c|c|c|}
\hline Idade & Sexo & Óbitos & P. Padrão & P. Ano & C.M / 100mil & Ób. esp. & \\
\hline \multirow[t]{3}{*}{ 15---19 } & $M$ & 17 & 50909 & 73699 & 23,07 & 11,74 & \\
\hline & $F$ & 1 & 51105 & 73644 & 1,36 & 0,69 & \\
\hline & $T$ & 18 & 102014 & 147343 & 12,22 & 12,46 & \\
\hline \multirow[t]{3}{*}{ 20---29 } & $M$ & 65 & 85216 & 134366 & 48,38 & 41,22 & \\
\hline & $F$ & 11 & 83963 & 137847 & 7,98 & 6,70 & \\
\hline & $T$ & 76 & 169179 & 272213 & 27,92 & 47,23 & \\
\hline \multirow[t]{3}{*}{ 30---39 } & $M$ & 40 & 54995 & 107797 & 37,11 & 20,41 & \\
\hline & $F$ & 4 & 52719 & 110392 & 3,62 & 1,91 & \\
\hline & $T$ & 44 & 107714 & 218189 & 20,17 & 21,72 & \\
\hline \multirow[t]{3}{*}{ 40---49 } & $M$ & 19 & 37421 & 65556 & 28,98 & 10,85 & \\
\hline & $F$ & 2 & 35328 & 65413 & 3,06 & 1,08 & \\
\hline & $T$ & 21 & 72749 & 130969 & 16,03 & 11,66 & \\
\hline \multirow[t]{3}{*}{ 50---59 } & $M$ & 11 & 22124 & 38301 & 28,72 & 6,35 & \\
\hline & $F$ & 2 & 22487 & 40158 & 4,98 & 1,12 & \\
\hline & $T$ & 13 & 44611 & 78459 & 16,57 & 7,39 & \\
\hline \multirow[t]{3}{*}{ 60---69 } & $M$ & 4 & 12516 & 21280 & 18,80 & 2,35 & \\
\hline & $F$ & 1 & 13704 & 25089 & 3,99 & 0,55 & \\
\hline & $T$ & 5 & 26220 & 46369 & 10,78 & 2,83 & \\
\hline \multirow[t]{3}{*}{70 e mais } & $M$ & 3 & 5781 & 11165 & 26,87 & 1,55 & \\
\hline & $F$ & 1 & 7769 & 15760 & 6,35 & 0,49 & \\
\hline & $T$ & 4 & 13550 & 26925 & 14,86 & 2,01 & $\begin{array}{l}\text { Coef. Padr. } \\
\text { por } 100.000\end{array}$ \\
\hline \multirow[t]{3}{*}{ Total } & $M$ & 159 & 268962 & 452164 & 35,16 & 82,74 & 30,76 \\
\hline & $F$ & 22 & 267075 & 468303 & 4,70 & 11,85 & 4,44 \\
\hline & $T$ & 181 & 536037 & 920467 & 19,66 & 94,59 & 17,65 \\
\hline
\end{tabular}




\section{ANEXO 3}

Taxa de Mortalidade por Acidentes de Transporte

Município de Belo Horizonte - 1990

\begin{tabular}{|c|c|c|c|c|c|c|c|}
\hline Idade & Sexo & Óbitos & P. Padrão & Pop. Ano & $\mathrm{CM} 100 \mathrm{mil}$ & Ób.esp. & \\
\hline \multirow[t]{3}{*}{$0--9$} & $M$ & 25 & 206523 & 199537 & 12,53 & 25,88 & \\
\hline & $F$ & 11 & 201410 & 195090 & 5,64 & 11,36 & \\
\hline & $T$ & 36 & 407933 & 394627 & 9,12 & 37,21 & \\
\hline \multirow[t]{3}{*}{ 10---19 } & $M$ & 41 & 190488 & 197443 & 20,77 & 39,56 & \\
\hline & $\mathrm{F}$ & 21 & 204880 & 207058 & 10,14 & 20,78 & \\
\hline & $T$ & 62 & 395368 & 404501 & 15,33 & 60,60 & \\
\hline \multirow[t]{3}{*}{$20---29$} & $M$ & 96 & 183605 & 189651 & 50,62 & 92,94 & \\
\hline & $F$ & 25 & 199544 & 208940 & 11,97 & 23,88 & \\
\hline & $T$ & 121 & 383149 & 398591 & 30,36 & 116,31 & \\
\hline \multirow[t]{3}{*}{$30--39$} & $M$ & 69 & 109390 & 147394 & 46,81 & 51,21 & \\
\hline & $F$ & 21 & 122428 & 167961 & 12,50 & 15,31 & \\
\hline & $T$ & 90 & 231818 & 315355 & 28,54 & 66,16 & \\
\hline \multirow[t]{3}{*}{$40--49$} & $M$ & 35 & 76021 & 95111 & 36,80 & 27,98 & \\
\hline & $F$ & 16 & 84978 & 111025 & 14,41 & 12,25 & \\
\hline & $T$ & 51 & 160999 & 206136 & 24,74 & 39,83 & \\
\hline \multirow[t]{3}{*}{$50--59$} & $M$ & 45 & 47351 & 61383 & 73,31 & 34,71 & \\
\hline & $F$ & 19 & 57746 & 74456 & 25,52 & 14,74 & \\
\hline & $T$ & 64 & 105097 & 135839 & 47,11 & 49,52 & \\
\hline \multirow[t]{3}{*}{$60--69$} & $M$ & 26 & 25313 & 35273 & 73,71 & 18,66 & \\
\hline & $F$ & 19 & 35207 & 50126 & 37,90 & 13,35 & \\
\hline & $T$ & 45 & 60520 & 85399 & 52,69 & 31,89 & \\
\hline \multirow[t]{3}{*}{$70--79$} & $M$ & 14 & 10570 & 15327 & 91,34 & 9,65 & \\
\hline & $F$ & 14 & 16512 & 25713 & 54,45 & 8,99 & \\
\hline & $T$ & 28 & 27082 & 41040 & 68,23 & 18,48 & \\
\hline \multirow[t]{3}{*}{80 e $m$} & $M$ & 9 & 2633 & 4825 & 186,53 & 4,91 & \\
\hline & $\mathrm{F}$ & 7 & 5275 & 10324 & 67,80 & 3,58 & \\
\hline & $\mathrm{T}$ & 16 & 7908 & 15149 & 105,62 & 8,35 & $\begin{array}{l}\text { Coef. padr. } \\
\text { por } 100.000\end{array}$ \\
\hline \multirow[t]{3}{*}{ TOTAL } & $M$ & 360 & 851894 & 945944 & 38,06 & 305,49 & 35,86 \\
\hline & $\mathrm{F}$ & 153 & 927980 & 1050693 & 14,56 & 124,21 & 13,39 \\
\hline & $\mathrm{T}$ & 513 & 1779874 & 1996637 & 25,69 & 429,70 & 24,14 \\
\hline
\end{tabular}

Fonte: Ministério da Saúde / DATASUS ${ }^{59}$ 


\section{ANEXO 4}

Taxa de Mortalidade por Acidentes de Trânsito.

Região Metropolitana de Belo Horizonte 1990

\begin{tabular}{|c|c|c|c|c|c|c|c|}
\hline Idade & Sexo & Óbitos & P. Padrão & P. Ano & C.M / 100mil & Ób. esp. & \\
\hline \multirow{3}{*}{$0---9$} & $M$ & 22 & 127496 & 172693 & 12,74 & 16,24 & \\
\hline & $F$ & 10 & 124176 & 167831 & 5,96 & 7,40 & \\
\hline & $T$ & 32 & 251672 & 340524 & 9,40 & 23,65 & \\
\hline \multirow[t]{3}{*}{ 10---19 } & $M$ & 26 & 104631 & 162156 & 16,03 & 16,78 & \\
\hline & $F$ & 10 & 104544 & 160612 & 6,23 & 6,51 & \\
\hline & $\mathrm{T}$ & 36 & 209175 & 322768 & 11,15 & 23,33 & \\
\hline \multirow[t]{3}{*}{ 20---29 } & M & 57 & 85216 & 134366 & 42,42 & 36,15 & \\
\hline & $F$ & 13 & 83963 & 137847 & 9,43 & 7,92 & \\
\hline & $\mathbf{T}$ & 70 & 169179 & 272213 & 25,72 & 43,50 & \\
\hline \multirow[t]{3}{*}{ 30---39 } & M & 72 & 54995 & 107797 & 66,79 & 36,73 & \\
\hline & $F$ & 6 & 52719 & 110392 & 5,44 & 2,87 & \\
\hline & $T$ & 78 & 107714 & 218189 & 35,75 & 38,51 & \\
\hline \multirow[t]{3}{*}{ 40---49 } & M & 32 & 37421 & 65556 & 48,81 & 18,27 & \\
\hline & $F$ & 8 & 35328 & 65413 & 12,23 & 4,32 & \\
\hline & $\mathbf{T}$ & 40 & 72749 & 130969 & 30,54 & 22,22 & \\
\hline \multirow[t]{3}{*}{ 50---59 } & M & 22 & 22124 & 38301 & 57,44 & 12,71 & \\
\hline & $F$ & 8 & 22487 & 40158 & 19,92 & 4,48 & \\
\hline & $T$ & 30 & 44611 & 78459 & 38,24 & 17,06 & \\
\hline \multirow[t]{3}{*}{ 60---69 } & M & 10 & 12516 & 21280 & 46,99 & 5,88 & \\
\hline & $F$ & 5 & 13704 & 25089 & 19,93 & 2,73 & \\
\hline & $\mathbf{T}$ & 15 & 26220 & 46369 & 32,35 & 8,48 & \\
\hline \multirow[t]{3}{*}{ 70---79 } & M & 13 & 4729 & 8839 & 147,08 & 6,96 & \\
\hline & $F$ & 4 & 5936 & 11672 & 34,27 & 2,03 & \\
\hline & $T$ & 17 & 10665 & 20511 & 82,88 & 8,84 & \\
\hline \multirow[t]{3}{*}{80 e mais } & M & 7 & 1052 & 2326 & 300,95 & 3,17 & \\
\hline & $F$ & 1 & 1833 & 4088 & 24,46 & 0,45 & \\
\hline & $T$ & 8 & 2885 & 6414 & 124,73 & 3,60 & $\begin{array}{l}\text { Coef. Padr. } \\
\text { por } 100.000\end{array}$ \\
\hline \multirow[t]{3}{*}{ Total } & $M$ & 261 & 450180 & 713314 & 36,59 & 152,88 & 33,96 \\
\hline & $F$ & 65 & 444690 & 723102 & 8,99 & 38,71 & 8,70 \\
\hline & $T$ & 326 & 894870 & 1436416 & 22,70 & 191,58 & 21,41 \\
\hline
\end{tabular}




\section{ANEXO 5}

Taxa de Mortalidade por Suicídios

Município de Belo Horizonte - 1990

\begin{tabular}{|c|c|c|c|c|c|c|c|}
\hline Idade & Sexo & Óbitos & P. Padrão & Pop. Ano & $\mathrm{CM} 100 \mathrm{mil}$ & Ób.esp. & \\
\hline \multirow{3}{*}{ 15---19 } & M & 4 & 100733 & 93548 & 4,28 & 4,31 & \\
\hline & $F$ & 5 & 112562 & 102606 & 4,87 & 5,49 & \\
\hline & $\mathrm{T}$ & 9 & 213295 & 196154 & 4,59 & 9,79 & \\
\hline \multirow[t]{3}{*}{ 20---29 } & M & 18 & 183605 & 189651 & 9,49 & 17,43 & \\
\hline & $F$ & 2 & 199544 & 208940 & 0,96 & 1,91 & \\
\hline & $\mathbf{T}$ & 20 & 383149 & 398591 & 5,02 & 19,23 & \\
\hline \multirow[t]{3}{*}{$30--39$} & M & 22 & 109390 & 147394 & 14,93 & 16,33 & \\
\hline & $F$ & 8 & 122428 & 167961 & 4,76 & 5,83 & \\
\hline & $T$ & 30 & 231818 & 315355 & 9,51 & 22,05 & \\
\hline \multirow[t]{3}{*}{$40--49$} & M & 6 & 76021 & 95111 & 6,31 & 4,80 & \\
\hline & $F$ & 3 & 84978 & 111025 & 2,70 & 2,30 & \\
\hline & $T$ & 9 & 160999 & 206136 & 4,37 & 7,03 & \\
\hline \multirow[t]{3}{*}{ 50--59 } & M & 5 & 47351 & 61383 & 8,15 & 3,86 & \\
\hline & $F$ & 3 & 57746 & 74456 & 4,03 & 2,33 & \\
\hline & $\mathbf{T}$ & 8 & 105097 & 135839 & 5,89 & 6,19 & \\
\hline \multirow[t]{3}{*}{ 60--69 } & M & 3 & 25313 & 35273 & 8,51 & 2,15 & \\
\hline & $F$ & - & 35207 & 50126 & - & - & \\
\hline & $\mathbf{T}$ & 3 & 60520 & 85399 & 3,51 & 2,13 & \\
\hline \multirow[t]{3}{*}{70 e m } & $M$ & 4 & 13203 & 20152 & 19,85 & 2,62 & \\
\hline & $F$ & - & 21787 & 36037 & - & - & \\
\hline & $T$ & 4 & 34990 & 56189 & 7,12 & 2,49 & $\begin{array}{l}\text { Coef. padr. } \\
\text { por } 100.000\end{array}$ \\
\hline \multirow[t]{3}{*}{ TOTAL } & $M$ & 62 & 555616 & 642512 & 9,65 & 51,49 & 9,27 \\
\hline & $F$ & 21 & 634252 & 751151 & 2,80 & 17,85 & 2,81 \\
\hline & $T$ & 83 & 1189868 & 1393663 & 5,96 & 69,34 & 5,83 \\
\hline
\end{tabular}

\footnotetext{
Fonte: Ministério da Saúde / DATASUS ${ }^{59}$
} 


\section{ANEXO 6}

Taxa de Mortalidade por Suicídios.

Região Metropolitana de Belo Horizonte 1990

\begin{tabular}{|c|c|c|c|c|c|c|c|}
\hline Idade & Sexo & Óbitos & P. Padrão & P. Ano & C.M / 100mil & Ób. esp. & \\
\hline \multirow[t]{3}{*}{ 15---19 } & M & 3 & 50909 & 73699 & 4,07 & 2,07 & \\
\hline & $F$ & 2 & 51105 & 73644 & 2,72 & 1,39 & \\
\hline & $\mathbf{T}$ & 5 & 102014 & 147343 & 3,39 & 3,46 & \\
\hline \multirow[t]{3}{*}{$20---29$} & M & 9 & 85216 & 134366 & 6,70 & 5,71 & \\
\hline & $F$ & 2 & 83963 & 137847 & 1,45 & 1,22 & \\
\hline & $T$ & 11 & 169179 & 272213 & 4,04 & 6,84 & \\
\hline \multirow[t]{3}{*}{ 30---39 } & M & 3 & 54995 & 107797 & 2,78 & 1,53 & \\
\hline & $F$ & 5 & 52719 & 110392 & 4,53 & 2,39 & \\
\hline & $\mathrm{T}$ & 8 & 107714 & 218189 & 3,67 & 3,95 & \\
\hline \multirow[t]{3}{*}{ 40---49 } & M & 6 & 37421 & 65556 & 9,15 & 3,42 & \\
\hline & $F$ & 3 & 35328 & 65413 & 4,59 & 1,62 & \\
\hline & $T$ & 9 & 72749 & 130969 & 6,87 & 5,00 & \\
\hline \multirow[t]{3}{*}{ 50---59 } & M & 3 & 22124 & 38301 & 7,83 & 1,73 & \\
\hline & $F$ & - & 22487 & 40158 & - & - & \\
\hline & $\mathrm{T}$ & 3 & 44611 & 78459 & 3,82 & 1,71 & \\
\hline \multirow[t]{3}{*}{ 60---69 } & M & 1 & 12516 & 21280 & 4,70 & 0,59 & \\
\hline & $F$ & - & 13704 & 25089 & - & - & \\
\hline & $T$ & 1 & 26220 & 46369 & 2,16 & 0,57 & \\
\hline \multirow[t]{3}{*}{70 e mais } & M & 2 & 5781 & 11165 & 17,91 & 1,04 & \\
\hline & $F$ & - & 7769 & 15760 & - & - & \\
\hline & $\mathrm{T}$ & 2 & 13550 & 26925 & 7,43 & 1,01 & $\begin{array}{l}\text { Coef. Padr. } \\
\text { por } 100.000\end{array}$ \\
\hline \multirow[t]{3}{*}{ Total } & M & 27 & 268962 & 452164 & 5,97 & 14,02 & 5,21 \\
\hline & $F$ & 12 & 267075 & 468303 & 2,56 & 5,23 & 1,96 \\
\hline & $T$ & 39 & 536037 & 920467 & 4,24 & 19,25 & 3,59 \\
\hline
\end{tabular}



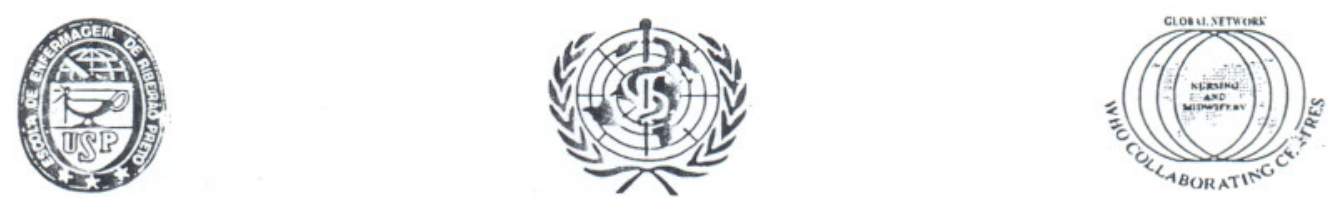

ESCOLA DE ENFERMAGEM DE RIBEIRÃO PRETO - UNIVERSIDADE DE SÃO PAULO CENTRO COLABORADOR DA ORGANIZAÇÃO MUNDIAL DA SAÚDE PARA O DESENVOLVIMENTO DA PESQUISA EM ENFERMAGEM

Avenida Bandeirantes, 3900 - Campus Universitário - Ribeirão Preto - CEP 14040-902 - São Paulo - Brasil FAX: $55-16-633-3271 / 55-16-630-2561$ - TELEFONES: $55-16-633-0379 / 602-3382$

\section{COMITÊ DE ÉTICA EM PESQUISA DA EERPIUSP}

Of.CEP-EERP/USP - 0154/2003

Ribeirão Preto, 17 de dezembro de 2003.

Prezada Senhora,

Comunicamos que o projeto de pesquisa, abaixo especificado, foi analisado e considerado APROVADO pelo Comitê de Ética em Pesquisa da Escola de Enfermagem de Ribeirão Preto da Universidade de São Paulo, em sua $59^{a}$ Reunião Ordinária, realizada em 17 de dezembro de 2003.

Protocolo: $\quad n^{\circ} 0419 / 2003$

Projeto: Mortalidade por Causas Externas no Municipio de Belo Horizonte - MG, em Série Histórica

Pesquisadores: SUZANA ALVES DE MORAES LENICE DE CASTRO MENDES VILLELA

Em atendimento à Resolução 196/96, deverá ser encaminhado ao CEP o relatório final da pesquisa e a publicação de seus resultados, para acompanhamento, bem como comunicada qualquer intercorrência ou a sua interrupção.

Atenciosamente,

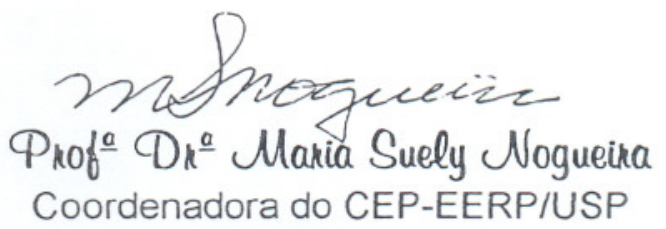

IIma. Sra.

Profa. Dra. Suzana Alves de Moraes

Dept $^{\circ}$ de Enfermagem Materno-Infantil e Saúde Pública

Escola de Enfermagem de Ribeirão Preto - USP 